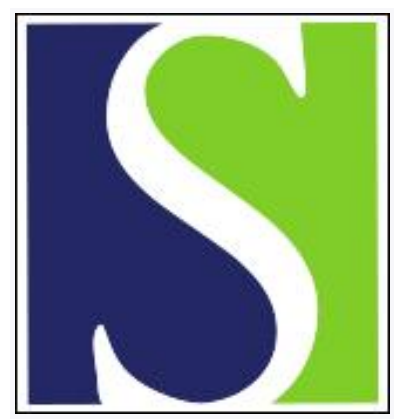

Scand J Work Environ Health 2001;27(3):161-213

https://doi.org/10.5271/sjweh.605

Issue date: Jun 2001

Epidemiologic estimate of the proportion of fatalities related to occupational factors in Finland

by Nurminen M, Karjalainen $\mathrm{A}$

Affiliation: Department of Epidemiology and Biostatistics, Finnish Institute of Occupational Health, Topeliuksenkatu 41 a A, FIN-00250 Helsinki, Finland. Markku.Nurminen@occuphealth.fi

Refers to the following texts of the Journal: 1997;23(4):257-265 $1999 ; 25$ suppl 2:1-116 1995;21(6):460-469 1998;24 suppl 2:71-80 1998;24 suppl 2:81-82 1998;24 suppl 1:1-51 1997;23(1):1-4 1998;24(1):3-7 1998;24(3):175-182 1999;25(5):436-441 2000;26(2):106-111 1999;25(6):550-557 1999;25(2):100-104 $1999 ; 25(6): 610-615 \quad 1997 ; 23(4): 241-242 \quad 1999 ; 25(2): 85-99$ 1998;24(5):351-357 1998;24(1):46-53 2000;26(5):443-448 1998;24(3):197-205

The following articles refer to this text: $2001 ; 27(3): 157-160$; 2001;27(3):214-215; 2002;28(1):58-63; 2003;29(1):64-70; 2003;29(4):304-313; 2001;27(4):295; SJWEH Supplements 2008;(5):22-26; 2009;35(4):294-300; 2009;35(4):284-293; 2009;35(4):241-243; SJWEH Supplements 2009;(7):15-23; 2013;39(1):106-111; 2020;46(5):542-551

Key terms: attributable fraction; burden of disease; epidemiologic estimate; epidemiologic method; fatality; Finland; health statistics; occupational exposure; occupational factor

This article in PubMed: www.ncbi.nlm.nih.gov/pubmed/11444413

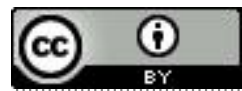




\title{
Epidemiologic estimate of the proportion of fatalities related to occupational factors in Finland
}

\author{
by Markku Nurminen, PhD, ${ }^{1}$ Antti Karjalainen, $M D^{1}$
}

Nurminen M, Karjalainen A. Epidemiologic estimate of the proportion of fatalities related to occupational factors in Finland. Scand J Work Environ Health 2001;27(3):161-213.

\begin{abstract}
Objectives This study attempts to estimate the proportion of annual deaths related to occupational factors in Finland and considers related methodological issues and associated uncertainties.

Methods Statistics on causes of death, numbers of subjects exposed, and risk ratios obtained from the epidemiologic literature were used to estimate the population attributable fraction and disease burden for causes of death from work-related diseases. Gender-, age- and disease-specific numbers of deaths were provided by Statistics Finland for 1996. Information on the size of the population, broken down by gender, age, occupation, and industry, was acquired from population censuses. A Finnish job-exposure matrix supplied data on the prevalence of exposure for specific agents and the level of exposure among exposed workers.

Results The attributable fraction of work-related mortality in the relevant disease and age categories was estimated to be $7 \%$ ( $10 \%$ for men and $2 \%$ for women), and for all diseases and ages the fraction was $4 \%$. For the main cause-of-death categories, the attributable fraction became $12 \%$ for circulatory system diseases, $8 \%$ for malignant neoplasms, $4 \%$ for respiratory system diseases, $4 \%$ for mental disorders, $3 \%$ for nervous system diseases, and $3 \%$ for accidents and violence. The following estimates were obtained for specific important diseases: $24 \%$ for lung cancer, $17 \%$ for ischemic heart disease, $12 \%$ for chronic obstructive pulmonary disease, and $11 \%$ for stroke. Based on these fractions, the total number of work-related deaths that occurred in Finland in 1996 was calculated to be on the order of 1800 (employed work force of 2.1 million); $86 \%$ involved men.

Conclusions High-quality epidemiologic studies and national survey data are essential for obtaining reliable estimates of the proportion of deaths attributable to occupational factors. The magnitude of work-related mortality is an insufficiently recognized contributor to total mortality in Finland, especially from circulatory diseases and other diseases caused by exposure to agents other than asbestos.
\end{abstract}

Key terms attributable fraction, burden of disease, epidemiologic methods, health statistics, occupational exposure.

Global estimates of the burden of disease due to occupational factors have been calculated through the application of Finnish rates of registered work-related diseases (1). The approach is subject to the following two fundamental uncertainties: (i) the validity of the data on disease incidence from the national reporting scheme and (ii) the validity of worldwide extrapolations to different regions with different exposure circumstances. With the exception of studies using workers' compensation records, only a few research projects have estimated the magnitude of morbidity or mortality induced by exposure to hazardous agents or stress factors in the work environment at a state or national level. The in- vestigations conducted in this area have covered New York State (2), the whole of the United States (3), Canada (4), and Australia (5). Given the lack of direct reliable data on morbidity or mortality due to work-related disease, these studies used the indirect method of applying the attributable fraction (6) to estimate incidence rates and the total number of deaths in major disease categories. In this approach, attributable fractions were applied to the vital statistics on disease incidence and mortality in the general population. However, for many disease categories, inadequate scientific evidence was available for an accurate estimation of the proportion of cases attributable to occupational factors.

Correspondence to: Dr Markku Nurminen, Department of Epidemiology and Biostatistics, Finnish Institute of Occupational Health, Topeliuksenkatu 41 a A, FIN-00250 Helsinki, Finland. [E-mail: Markku.Nurminen@ occuphealth.fi] 
Consequently, the assigned proportions and their ranges represent crude approximations that relied on professional, though subjective, judgment concerning the work-relatedness of various diseases.

The aim of this study was to estimate the mortality from work-related disease (or injury) in Finland and to consider methodological issues and associated uncertainties. We tried to obtain gender-specific estimates of the population attributable fractions by reviewing epidemiologic studies of cancers and other major diseases that contribute to the burden of fatal work-related disease. We aimed to find, for each disease, the risk estimate that would be the most valid for the Finnish exposure circumstances. Fortunately, many high-quality epidemiologic studies have been conducted in occupational health in recent years in Finland. These studies, supplemented by studies from Scandinavia and other industrialized countries similar to Finland, yielded sufficiently specific and valid data for the accurate estimation of the attributable fractions. These estimates were applied to the cause of death statistics in Finland for 1996 to compute the total number of fatalities. Although this paper is written from the point of view of Finnish conditions, it may nevertheless offer a perspective of work-related mortality for wider circumstances.

\section{Example of the description of agents in FINJEM (14)}

Domain: Chemical agents Name: Polycyclic aromatic hydrocarbons (PAHs)

Definition of unit: $\mu \mathrm{g} / \mathrm{m}^{3}$, microgram of all PAH compounds in cubic meter of workroom air

Definition of exposure: Occupational, inhalatory exposure to particulate or volatile PAH compounds including 2-ring PAHs (naphthalene), 3-ring PAHs (phenanthrene, anthracene, carbazole, fluorene), and 4-n -ring PAHs (e.g., pyrene, benzo(a)pyrene, chrysene, benzo(ghi)perylene)

Assessment threshold: Possibly at least $5 \%$ of the occupation exposed to an annual mean level of $0.1 \mu \mathrm{g} / \mathrm{m}^{3}$ of the agent at any time in 1945-95

Lowest mean value: $0.05 \mu \mathrm{g} / \mathrm{m}^{3}$ Highest mean value: $70.0 \mu \mathrm{g} / \mathrm{m}^{3}$

Remarks: Nonoccupational annual mean exposure originating from indoor emissions (tobacco smoke, fireplaces) and ambient air (traffic, combustion processes) does not usually exceed 0.1 $\mathrm{mg} / \mathrm{m}^{3}$

\begin{tabular}{lccr} 
Occupation & $\begin{array}{l}\text { Time } \\
\text { period }\end{array}$ & $\begin{array}{l}\text { Percentage } \\
\text { of exposed } \\
\text { persons }\end{array}$ & $\begin{array}{l}\text { Level of } \\
\text { exposure }\end{array}$ \\
\hline Metal smelting furnacemen & $1960-84$ & 100 & 12.0 \\
Welders and flame cutters & $1960-84$ & 9.6 & 1.1 \\
Cookers and furnacemen & $1960-84$ & 18.3 & 70.0 \\
(chemical processes) & & & \\
Etc & & & \\
\hline
\end{tabular}

Total number exposed workers in 1960-84 (percentage of the 1970 population)

Men: $68928(6.6 \%) \quad$ Women: $1773(0.2 \%)$

\section{Data and methods}

\section{Cause-of-death statistics and population statistics}

The numbers of subjects exposed, the population sizes, and the risk ratios (RR) were used to estimate the population attributable fractions of death in the cause-, gender-, and age-specific categories that conceivably could be at risk from work-related disease in Finland. The number of fatalities was available from Statistics Finland by cause of death (3-digit code), gender, and age (5-year group). The official cause-of-death statistics, which use the 10th revision of the International Classification of Diseases (ICD-10) (7), were for 1996 (8). Occupational accidents were compiled by the Federation of Finnish Insurance Companies (9) and the Farmers' Social Insurance Institution (10). We did not rely on the Register of Occupational Diseases in Finland maintained by the Finnish Institute of Occupational Health (11) because the reporting activity is probably influenced by the national practice of compensating occupational diseases. Accordingly, the register underestimates the number of workers who become incident cases annually, especially for ischemic (or coronary) heart disease (IHD) and chronic obstructive respiratory disease. Neither does the register provide data on deaths.

Information on the size of the population, broken down by gender, age, and occupation and industry, was acquired from Finnish censuses in 1970 (12) and 1990 (13); the former data were used for diseases with a long latency period (eg, typically 25 to 40 years for asbestos-induced cancers). A national job-exposure matrix, FINJEM (14), provided data on the average number of exposed workers in Finland in 1960-1984 and 19851994. The occupational exposures consist of 74 chemical, physical, and microbiological agents based on occupational hygiene measurements. In addition, we used questionnaire information on ergonomic and psychological or stress factors from quality of worklife surveys performed by the Finnish Institute of Occupational Health in cooperation with Statistics Finland. (For an example, see reference 15.) The exposures included in FINJEM are described by the prevalence and level of exposure among the exposed, both estimated mainly according to continuous scales. Thus the system enables one to quantify the exposure-response relation.

The assumption about the relevant age range is crucial because deaths are heavily skewed towards older persons. In estimating the deaths due to occupational factors, we excluded decedents aged $\leq 24$ years for all causes of death from disease. The exposure interval before the age of 25 years is probably too short to have a pathological effect for most young workers. For most carcinogens the exposure interval even before the age of 40 years may be too short. However, we did not 
exclude the very few deaths in this age range. For malignant neoplasms, chronic respiratory diseases, mental disorders, and nervous system diseases, it is important to include the age category $\geq 65$ years because of the long latency period of these diseases. For circulatory diseases, whose mortality risk carries over to retirement age $(16,17)$, which is about 59 years on the average in Finland (although the official retirement age is 65 years), we reduced the risk, somewhat arbitrarily, by $25 \%, 50 \%$, and $75 \%$ in the vulnerable age ranges of $60-64,65-69$, and $70-74$ years, respectively. We ignored decedents aged $\geq 75$. (See, for example, reference 18). For diseases of the digestive system and for infectious diseases, the upper age limit was set at 64 years. For accidents at work, the included age range was 15-64 years because of the exact records.

In estimating the proportion of the total population exposed to an occupational factor, we restricted the age range to 25-64 years. People under 25 years of age were excluded because deaths that occurred in this age category were not counted. People $\geq 64$ years of age were also excluded because very few persons are employed after the official retirement age.

\section{Attributable fraction methodology}

The population attributable fraction measures the fraction of disease cases that is attributable to an exposure in a population and that would not have been observed if the exposure had been nonexistent. The population attributable fraction can be estimated both for cohort and case-referent studies.

For cohort data on disease risk (under the assumption of no confounding), the formula is as follows (19):

$$
\mathrm{AF}=\mathrm{P}(\mathrm{RR}-1) /[\mathrm{P}(\mathrm{RR}-1)+1],
$$

(equation 1)

where $\mathrm{AF}$ is the attributable fraction, $\mathrm{RR}$ is the risk ratio or rate ratio (whichever measure was estimated) for the exposed, with the unexposed as the referent, and $\mathrm{P}$ is the proportion exposed in the cohort (source population). If adjustment for confounding is needed, an equivalent formula that produces an unbiased attributable fraction estimate is as follows (20):

$$
\mathrm{AF}=\mathrm{P}_{\mathrm{c}}\left(\mathrm{RR}_{\mathrm{a}}-1\right) / \mathrm{RR}_{\mathrm{a}},
$$

(equation 2)

where $R R_{a}$ is the adjusted estimate of the RR (assumed to be uniform across the strata of the confounding factors) and $\mathrm{P}_{\mathrm{c}}$ is the exposure prevalence among the cases. Unfortunately, information about $\mathrm{P}_{\mathrm{c}}$ is seldom available for a total target population that would permit the estimation of the adjusted attributable fraction according to equation 2 . If the only information available is $P$, then the substitution of $R_{\mathrm{a}}$ to equation 1 may be the best possible method. However, this method produces biased estimates $(21,22)$. The magnitude of bias will depend on the degree of confounding. If the unadjusted RR were available, then an unbiased estimate can be obtained by replacing $\mathrm{P}_{\mathrm{c}}$ in equation 2 by the expression $\mathrm{P} \times \mathrm{RR} /[\mathrm{P}(\mathrm{RR}-1)+1]$ to obtain $(20)$ :

$$
\mathrm{AF}=\{\mathrm{P} \times \mathrm{RR} /[\mathrm{P}(\mathrm{RR}-1)+1]\}\left(\mathrm{RR}_{\mathrm{a}}-1\right) / \mathrm{RR}_{\mathrm{a}} \text {. (equation 3) }
$$

A corresponding equation for case-referent sampling studies, analogous to equation 2, is as follows (23):

$$
\mathrm{AF}=\mathrm{P}_{\mathrm{c}}\left(\mathrm{OR}_{\mathrm{a}}-1\right) / \mathrm{OR}_{\mathrm{a}}
$$

where $\mathrm{OR}_{\mathrm{a}}$ is the adjusted odds ratio. Equation 4 can be derived from equation 1 if it is assumed that the disease risk is low in the population from which the cases arose. Hence the proportion exposed in the study population (P) can be estimated from the exposure prevalence among the noncase ("reference") subjects, and the odds ratio approximates RR (23).

However, the exposure proportion in the source population - especially in a study population located outside Finland (as, eg, in reference 24) — may be markedly different from that in the target population to which the RR estimate would be applied in Finland. In this case, the estimate of $\mathrm{P}$ obtained from Finnish sources was used in the presented equations.

Given an array of significant risk factors, the computation of the attributable fraction due to all of the risk factors simultaneously can be performed by a general method for both cohort and case-referent studies (25). However, the original data sets were not available for the multivariate analysis. Therefore, we estimated an overall

\section{Attributable fraction concept}

- The population attributable fraction is the proportion of the total burden of a disease that is related to a given risk factor in a population.

- The attributable fraction can be interpreted as the fraction of a disease which would not have occurred had the factor been nonexistent in the population in question.

Illustration of the estimation of attributable fraction

- In a pooled analysis of two case-referent studies on lung cancer in Germany (24), 716 of the 3498 men who formed the cases were exposed to diesel engine exhaust (ie, the exposure prevalence among the cases was $20.5 \%$ ). The unadjusted odds ratio $(\mathrm{OR})$ was 1.91 , and the adjusted $\mathrm{OR}$ was $O R_{a}=1.43$. The application of equation 4 yields an attributable fraction (AF) estimate of $0.205 \times(1.43-1)$ / $1.43=6.2 \%$ for the German study population.

- The German occupational exposure levels may, however, not be comparable to the Finnish ones. Therefore, we calculated an alternative attributable fraction estimate. In the Finnish male population the proportion of men occupationally exposed to diesel engine exhaust in around 1970 was $46780 / 1041720=4.5 \%$. Using the preceding OR estimates, equation 3 yields $A F=\{0.045 \times 1.91 /[0.045 \times(1.91-1)+1]\}$ $\times(1.43-1) / 1.43=2.5 \%$. 
attributable fraction for multiple risk factors in terms of the component attributable fractions by making a strong assumption of statistical and biological independence between the factors as follows (20):

$$
\mathrm{AF}=1-\left(1-\mathrm{AF}_{\mathrm{a}}\right) \times\left(1-\mathrm{AF}_{\mathrm{b}}\right) \ldots, \quad \text { (equation 5) }
$$

where $\mathrm{AF}_{\mathrm{a}}$ is related to exposure a, and so forth. As an example, occupational exposures to metal dust and wood dust were considered biologically independent risk factors for cryptogenic fibrosing alveolitis (26) (ie, both factors predict the disease occurrence, but the factors do not modify each other's effects). In this case both factors were jointly present in equation 5 . We attempted to achieve the assumption of statistical independence by excluding risk factor $b$ from equation 5 if an occupational hygienist of the Finnish Institute of Occupational Health assessed that exposure to $b$ was highly associated with exposure to a. For instance, insulators engaged in construction work were exposed to asbestos and silica, both of which are recognized lung carcinogens. Therefore, calculating the component attributable fractions for the two factors involving simultaneous exposure to both, and including them in equation 5, would result in an overestimate of the composite attributable fraction for lung cancer.

If the exposures overlap only partly, then one way of dealing with the problem is to estimate the number of workers exposed to factor a plus those exposed to factor $b$ but not to factor $a$. This worker population can be identified from the job-exposure matrix by examining the occupational distribution of workers exposed to agents. For example, shift work and environmental tobacco smoke $^{2}$ are putative risk factors of IHD. Some shift-work professions (eg, waitering work in restaurants, cafés, and bars) expose workers to environmental tobacco smoke. It was estimated that about $40 \%$ of the employees who were passive smokers at work had a work pattern that extended beyond the conventional 8hour workday in Finland in 1997 (15). To avoid an overestimation of the total attributable fraction for IHD due to work characteristics, we reduced the number of those exposed to environmental tobacco smoke by $40 \%$.

There may be situations, however, in which an excluded factor acts synergistically with one of the included factors (27). For example, it may not be correct to assert that the risk of lung cancer due to lead exposure is the same regardless of whether the work environment is polluted by engine exhaust or is free of gases. Ignoring such a synergistic effect results in bias. As for the direction of the bias, the composite estimate of the attributable fraction is prone to be "diluted" relative to what would prevail if the excluded factor would be properly modeled in a multivariate analysis. Despite the importance of the interactions between occupational exposures and other risk factors, we did not attempt to estimate separately their main effects and synergistic effects because of the general lack of reliable data on such relations and on the pertaining numbers of exposed workers. Two notable examples of such effects were the multiplicative interaction of asbestos exposure and tobacco smoking on lung cancer risk (28) and the interaction (intermediate between additive and multiplicative) between arsenic exposure and tobacco smoking in relation to the risk of developing lung cancer (29).

Estimates of RR values for disease incidence were used instead of mortality RR values when the latter were not available. When an epidemiologic study was based only on the experience among men, the same estimated RR was also applied to women, given that the exposure to the risk factor was comparable, and vice versa. The attributable fraction for women was then computed as follows:

$$
\mathrm{AF}_{\mathrm{w}}=\mathrm{AF}_{\mathrm{m}} \times \mathrm{P}_{\mathrm{w}} / \mathrm{P}_{\mathrm{m}}
$$

(equation 6)

where $\mathrm{P}_{w}$ and $\mathrm{P}_{\mathrm{m}}$ are the respective proportions of exposed women and men in the population. When attributable fractions were only available for both genders combined, the gender-specific attributable fractions were computed from equations $2-3$, on the assumption that the RR or OR values were equal for both genders.

Example. As an illustration of the estimation of attributable fraction using the alternative formulas, consider shift work as a risk factor for IHD. The proportion of shift workers in a Finnish cohort of 1806 industrially employed men equaled $\mathrm{P}=666 / 1806=36.9 \%$ (30). The "crude" (ie, only age-adjusted) estimate of the risk ratio for total IHD (incidence and mortality) was $\mathrm{RR}=1.48$, and the multivariate-adjusted one was $\mathrm{RR}_{\mathrm{a}}=1.38$, according to Cox's regression (proportional hazards) models (31). An unbiased estimate of the attributable fraction was obtained using equation 3 with the values of $P$, $\mathrm{RR}$, and $\mathrm{RR}_{\mathrm{a}}: \mathrm{AF}=\{(0.369 \times 1.48) /[0.369 \times(1.48-1)+$ $1]\}(1.38-1) / 1.38=12.8 \%$. Of all the 153 industrial workers who suffered a myocardial infarction, 73 were shift workers (L Tenkanen, personal communication), so that the exposure prevalence among the cases of IHD was $\mathrm{P}_{c}=47.7 \%$. The application of equation 2 gave an alternative estimate of $\mathrm{AF}=$ $0.477 \times(1.38-1) / 1.38=13.1 \%$. Equation 1 , with the values

2 Definition of environmental tobacco smoke at work in the FINJEM (14): occupational, inhalatory exposure to tobacco smoke from cigarettes, pipes, or cigars due to smoking of workmates or clients. Does not include passive smoking at home (spouse, other people of the household) or during leisure time (bars, etc). The estimates of the proportion of workers exposed to environmental tobacco smoke are based on the data from the quality of worklife survey made in 1990 by Statistics Finland. Only persons reporting exposure during at least $25 \%$ of their workhours are considered exposed. Only occupations having at least $5 \%$ of workers exposed are included. 
of $\mathrm{P}$ and $\mathrm{RR}_{\mathrm{a}}$, produced only a slightly attenuated point estimate, $\mathrm{AF}=0.369 \times(1.38-1) /[0.369 \times(1.38-1)+1]=$ $12.3 \%$, because confounding was minor.

However, the aforementioned proportion of shift workers $(\mathrm{P}=37 \%)$ pertained to an industrial population, and it is probably an overestimate of the proportion in the general population. The average proportion of people with worktime arrangements in the total Finnish male population aged 25-64 years in 1985-1994 was estimated using the quality of worklife survey conducted in 1990 to be $\mathrm{P}=328700 / 1363800=$ $24.1 \%$ (source: FINJEM). For women the corresponding proportion was $\mathrm{P}=24.3 \%$. These figures may be underestimates because of the difficulty to define shift work unambiguously. A part of irregular work and night work may not be included in the definition of shift work. A population-based survey (32), which targeted the entire employed workforce, came up with an estimate of $\mathrm{P}=29 \%$. Another survey (33) on work conditions reported that $30 \%$ of salaried workers are not employed in regular daytime work. We thus took the proportion of shift workers to be $30 \%$. When this figure was inserted into equation 3 , the final estimate of the attributable fraction for men became $10.7 \%$.

In a United States cohort study (34) on shift work and IHD among female nurses, the multivariate-adjusted risk ratio estimate was $\mathrm{RR}_{\mathrm{a}}=1.19$ for fatal myocardial infarction, and the age-adjusted one was $\mathrm{RR}=1.23$. In this study, also the total IHD risk (nonfatal myocardial infarction and fatal IHD) was lower for the women than the corresponding risk in the Finnish study on men. An application of equation 3 for women yielded an attributable fraction estimate of $5.5 \%$.

As statistical criteria for a significant association, we used an RR with the lower limit of the $95 \%$ confidence interval $(95 \% \mathrm{CI})$ exceeding 0.9 and a positive trend for the RR over increasing exposure levels at the $5 \%$ significance level. We were unable to provide interval estimates of the attributable fractions for three reasons. First, the data needed to calculate the standard errors of the attributable fraction estimates for individual risk factors were not obtainable from most of the study reports. Second, estimation of the standard errors of the attributable fractions is problematic when the RR and population exposure prevalence data come from different sources. Third, the interval estimation of attributable fractions for a composite risk factor is generally not feasible unless one uses the regression approach (25). In any case, the imprecision due to statistical variability, especially in a meta-analysis, is likely to be overridden by the uncertainty arising from the many assumptions underlying the estimation of the attributable fraction. Instead, we performed a sensitivity analysis (see the Discussion section) for the most important associations (asbestos and lung cancer, shift work and IHD).

Finally, attributable fraction is not to be interpreted as the "probability of causation" (or its generalization, the "attributable proportion of risk") $(35,36)$, a term used in compensation lawsuits. The public-health interpretation of the attributable fraction is the potential caseload reduction as a result of the removal of the risk factor in question. In addition to the preceding assumptions, this interpretation assumes that removing the risk factor will not affect the size of the population at risk (6).

\section{Evidence and rationale for risk ratios and attributable fractions}

Estimates of "causal" RR values, that is, the proportionate increases in average risks among the exposed due to a causal exposures (6), were based on the evidence culled from epidemiologic literature and register statistics, as well as from consultations with experts in the fields of occupational medicine, occupational hygiene, toxicology, and the like. (See the acknowledgments.) We considered both known and suspected occupational risk factors. We prioritized studies in which specific agents were implicated in the etiology of the diseases; secondarily, we considered studies that linked diseases with occupations or branches of industry. Preference was given to studies conducted in Finland and Scandinavia, but estimates were also taken from studies carried out in western Europe, North America, and countries with a basically similar industrial development as in Finland. We included findings from cohort studies, population-based (or hospital-based) case-referent studies, and record-linkage studies. In the assessment of the best available evidence, we considered the main criteria for causation to be the strength of the association, the presence of a dose-response relation, the specificity of the association, the consistency of the results, and the analogy to a previously proved causal relation (6). We evaluated the methodological quality of the reviewed studies with a special view to the recording of occupational histories and to the consideration of biases. Only high-quality studies, in which exposures were fairly

\section{Basic estimation approach}

- Risk ratio (RR) estimates for specific exposure-disease associations were identified from epidemiologic studies

- When the RR values were based on disease incidence studies, an assumption was made that the incidence rate ratio was comparable to the corresponding mortality risk ratio.

- The proportion of people exposed to an occupational risk factor was obtained from census data on occupation and branch of industry with the aid of a Finnish job-exposure matrix.

- The RR values and exposure proportions were then used to calculate the attributable fractions (AF) of deaths according to equations 1-6.

- Finally, the attributable fractions were applied to the causeage-, and gender-specific mortality statistics of Finland for 1996 to obtain estimates of the number and proportion of work-related fatalities. 
accurately measured or recalled, disease outcome was classified according to the ICD, and confounding by extraneous factors was reasonably well prevented in the study design or controlled in the data analysis, were accepted as references for the cause-effect relations. In this section, we concentrate on categories that carry the greatest burden of disease and on select exposure-disease associations for which new epidemiologic knowledge has recently been gained. The disease-by-exposure list with references is presented in the appendix. Although the attributable fraction estimates are given with one decimal, one should consider their relative magnitude, rather than be concerned about overprecision. We have given precise figures not because we think that they are absolutely correct but so that our estimates can be corrected as further information accrues from future studies of specific diseases.

\section{Cancers}

The International Agency for Research on Cancer (IARC) classifies the evidence for human carcinogenicity of specific exposures into the following five categories (37): carcinogenic, probably carcinogenic, possibly carcinogenic, not classifiable as to carcinogenicity, and probably not carcinogenic. For an agent to be classified as carcinogenic there must be sufficient evidence from studies on humans. Sufficient evidence implies that a causal relation has been established between exposure to the agent, mixture, or exposure circum-

\section{Criteria used for selecting the studies}

The studies that served as the basis for the attributable fraction estimates were selected primarily using the following criteria:

- Epidemiologic studies conducted in

- Finland and Scandinavia

- western Europe

- North America

- other countries with industrial development that resembled Finland's

- High methodological quality with regard to

- accurate assessment of exposure

- precise diagnosis of disease according to international classification

- important confounding factors reasonably well under control

- Causality of the exposure-disease association assessed mainly by

- specificity of the association

- strength of the association, including the presence of a dose-response relation

- consistency of the result with summary results from reviews and meta-analyses

- analogy to a previously proved causal relation stance and human cancer and that chance, bias, and confounding can be ruled out with reasonable confidence. By 1995, IARC had classified 22 occupational agents as human carcinogens and an additional 22 agents as probable human carcinogens (38). In addition, evidence of increased risk of cancer has been associated with particular industries and occupations, although no specific agents have been identified as etiologic factors. Although IARC classifies agents according to their carcinogeneity only overall, specific sites are also considered. Most estimates of the attributable fractions used by us were supported by recent investigations on the links between the exposure to a number of definite and probable carcinogenic agents or processes in the workplace, and the incidence and mortality risks of specific cancers. Today many of the significant risks represent well-known relations, whereas other agents are classified as possible or suspected carcinogens. Examples of the former links include that between asbestos and lung cancer and that between wood dust and nasal cancer, whereas examples of the latter links include that between asbestos and gastrointestinal cancer and that between polycyclic aromatic hydrocarbons and urothelial cancer. Other work-related cancer studies have demonstrated increased risks for specific industrial branches and job titles without a clear identification of the responsible agent, although certain exposures are suspected $(39,40)$. The following are examples of such work-related associations: tobacco workers (cigarette smoking) and restaurant and bar workers (environmental tobacco smoke) with rectum cancer, milkmaids [aflatoxins (41)] with liver cancer, hairdressers and barbers [with limited evidence that occupation as a hairdresser or barber entails exposures that are carcinogenic (42)] with ovarian cancer, and rubber industry workers (aromatic amines, solvents) with bladder cancer (39). Nonmalignant neoplasms and malignant neoplasms of unspecified sites were excluded. Some well-known relations, such as that between arsenic and skin cancer (nonmelanoma) and that between ionizing radiation and leukemia, were excluded because occupations with the exposures are rare in Finland.

Lung cancer. Our selection of the attributable fraction estimates for lung cancer relied on the results from occupational cohort studies conducted in Finland (43-47) and Sweden $(29,48)$ and also on results from population-based case-referent studies carried out in Finland (49), Norway (50), Germany (24, 51—55), and Belgium (56).

A Finnish case-referent study (49) of male surgically treated patients from the greater Helsinki area was the primary basis for our RR estimate of 2.3 (95\% CI 1.3-3.9) for asbestos-induced lung cancer. An early cohort mortality study (57) of workers in an anthophyllite 
asbestos factory in eastern Finland had given the same RR point estimate. A combined RR estimate of $2.0(95 \%$ CI 1.9-2.1) was obtained in a meta-analysis of 20 cohort studies of asbestos-exposed workers (58). The Helsinki study used lung asbestos content measurements as an objective measure of exposure (59) and obtained an estimate of $19 \%$ (95\% CI 8-26\%) for the population attributable fraction for men. The attributable fraction of asbestos is mainly due to exposure in construction work. Extrapolation of this estimate to the whole male population of Finland in a comparison of the incidence rates of reported asbestos-related malignancies in the greater Helsinki area and all of Finland (60) resulted in an attributable fraction estimate of $14 \%$ (95\% CI 6$19 \%$ ).

A Norwegian study (50) on male lung cancer cases was conducted in two neighboring counties in the southern part of the country. When either title-related or exposure-related occupational information was used (altogether 22 agents or processes were assessed), this study showed a statistically increased risk for lung cancer among persons judged to have been exposed to respiratory carcinogens, especially asbestos, and other industrial pollutants, in their work. However, several of the exposures were correlated. For instance, half of the cases exposed to either stainless steel welding fumes or fertilizers were also exposed to asbestos. This study provided useful quantitative information on the interaction between asbestos exposure and smoking.

The design of the German study (51) resembled that of the Norwegian one (50), but was much larger and involved both genders (839 male cases and 686 female cases; a later pooled analysis of two case-referent datasets (55) involved 3498 cases among men. The assessment of occupational exposure was derived from a job history, an exposure checklist for known and suspected carcinogens, and 33 job-specific questionnaires. The analysis adjusted for smoking and asbestos exposure and found that their joint effect was multiplicative. As expected a priori, significant associations with increased lung cancer risk were observed for several industries, occupations, and specific exposures such as asbestos (54), crystalline silica (54), man-made mineral fibers (54), polycyclic aromatic hydrocarbons (54), welding fumes (52), and diesel engine emission (24). Many of the industries or occupations for which an increased risk was found were ones for which the responsible agent was known or suspected, for example, the rubber industry (solvents) and metal production (cadmium and nickel) among men and personal service work in hotels and restaurants (environmental tobacco smoke), stock clerking and storage and warehousing work (diesel engine exhaust) among women.

There is sufficient evidence of an increased risk for lung cancer among miners in underground work due to radon and its progeny (61). In Finland, the risk of lung cancer among radon-exposed workers in a copper and a zinc mine was 2.3 times that expected (44). The impact of occupational exposure to radon in mining and quarrying is minor, owing to the small number of exposed workers: the number of miners has decreased from 3600 in 1970 to 400 in 1998 (62). However, there is potential radon exposure to large numbers of workers in poorly ventilated buildings, although generally less than miners' exposure (58). According to a carcinogen exposure database (63), 49000 people were regularly working in Finland in the early 1990s in workplaces whose average annual radon dose exceeded the nonoccupational dose limit of $400 \mathrm{~Bq} / \mathrm{m}^{3}(62)$.

There is also sufficient evidence that exposure to crystalline silica is carcinogenic in humans (64). Data on a cohort of 1026 Finnish granite workers exposed to pure silica dust showed a $40 \%$ increased mortality from lung cancer (47). This finding is supported by earlier Finnish studies on male silicotics $(65,66)$. A combined excess risk of $33 \%$ was estimated in a meta-analysis of 16 larger cohort and case-referent studies of silica-exposed workers (58). In a new German study (54), 23\% of the 3498 men who formed the case group had worked for at least half a year in a job with a silicosis risk. Their risk was also elevated by about $40 \%$. Thus we applied the RR of 1.4.

To avoid co-exposure with asbestos in the calculation of the attributable fraction, we excluded most construction work, metallurgical work, and foundry occupations from occupations carrying a risk of exposure to silica. Miners were also excluded because of their concomitant exposure to radon and diesel exhaust. We included only stone cutters, glass, ceramic and clay workers, bricklayers, plasterers and tile setters, concrete shutterers and finishers, and assisting building and construction workers.

Several other agents capable of causing lung cancer in humans have been classified as definite or probable carcinogens by IARC. These agents include acrylonitrile, arsenic, cadmium, hexavalent chromium, and nickel. However, new evidence and a review of the previous literature do not support a causal relation between acrylonitrile exposure and lung cancer $(67,68)$. For arsenic, a combined RR estimate of 3.7 was obtained from seven studies in which worker populations had primarily a history of high exposures in the past (58). We used the summary RR estimate of 3.2 found in a Swedish study (29) for workers with 10 to 29 years of arsenic exposure and who smoked 1 to 10 cigarettes per day. Recent studies on humans support the conclusion that the evidence for cadmium as a definite carcinogen is rather weak; its probable carcinogenicity to humans has been suggested as a more appropriate classification (69). We used the RR estimate of 1.2 found in five studies of 
cadmium workers (48). In one review, the ten selected largest and best-designed studies of workers exposed to hexavalent chromium yielded an overall RR of 2.8 (58). Our estimate for chromium comes from a Belgian hospital-based case-referent study (56) conducted in a highly industrialized region; it showed a weaker risk ratio of 1.4. Data from 13 international studies of the nickel and lung cancer relation gave a summary RR estimate of 1.6 (95\% CI 1.4-1.7) (70). Our RR estimate of 1.4 comes from a Finnish study of workers exposed to nickel sulfate (43).

Six studies conducted between 1986 and 1990 on lung cancer and exposure to diesel engine exhaust were fairly consistent, and they indicated a combined RR of 1.3 (58). The weight of evidence tends to confirm the judgment of IARC that occupational diesel engine exhaust is a probable lung carcinogen (71). A more recent pooled analysis of two large population-based case-referent studies carried out in Germany (24) yielded a pooled RR estimate of 1.4 for men. This estimate was based on job code information of having ever worked for at least 6 months in a job that involved exposure to diesel engine exhaust. When this RR was applied to the Finnish population, the attributable fraction estimate was $2.5 \%$ for men. (See the illustration of the estimation of attributable fraction on page 163.) In a new populationbased case-referent study (72) in Stockholm County, Sweden, occupational exposures were assessed by an occupational hygienist, who coded the intensity and probability of each exposure. This study estimated an attributable fraction of $2.7 \%$ for men and provided further evidence that emission from diesel engines is causally associated with an increased lung cancer risk. Diesel exhaust includes polycyclic aromatic hydrocarbons and other combustion by-products. These agents are also known to cause cancer of the urinary bladder and the esophagus (73).

The epidemiologic evidence for lead exposure has previously shown a fairly consistent increase, although small, in lung cancer risk $(74,75)$. Results from a cohort study from Finland (46) showed an excess risk for lung cancer and bladder cancer among 20700 workers exposed to lead. In view of these new data, an editorial on lead and lung cancer concluded (76): "When all the available evidence is taken into account, occupational exposure to lead and lead compounds should therefore be considered as carcinogenic to humans [p 3]."

For calculating the summary attributable fraction for lung cancer among men we scrutinized the interdependencies between several of the exposures and the provision of adjustment for concomitant occupational exposures. The following substances were included as independent risk factors: asbestos (and its interaction with smoking), arsenic (and its interaction with smoking), and cadmium, chromium, crystalline silica, diesel en- gine exhaust, lead, nickel, radon and welding fumes [mild steel welding $(52,77)]$. Hexavalent chromium and nickel welders [stainless steel welding (78)] were excluded from the estimate of the size of the chromium- and nickel-exposed populations in Finland. Excluded exposures included, among others, polycyclic aromatic hydrocarbons, man-made mineral fibers, metal dust (replaced by specific studies on exposure to arsenic, cadmium, lead, and nickel), leaded engine exhaust (46), solvent exposure of painters, and fertilizer exposure of chemical process workers. Some of the occupations, such as welder, sheet-metal worker, and transportation worker, can directly be connected with the exposure that the work involves (welding fumes, metal dust, and engine exhaust). However, we chose not to include any nonspecific industry or occupation categories that were highlighted in the Norwegian or German studies in the quantitative assessment; rather, we used the nonspecific results as corroborative evidence for the specific agents. In two occupational cohort studies, one among Finnish hairdressers (45) and the other among Finnish seafarers (79), women were found to have an elevated risk of lung cancer. The suspected agent in hairdressers' work was hair dyes. Because an elevated risk for lung cancer was also reported for hairdressers in the German study (51), hairdressing was added to the list of risky occupations. The seafarers' excess risk was probably caused by exposure to asbestos.

We also included environmental tobacco smoke as a risk factor for lung cancer. The causal relation between this factor and lung cancer has been strongly established $(80,81)$, but estimates of the magnitude of the risk vary. The Occupational Safety and Health Administration (OSHA) in the United States estimated that the RR for lung cancer among nonsmokers as a result of chronic exposure to environmental tobacco smoke ranges between 1.2 and 1.5 (82). In a meta-analysis of 37 studies on environmental tobacco smoke and lung cancer, Hackshaw et al (83) used a log-linear model for an exposureresponse relation to estimate a summary RR of 1.23 (95\% CI 1.13-1.34) for both genders on the basis of smoking patterns of spouses. Wells (84) reported the best summary estimate of the RR for lung cancer, specific to the sources of exposure to environmental tobacco smoke at work from the five studies (out of 14) that satisfied his rather strict quality criteria, to be 1.4 (95\% CI 1.2-1.7). Another meta-regression analysis of five eligible United States studies by Brown (85) predicted the increase in lung cancer risk due to the average exposure to environmental tobacco smoke at work (among those exposed at work) among nonsmoking women to be on the order of $25 \%$ (95\% CI $8-41 \%$ ). The excess risk from environmental tobacco smoke at work is typically lower than that from spousal smoking, but it may 
be greater at high levels of exposure (85). In yet another review, of 12 hospital-based and 4 population-based studies, Raynolds (86) concluded that the workplace risk estimates across studies tend to be consistent with those from exposure to a smoking spouse. A large IARC study (87) estimated an RR of 1.17 (95\% CI 0.94-1.45). The study found weak evidence of a dose-response relation between risk of lung cancer and exposure to environmental tobacco smoke at work. The IARC results on exposure to environmental tobacco smoke during adulthood are in agreement with the available evidence and, in particular, with the two large studies from the United States (88, 89). The former study showed a $39 \%$ excess risk for women ever exposed to environmental tobacco smoke in the workplace. The somewhat lower risk estimate found in the IARC study may be explained by the fact that most of its subjects reported having ended their environmental tobacco smoke exposure in relation to their spouse or workplace several years earlier. When the duration of exposure exceeded more than 30 years, the RR increased to about 1.25. For comparable exposure to tobacco smoke, the risk of lung cancer is comparable for men and women $(83,90)$. Therefore, our preferred estimate of the RR for exposure to environmental tobacco smoke at work was set equal to 1.25 for both genders. In 1985-1994, the estimated proportions of Finnish male and female workers reporting exposure to environmental tobacco smoke during at least $25 \%$ of their workhours were $12 \%$ and $8 \%$, respectively. [For men in the United States, the estimate of the fraction taken from the reference series of the Correa et al study (91) was $14 \%$ for those exposed to environmental tobacco smoke.] Under these assumptions, the attributable fractions for Finnish male and female populations became $3 \%$ and $2 \%$, respectively. However, the excess number of lung cancer deaths due to environmental tobacco smoke in 1996 reflects the exposures from previous decades when the number of passive smokers was considerably greater than today. But only a few of the published studies give quantitative estimates of exposure to environmental tobacco smoke (eg, in terms of exposure level and duration per workday). The new German study (55) quantified exposure as an index of duration and level of smokiness and concluded that the risk of ever exposure in the workplace was elevated $14 \%$ for women. Moreover, for the highest category of exposure, the lung cancer risk was nearly threefold, with a statistically significant trend.

Overall, our summary estimate of the attributable fraction for lung cancer became $29 \%$ for men and 5\% for women. Although there is clear analogy, we did not attribute cancers of other sites that are causally associated with active smoking (such as the larynx, esophagus, mouth and tongue, pancreas, lower urinary tract, and kidney) to environmental tobacco smoke because of inadequate data.
Prostate cancer. Prostate cancer is now the second leading cause of cancer mortality among men in Finland, after lung cancer. The evidence reviewed $(92,93,94)$ indicates that nonoccupational life-style and dietary factors have not been consistently associated with prostate cancer. A slightly elevated risk has been found for metal workers (95) and farmers and other agricultural workers (96-101). Of the occupational risk factors, cadmium compounds $(48,102)$ and herbicides (RR $1.3,95 \%$ CI 1.0-1.8) (103) have been linked with an excess risk of prostate cancer. In a study of rubber workers, the highest risk was observed in the work area with the greatest exposure to oxides of heavy metals (104). In a Swedish study (105), nitrate fertilizer workers had an elevated prostate cancer risk. A population-based casereferent study (106) among men in Montreal, Canada, provided evidence on the possible associations between many types of cancer, including prostate cancer, and hundreds of occupational exposures. There was moderately strong support for risk of prostate cancer due to metal dust (RR 1.2, 95\% CI 0.9-1.8). Aronsen et al (106) concluded: "While the population attributable risk, estimated at between $12 \%$ and $21 \%$ for these occupational exposures, may be an overestimate due to our method of analysis, even if the true attributable fraction were in the range of 5-10\%, this represents an important public health issue [p 363]." The upper limit of the 95\% CI for the attributable fraction for prostate cancer was 30\%. Extrapolation to Finland, based on the risks from exposure to metal dusts and herbicides, yielded a conservative estimate of $6 \%$.

Pancreatic cancer. Several occupational exposures seem to be associated with the risk of pancreatic cancer, but the results are not fully consistent (107). The Finnish examination of the risk of pancreatic cancer associated with occupation, by industrial branch and job titles, was conducted in a nationwide case-referent study (108). This study was designed in such a way as to be able to implicate also specific hazardous substances (109). Ionizing radiation, organic solvents (including aliphatic and aromatic hydrocarbons), pesticides (insecticides and herbicides), inorganic dust containing crystalline silica, and rubber chemicals including acrylonitrile were identified as plausible causative factors. A Spanish case-referent study (110) using FINJEM lent moderate support to the association between exposure to each type of pesticide group and pancreatic cancer. A meta-analytic study (111) of 20 populations published between 1969 and 1998 concluded that verified exposure to chlorinated hydrocarbon solvents and nickel carried an excess risk for pancreatic cancer. Excesses were also found for, among other agents, particulate and volatile polycyclic aromatic hydrocarbons, organochlorine insecticides, silica dust, and aliphatic and aromatic hydrocarbon 
solvents. The occupational attributable fraction of pancreatic cancer was estimated to be $12 \%$. With the selection of the aforementioned agents, our attributable fraction estimate of pancreatic cancer was set at $13 \%$ for men and $3 \%$ for women.

Cancer of the stomach, colon and rectum. Several epidemiologic studies have reported associations between occupations and stomach cancer (112). However, the results have been inconsistent. More recently, specific workplace exposures have been studied in more detail in a large population-based case-referent study in Montreal, Canada (113). The referents in a Finnish pancreatic cancer study $(108,109)$ were cases of cancer of three sites, primary malignant neoplasms of the stomach, the colon (the large intestine) and the rectum. We inverted the design and reanalyzed the data to yield risk estimates for these three cancers with pancreatic cancer cases serving as the reference series. Some occupations with an increased risk involved plausible exposures to carcinogenic substances. In particular, asbestos exposure was associated with elevated RR values for stomach cancer, colon cancer, and rectum cancer (109). In a Canadian study (114) of chrysotile asbestos workers, severe exposure was associated with elevated $R R$ values for cancers of the upper and lower gastrointestinal tract, but rather unclearly. For other abdominal cancers, risks and exposure were not positively associated. A Swedish population-based case-referent study (115) also found elevated risks of colon and rectal cancer among subjects exposed to asbestos. To be consistent with these results, we excluded the relation of asbestos exposure with stomach cancer, but included the relation of asbestos with colon cancer and rectum cancer. In case of gastric cancer, we included farming work that involved exposure to herbicides (116) and also grain and animal dust as a risk factor. A dusty work environment in many other occupations has been linked with a risk of gastric cancer $(117,118)$. The Montreal study (113) also reported an elevated risk of gastric cancer for specific workplace dusts (grain dust, lead dust, and zinc dust). For colon cancer, the other included occupational exposures were welding and soldering fumes and gases. A consistent observation in a Swedish register-linkage study (119) reported a significant excess of colon cancer among metal smiths and foundry workers in the metal manufacturing industry.

Cancer of the urinary bladder. The best-known etiologic cause of work-related cancer of the urinary bladder is a group of aromatic amines that includes industrial chemicals used as intermediates in the manufacture of dyes, paints, and plastics and also chemicals used as antioxidants in the preparation of rubber for the manufacture of tires and cables (120). The proportion of bladder cancer due to occupational exposure varies with the industrialization of the area in question. In heavily industrialized countries the attributable fraction may be as high as $25 \%$ for men (121). A combined analysis of data from six European countries furnished an estimate of attributable fraction of $8 \%$ for women (122). Our overall attributable fraction estimate became $14 \%$ for men and $1 \%$ for women. Other included occupational exposures were lead (46), hydrocarbon solvents (14), and polycyclic aromatic hydrocarbons $(73,123)$.

Cancer of the female breast and genital organs. A comprehensive review of occupational risk factors for breast cancer among women revealed that few high-quality studies have been conducted that allow unambiguous conclusions (124). Notable exceptions are the longitudinal studies from Finland $(125,126)$, in which occupations from censuses were linked with subsequent cancer incidence. One of these studies (125) found an increased risk of breast cancer among health care personnel (RR 1.4, 95\% CI 1.2-1.5), especially among registered nurses (RR 2.0, 95\% CI 1.7-2.3). The other study (126) was directed towards specific agents with the aid of a job-exposure matrix and controlled for confounding by reproductive factors. For postmenopausal women, exposure to ionizing radiation was associated with an increased risk of breast cancer, an RR of $1.2(95 \%$ CI 1.1-1.3) for low-level and 1.4 (95\% CI 1.1-1.8) for medium- or high-level exposure, and there was a significant trend for the incidence RR values. The excesses for ionizing radiation were largely caused by slight excesses in large groups of physicians and nurses (126). A significant excess of breast cancer (RR 1.9, 95\% CI 1.2-2.2) has also been found among Finnish airline cabin attendants (long-haul passenger flights), most apparently after at least 10 years of exposure to cosmic radiation at work (127). An updated review concluded that ionizing radiation probably increases the risk of breast cancer among women (128). (See also reference 129.) An increased risk has also been observed among Finnish hairdressers (RR 1.2, 95\% CI 1.0-1.6) (45). Finally, exposure to asbestos, chlorinated hydrocarbons, and textile dust showed a significant association (126), indicating that there may be causal risk factors, but the evidence is still inadequate. Thus the attributable fraction estimate became $2 \%$.

Ovarian cancer is the primary cause of gynecological cancer fatalities in several industrialized countries. The current evidence of occupational risk factors related to ovarian cancer is inadequate, however (130). Previous studies have found significant associations with exposure to solvents in a wide range of industries and processes, for example, in rubber manufacturing and the printing industry (131). Hairdressing has also been linked to an excess risk of ovarian cancer $(45,132)$, the 
suspected agent being some constituent of hair dyes. Furthermore, excess risks have been reported for occupational exposure to asbestos and, even more convincingly, to talc-containing asbestiform fibers (130). The new record-linkage study (132) carried out in Finland found significant associations with exposure to aromatic hydrocarbon solvents (RR 1.3, 96\% CI 1.0-1.7), asbestos (RR 1.3, 95\% CI 0.9-1.8), and man-made vitreous fibers (RR 1.3, 95\% CI 1.1-1.9), leather dust (RR 1.3, 95\% CI 1.0-1.8), diesel engine exhaust (RR 1.3, 95\% CI 0.9-1.8), and gasoline engine exhaust (RR 1.5, 95\% CI 1.0-2.0). In accordance with these results the following job-titles were associated with the agents (132): rubber product worker and printer (chlorinated hydrocarbon solvents), assisting building worker (asbestos and man-made vitreous fibers), pattern maker and cutter for footwear (leather dust), and forklift operator (diesel and gasoline engine exhaust). Regarding cancers of the uterus, a putative risk factor was exposure to hydrocarbon solvents $(133,134)$ and a low level of occupational physical activity $(134,135)$. For details, see the appendix.

Malignant lymphomas and leukemias. Hodgkin's disease has been associated with farming, although no specific exposure has been identified (136). In Finland, the lack of the excess risk among female farmers and the observation that the highest risk occurred for male farmers without animals suggests that the potential causes may lie in exposure to pesticides and other chemicals used in cultivating grain, potatoes, and the like (137). Increases in the risk of non-Hodgkin's lymphoma have also been noted for exposure to herbicides and fungicides (138), as well as to various organic solvents $(133,139)$. For details, see the appendix.

Workers exposed to benzene carry an increased risk of acute nonlymphocytic leukemia and myelogenous leukemia, especially workers engaged in painting and rubber production and in chemical processing (120). There is also limited evidence to the effect that exposure to low-frequency electric fields is carcinogenic to humans on the basis of studies of chronic lymphocytic leukemia (140). A fairly consistent pattern of a small, increased risk of leukemia pertaining to occupational exposure to electromagnetic fields was found in 38 studies for a broad group of electrical occupations such as electric utility workers, machinists, and welders (141). Our risk estimate was taken from a recent Swedish study (142) that provides unique information on the potential importance of combined occupational and residential exposure among adults. For occupational exposure of $\geq 0.2 \mu \mathrm{T}$, excluding residentially exposed subjects from the occupationally unexposed category, the study derived an RR estimate of 1.7. In Finland, the prevalence of occupational exposure to low-frequency electromag- netic fields over $0.2 \mu \mathrm{T}$ was $27 \%$ for men and $4 \%$ for women (source FINJEM). Our overall attributable fraction estimate for leukemia became $18 \%$ for men and $2 \%$ for women.

Skin cancer. Excess exposure of the skin to sunlight causes skin cancer (143). Almost all nonmelanocytic skin cancers and malignant melanomas are due to the damage to skin cells caused by ultraviolet radiation (144, $145)$. Whereas nonmelanocytic skin cancers occur with increased risk in the occupational groups most exposed to sunlight, the highest risks for malignant melanomas are often registered in indoor occupations. For these cancer types, excess risks have been reported in studies on airline pilots conducted in Finland (79), Canada (146, 147), the United States (148), Iceland (149), and Norway (150). In the Norwegian study (150), an increasing trend was observed for the standardized incidence rate with a cumulative dose for malignant melanoma. Exposure to cosmic radiation is also an important occupational risk factor for malignant melanoma and nonmelanoma skin cancer (151). The origin of cosmic rays is not known with certainty, although some appear to emanate from the sun (152). But it may be that the excess risk is explained in part by factors related to leisure-time activities (sunbathing) rather than to conditions at work. Repeated sunburns can occur also in outdoor work, for example, among the deck crew of seafaring vessels (79). Almost 90\% of these Finnish seafarers were exposed to an average ultraviolet radiation energy level of about $190 \mathrm{~J} / \mathrm{m}^{2}$ at some time from 1960 to 1996 (source FINJEM). In addition to natural sunlight, X-rays and ultraviolet light from artificial sources expose workers in certain occupations to risk. Only occupations with exposure to ultraviolet radiation that corresponds to the level of Finnish seafarers were included in the estimation of the attributable fraction. See the appendix.

\section{Circulatory diseases}

The impact of the work environment on illnesses of the circulatory system is considerable. In the United States, IHD (including heart attack) and cerebrovascular diseases (including stroke) were the cause of death in $75 \%$ of the cases within a large workers' compensation data set (153). However, many of the occupational factors linked to heart conditions in the literature are still not well established as causal risk factors (154). Olsen \& Kristensen (155) estimated that, in Denmark, the attributable fraction for all occupational risk factors for premature cardiovascular disease mortality, due to both chemical and nonchemical (excluding sedentary work) risk factors, was $16 \%$ for men and $22 \%$ for women. The figure was higher for women because monotonous highpaced work, which was used as a proxy measure for job 
strain, was more widespread among women. Our attributable fraction estimates were based on studies measuring both incident cases of nonfatal myocardial infarction and fatal IHD. Similarly, the attributable fractions for stroke were estimated from both incidence and mortality data.

Cardiovascular diseases. Regarding the nonchemical risk factors of cardiovascular diseases, there is a burgeoning body of epidemiologic studies regarding the etiologic function of workplace factors in the risk of hypertension and IHD morbidity and mortality (156, 157). The empirical, theoretical, and biological evidence is the most abundant and most convincing for psychosocial factors, especially job strain (high psychological demands and low decision-making latitude) (158-165). [The Job Stress Network site (http://www.workhealth. org) gives information about job strain (specifically) and work stress (in general).] One plausible pathway between job strain and heart disease is elevated blood pressure (166), possibly mediated by increases in catecholamines and cortisol (167), increased autonomic nervous system activity (eg, increased heart rate), or increased mass of the heart's left ventricle (168). Extensive evidence is not available showing that stressful work conditions and psychosocial personal characteristics contribute to the development of coronary dysfunction and diseases via sustained autonomic nervous system activation. For example, in several series of Swedish studies (169) it has been shown that the output of "stress hormones" of the sympathetic nervous system is stepped up in almost every form of exposure to psychosocial stressors, including job stressors. A German prospective study (170) of blue-collar workers indicated that high work pressure and cumulative workload in combination with low status control and monetary gratification obtained ("effort-reward imbalance") are strongly related to new coronary events and to elevated levels of established IHD risk factors (eg, hypertension, atherogenic lipids), as well as to reduced cardiovascular responsiveness.

Although the association between exposure to job strain and IHD is particularly pronounced among those with lower occupational status $(30,161)$, the risk is not in excess only among blue-collar workers. In a population study in eastern Finland (171), the multifactorially adjusted risk of death from heart disease among both blue-collar collar workers and white-collar workers was equal. In the United States, managers, administrators, supervisors, and proprietors were among the white-collar occupations with top-ranking fatality rates from compensated heart conditions (including heart attack) and illnesses of the cerebrovascular and circulatory systems (including strokes and varicose veins) (153).
There is also sufficient evidence that shift work is a "quite definite" causal risk factor for IHD (155, 172174). Shift workers tend to have heavier work, experience more stress, have less influence on their work, and have a lower level of education than day workers (174). A comparative study in the European Community (175) identified occupations at high risk of IHD. None of the groups worked day work only, and several of the groups had psychologically demanding work but low decision latitude. According to a review of 17 studies (176), shift work seems to entail about a $40 \%$ increase in IHD risk. Even if the magnitude of the risk is not high, the exposure prevalence in Finland is about 30\% (172), which would yield a population attributable fraction of $11 \%$.

The Helsinki Heart Study (30) drew a representative sample of 1806 men from a Finnish industrial population. The cohort comprised 37\% shift workers, $48 \%$ among blue-collar workers compared with only $9 \%$ among white-collar workers. The IHD end points were obtained from the Hospital Discharge Register maintained by the National Research and Development Centre for Welfare and Health and the Register of Deaths kept by Statistics Finland. The study suggested that job strain is responsible for part of the $38 \%$ increased IHD risk among industrial workers. Moreover, shift work seemed to accentuate persistently the effect of adverse life-style-related risk factors of IHD, such as smoking, physically nonactive life-style and obesity, the joint effect being at least multiplicative (177). Thus it is important that the epidemiologic studies adjust for the possible confounding effects of social class (178) and lifestyle factors, as well as for the effects of smoking and other established cardiovascular risk factors. In fact, the effect of shift work should also be analyzed within a social class, as was done in the Helsinki Heart Study (30). Interestingly, the restriction of the occupational group to blue-collar shift workers and those on gem-fibrozil medication (or with previously diagnosed IHD excluded) raised the risk (RR 1.6).

The Nurses' Health Study (33) on IHD followed a cohort of 79109 women prospectively. Having ever worked in rotating night shifts was associated with an approximately 1.4-fold increase in the risk of nonfatal IHD and an approximately 1.2-fold increase in fatal IHD. The excess risk persisted after adjustment for a variety of cardiovascular risk factors. However, if high blood pressure and serum cholesterol are the hypothesized mechanisms through which shift work raises the risk of IHD, then the RR estimate based on the multivariate-adjusted model controlling for these factors may constitute statistical overadjustment. The authors concluded that these data were compatible with the possibility that $\geq 6$ years of shift work may increase the risk of IHD among women.

Lately Knutsson et al (179) shed further light on the alleged relation between shift work and the risk of IHD 
by conducting a population-based case-referent study in two Swedish counties (Stockholm and Västernorrland). The study base comprised 2006 cases in the age category $45-70$ years. Acute first-time myocardial infarction was associated with shift work for both the men (OR 1.3, 95\% CI 1.1-1.6) and the women (OR 1.3, 95\% CI $0.9-1.8)$. The results could not be explained by job strain, age, region, job education, or smoking. However, insufficient control for socioeconomic status may have caused residual confounding. No interaction between shift work and job strain was found that may induce or modify the development of disease. In the older age groups, many people were already retired when their heart attack occurred, and the exposure to shift work could have taken place more than 5 years earlier. The authors concluded that the present study strengthened the evidence of a relation between shift work and IHD and that job strain was not a mediating factor.

The prevalence of workers with strain (dichotomized mean score of workload) in Finland was estimated to be $19 \%$ for men and $23 \%$ for women (14). With the use of an RR of 2.0 (156), the component attributable fractions due to work strain took on the values of $16 \%$ for men and $19 \%$ for women. These figures were calculated using a prevalence ratio of 2.0 for IHD in a randomly selected representative sample of 13800 Swedish male and female workers exposed to the combined effect of job strain and social isolation (158). As it turned out, the magnitudes of the attributable fractions for shift work were lower than those for work strain ( $11 \%$ for men and $6 \%$ for women). Thus it can be hypothesized that, even if shift work would exert an effect on cardiovascular risk via the strain pathway, strain at work nevertheless carries an extra IHD risk. Because the disease mechanism is still not completely clear, however, we did not account for the independent effect of work strain, so that the applied attributable fractions for the shift work or work strain-induced IHD or both may represent marked underestimates of the combined effect of these two risk factors.

Most of the reviews on noise and nonauditive effects point out that noise is a physical stressor and that the nonauditive effects are based on this fact (156). Despite the methodological deficiencies of earlier epidemiologic research on noise, Kristensen (156) concluded, in 1989 , that “... this research yields reasonable support for the noise-CVD [cardiovascular disease] hypothesis, which actually can be regarded as a partial hypothesis in relation to the question of a causal relationship between stressors and CVD. The hypothesis is furthermore supported by experimental research and is biologically plausible [p 171]".

More recent occupational and community noise studies have shown that exposure to high noise levels (mostly $>65 \mathrm{dBA}$ ) is a risk factor for cardiovascular disease (180). [In FINJEM (14), exposure to sound levels above
$85 \mathrm{~dB}$ was defined as noise.] If the exposure is of sufficient intensity and unpredictability, cardiovascular and hormonal responses can appear, including increases in heart rate and peripheral vascular resistance and changes in blood pressure, blood viscosity, and blood lipids. These effects are of interest because of noise-related IHD (181). Many studies in occupational settings have indicated that workers exposed to high levels of industrial noise for 5-30 years have increased blood pressure and statistically significant increases in risk for hypertension, in comparison with workers in reference areas (182). Today there is sufficient scientific evidence that noise exposure can induce hypertension and IHD (183). The current overall conclusion is that cardiovascular effects are associated with long-term exposure to noise levels in the range of $\geq 65-70 \mathrm{~dB}$ (for LAeq, 24 hours) [Source: World Health Organization (http://www.who.int/ environmental_information/Noise/Comnoise3.htm)]. An RR of 1.3 (95\% CI 0.8-2.2) was estimated for IHD due to prolonged exposure to traffic noise (184). We preferred the estimate of 1.2 proposed by Olsen \& Kristensen (155) for IHD risk in the occupational setting.

Other nonchemical factors that could contribute to IHD have also been implicated. These include high risk of physical injury (185), long workhours, social isolation, and the physical inactivity inherent in many jobs. Although over 10\% of Finnish workers do sedentary work, which is regarded as a stress factor, we did not consider it to be a risk factor of IHD because its adverse effect can be compensated by leisure-time physical activity.

The attribution rate for IHD due to chemical risk factors has been calculated to be $1 \%$ for Australian men and women (5). Only for two cardionoxious chemical agents, carbon disulfide (186) and nitroglygol or nitroglycerin (187), was the causal relation with IHD well documented and graded as "very definite", on the basis of the methodological quality of the studies $(155,188)$. In Finland, a large excess risk was found for fatal IHD in a 5-year follow-up of a small cohort of male workers exposed to carbon disulfide in a viscose rayon plant (186). The risk was eliminated after vigorous intervention; calculations yielded a "preventive fraction" (20) of 68\% (189). Other putative chemical risk factors for IHD include lead, cobalt, arsenic, antimony, dioxin, carbon monoxide, and other combustion products, as well as environmental tobacco smoke and its constituents, such as benzo(a)pyrene (188). With the exception of environmental tobacco smoke, Olsen \& Kristensen (155) rated the causality of carbon monoxide as "quite possible" and the causality of the other factors as "quite definite". The other factors mentioned were not included in the present study because of inadequate evidence.

It has been estimated that there are about 10 times more cases of death due to environmental tobacco 
smoke in relation to heart disease than to environmental tobacco smoke in relation to lung disease at the $28 \%$ prevalence of unrestricted smoking in office workplaces (190). The occupational Safety and Health Administration in the United States estimated that the RR for IHD among nonsmokers due to chronic exposure to environmental tobacco smoke ranges between 1.2 and 3.0 (82). The evidence relating IHD with exposure to environmental tobacco smoke from a spouse has become substantially stronger since risk assessment of the Occupational Safety and Health Administration in 1994. A meta-analysis (191) of 19 epidemiologic studies has found an adverse effect of exposure to environmental tobacco smoke at home on the subsequent risk of IHD (RR 1.30, 95\% CI 1.22-1.38). Summary estimates were similar for the women and men in cohort studies (in which almost all the IHD events were fatal) and in case-referent studies (in which most events were nonfatal myocardial infarctions). However, the causality of the relation between environmental tobacco smoke and IHD is still being debated (192-196). The latest review (197) of 17 epidemiologic studies concluded that the magnitude of the relation (RR 1.25) across the combined studies is remarkably consistent, and it does not weaken the association when adjustment is made for potential confounders in these studies. The eight studies reporting RR values for environmental tobacco smoke at work have been reviewed by Wells (198) and Steenland (17), who gave a pooled RR estimate of 1.2. Two of the best studies $(199,200)$ suggested a positive dose-response trend. In the case-referent study by $\mathrm{He}$ et al (199), the adjusted odds ratio for IHD among women exposed to environmental tobacco smoke at home was 1.2 , compared with 1.8 for exposure at work. The recently released prospective nurses' health study by Kawachi et al (200) prospectively followed, for 10 years, a cohort of 32000 women aged 36-61 years in 1982; these women had never smoked. The authors managed to adjust for a broad range of IHD risk factors (see the appendix), and found a significant total IHD (nonfatal myocardial infarction and IHD death) RR of 1.7 for those reporting any exposure to environmental tobacco smoke in comparison with those with no such exposure. There was no apparent difference in the magnitude of the association of passive smoking with nonfatal events compared with fatal end points. Among women exposed only at work, the RR was 1.5 for those occasionally exposed to second-hand smoke and 1.9 for those the regularly exposed to this agent, and there was a significant dose-response. Thus the emerging epidemiologic data on exposure to environmental tobacco smoke in the workplace indicate a raised risk for IHD that points to a causal relation (201). We accepted an intermediate RR value of 1.3 as the basis for our attributable fraction calculation for both genders; it yielded 3.6\% for men and $2.4 \%$ for women. [These percentages were reduced to $2.2 \%$ for men and to $1.5 \%$ for women when we accounted for the co-exposure with shift work.] These estimates can be compared with the attributable fraction of $4 \%$ obtained by Steenland (17), who assumed that $20 \%$ of nonsmokers are exposed to environmental tobacco smoke at work.

The analogous findings from the study of the effect of occupational exposure to carbon monoxide on heart disease mortality (16) and the studies showing a relation between cigarette smoking and cardiovascular mortality suggest that carbon monoxide is probably an important occupational risk factor for heart diseases. A Finnish study (202) observed an increased mortality from IHD among foundry workers. The long-term effects of carbon monoxide may aggravate arteriosclerotic disease (203). A Swedish cohort study on 5500 chimneysweeps over a period of 40 years (1951-1990) found a $26 \%$ increase in mortality from IHD and implicated carbon monoxide and other combustion products (73). An earlier similar result was found for Danish chimneysweeps (204). A cohort study of 1200 traffic control officers working in tunnels and exposed to carbon monoxide as a constituent of vehicle exhaust at or above the current standards in New York City (16) showed a $24 \%$ excess standardized mortality risk (SMR) of all heart disease (ICD-9 codes 390-458, excluding codes 430-438) and a 35\% increase in arteriosclerotic heart disease (ICD-9 codes 410—414) mortality compared with the mortality experience of the New York City population. A proportional hazard analysis showed an even more pronounced excess risk from arteriosclerotic heart disease mortality for tunnel officers when compared with that of less-exposed bridge officers, adjusted for duration of employment, age, and calendar time (RR 1.54). Because tunnel officers' work entails heavier exposure than in most other occupations in which workers are exposed to engine exhaust gases, we used a more conservative risk ratio estimate, which was equal to the estimated SMR of 1.24. The mortality risk of arteriosclerotic heart disease started to decline after the workers had been retired at least 5 years. But, the risk was still greater among former officers who died at the age of 65 years than the corresponding risk among the comparison group of bridge workers. This finding supports the general hypothesis that the effects of chemicals on cardiovascular mortality persist some years after the cessation of environmental exposure.

For the IHD risk factors combined, our overall attributable fraction became 19\% for men and 9\% for women.

Cerebrovascular diseases. A register study based on longitudinal census data on Finnish men between 1981 and 
1994 indicated a $17 \%$ (95\% CI $0-37 \%$ ) increase in mortality caused by cerebrovascular diseases in association with shift work (205). The excess risk could not be explained away by adjustment for other work and socioeconomic factors.

A hospital-based study (206) with community-based neighborhood referents showed that exposure to smoking by a spouse was an independent risk factor for a whole group of patients with cerebral ischemia (OR 1.7, 95\% CI 1.1-2.6). The recent Auckland Stroke Study (207) provides compelling evidence to the effect that passive smoking, analogously with active smoking, can increase a nonsmoker's risk of having a cerebrovascular stroke of vascular origin. In this population-based case-referent study, the 1851 referents were derived from the same population as the 521 cases aged 35-74 years. All strokes, whether fatal or not, were included. At least for IHD there does not appear to be a difference in the magnitude of the association with passive smoking with respect to fatal and nonfatal outcome (200). Furthermore, the researchers made no attempt in the analyses to differentiate between exposure to environmental tobacco smoke at home, at work, or elsewhere, because exposure at work has been found to confer a greater risk from IHD than exposure at home (208, 209). The study showed that nonsmokers exposed to environmental tobacco smoke have a significantly increased risk of stroke incidence and fatality among both men (OR 2.1, 95\% CI 1.3-3.3) and women (OR 1.7, 95\% CI 1.1-2.6) when compared with nonsmokers not exposed to environmental tobacco smoke.

For the stroke risk factors combined, our overall attributable fraction became $12 \%$ for men and $8 \%$ for women.

\section{Mental disorders and neurological diseases}

Vascular dementia. One of the ICD-10 diagnostic criteria of vascular dementia is that evidence of cerebrovascular disease etiologically related to the dementia (7). Therefore, several reported risk factors for vascular dementia are the same as those for stroke (210). Nonvascular risk factors include psychosocial stress in early life (211) and work in a blue-collar occupation (212). Because vascular dementia is preventable (213), the determination of risk factors for the disease is vitally important (214). The population-based Canadian Study of Health and Aging (215) analyzed risk factors for vascular dementia for which an a priori hypothesis existed along with additional risk factors that were statistically significantly elevated in the study data (subjects aged $\geq 65$ years). The study confirmed that occupational exposure to pesticides and fertilizers (OR 2.6) were associated with vascular dementia. The association with exposure to liquid plastics or rubbers (OR 2.6) should be further considered for biological plausibility and studied in more detail before it is counted as a risk factor for vascular dementia.

Parkinson's disease and Alzheimer's disease. Exposure to pesticides has also been linked to an increased risk of Parkinson's disease $(216,217)$ and Alzheimer's disease (218). The contribution of pesticides (fungicides, herbicides, and insecticides) to the nonvascular etiology of these neurological diseases is important because pesticide exposure is prevalent in the general population, especially among farmers. The foremost categories of pesticides that are thought to cause neurological diseases are herbicides and insecticides $(215,216,218)$. However, the epidemiologic data are too sparse to establish whether a particular herbicide (eg, paraquat) or an insecticide is associated with the greatest risk. Moreover, the mix of pesticides to which workers are exposed often varies from one population to another.

In addition, data from three independent clinical series ( 2 from Finland and 1 from California) indicated that working in occupations (such as seamstress, dressmaker, and tailor) with exposure to extremely low-frequency electromagnetic fields is etiologically a possible relevant risk factor for sporadic Alzheimer's disease (219). These findings were supported by the populationbased Swedish twin-register study (220), which indicated that occupational magnetic field exposure at the level of $\geq 0.2 \mu \mathrm{T}$ may possibly raise the risk ratio for Alzheimer's disease to approximately 2.5. Additional support for an association with Alzheimer's disease mortality among electric utility workers was provided by a cohort study in the United States (221). Exposure to styrene in the reinforced plastics industry may also increase mortality from chronic diseases of the nervous system, especially from epilepsy (222). Although epidemiologic studies have associated exposures to organic solvents with epileptic seizures $(223,224)$, the evidence is still inadequate to infer causality. For details of the attributable fraction estimates, see the appendix.

\section{Respiratory diseases}

In addition to pneumoconiosis (asbestosis, silicosis, and "farmer's lung"), other respiratory diseases are being recognized as job-related. Exposure to occupational dusts and, to a less extent, gases and fumes has been shown to be associated with an increase in symptoms and pulmonary function deficit, which is characteristic of chronic obstructive pulmonary disease (225). Only some of the many occupational exposures that are associated with asthma have been assessed in epidemiologic studies on the general population (226). Even though chronic obstructive pulmonary disease and asthma are common respiratory disorders in many industrialized 
countries their contribution to the occupational health problem has not received enough attention.

Chronic obstructive pulmonary disease. Evidence implicating occupational exposure as an etiological factor in association with chronic obstructive pulmonary disease has accumulated from community-based studies, longitudinal studies of lung function, pathology studies, and cohort mortality studies. This evidence, reviewed by Becklake (227) according to accepted criteria for establishing causality, leaves little doubt that occupational exposure to dust and welding fumes plays an important role in the genesis of chronic obstructive pulmonary disease. To recognize the likelihood that occupational exposure (including exposure to coal, silica, and grain dust) plays a limited but definite part in deaths from chronic obstructive pulmonary disease, Leigh et al (3) assigned an attributable fraction estimate of $10 \%$ to mortality from chronic obstructive pulmonary disease in the United States. A nationwide study carried out among male farmers in Finland revealed a mortality rate for respiratory diseases that was about $40-50 \%$ greater than that of all economically active men (228). Occupational exposure to dust may independently provoke the development of chronic airflow obstruction (229). Farming work involves exposure to organic dusts, microbial dusts, and endotoxins. The prevalence of chronic obstructive pulmonary disease in an elderly Finnish population living in a semi-industrialized rural district was common (17\%) among those with a history of work in dusty occupations such as manufacturing and construction work (230). In these studies, there was no confounding by smoking, but especially among women the effect of exposure to dust was related to low social class. In addition to dusts, we regarded occupational exposure to welding fumes as having a causal role in mortality from chronic obstructive pulmonary disease. The RR estimate that we applied to welding fumes derives from a survey of sheet metal workers (excluding welders) with $1-3$ years of exposure (231). Therefore, as exposed workers in the employed Finnish population, we included only persons who regarded the welding fumes occurring in their workplaces as either considerably harmful or very harmful (prevalence $2.0 \%$ for men and $0.4 \%$ for women). Last, environmental tobacco smoke in the workplace has been associated with increased risk of symptoms of chronic obstructive pulmonary disease (232-234). In a study of 36800 Seventh-day Adventists (232), working in the same room with a smoker for at least 10 years increased the risk of symptoms of the disease by $11 \%$ (statistically significant increase). Seventh-day Adventists are similar to the general population in most of the pertinent life-style characteristics, except for alcohol intake, tobacco smoking, and in-home passive smoke exposure, which are extremely low. A dose-response relation has also been observed between environmental tobacco smoke and the occurrence of symptoms of chronic obstructive pulmonary disease (235). Our overall attributable fraction estimate became $14 \%$ for men and $4 \%$ for women.

Asthma. Work-related asthma can be caused by more than 200 specific agents detected in the workplace (236). In Finland, the mean annual incidence rate of notified occupational asthma for 1989-1995 was 17.4 cases per 100000 employed workers (237). The incidence rate was highest for bakers, spray painters and lacquerers, farmers, welders, and plastic product workers. An upto-date review (238) obtained 43 attributable fraction estimates for occupationally associated asthma from 19 countries with a median of $9 \%$ (interquartile range 5$19 \%$ ). The 12 highest-quality studies yielded a median attributable fraction estimate of $15 \%$. These percentages may nevertheless underestimate the true attributable fractions, because adjusted RR estimates were used in the calculations using equation 1 (22). The European Community Respiratory Health Survey estimated that the attributable fraction of work-related asthma in the general population is $10 \%$ (226). High-risk groups included, among others, farmers and cleaners. A regional prevalence study conducted in Finland showed that the prevalence of asthma was related to exposure to dust in the workplace (239); dusty occupations are multiple and include agricultural workers, textile workers, cleaners, and others. A Finnish retrospective cohort study indicated that female hairdressers are at a greater risk of developing asthma (240). This finding was corroborated by a Swedish mortality study (241) that also disclosed increased mortality from asthma among male farmers. In a case-referent study (242) from Göteborg, Sweden, exposure to welding fumes, man-made mineral fibers, solvents, and textile dust was related to an increased risk of asthma. In that study, the proportion of asthma attributed to occupational factors was $11 \%(95 \%$ CI $7-$ $14 \%$ ). With respect to welding fumes, textile dust, and solvents a causal relation may well exist. For man-made mineral fibers, the causality is not so evident because other interacting exposures may be of importance, and we chose not include them in the calculations. For welding fumes, we applied the same low exposure prevalences as for chronic obstructive pulmonary disease. Finally, there are limited but consistent epidemiologic data on the relation between environmental tobacco smoke exposure at work and adult asthma (234, 243-245). A large Swiss study (234) found an elevated risk of physician-diagnosed asthma (OR 1.4). In the longitudinal study (232) of nonsmoking California Seventh-day Adventists, the diagnosis was made on the basis of the 
diagnosis reported in a questionnaire (RR 1.45). In a Swedish population-based case-referent study (244), the diagnosis of asthma was based on clinical examinations (OR 1.5). Our risk estimate for environmental tobacco smoke comes from the Swedish study (244) because of its best diagnostic validity and adjustment for several potential confounders. Our overall attributable fraction estimate became $18 \%$ for both genders.

\section{Results}

The attributable fraction for work-related mortality of all deaths in the total Finnish population was estimated to be $3.7 \%, 6.4 \%$ for men and $1.0 \%$ for women. When only the relevant disease and age categories were included, the corresponding attributable fraction estimates became $6.7 \%, 10.2 \%$ for men and $2.1 \%$ for women. (See the appendix.) For the main categories for cause of death, the estimated attributable fractions were as follows: $12 \%$ for circulatory system diseases, $8 \%$ for malignant neoplasms, $4 \%$ for respiratory system diseases, $4 \%$ for mental disorders, $3 \%$ for nervous system diseases, and $3 \%$ for accidents and violence. For specific important diseases, we obtained the following estimates: $24 \%$ for lung cancer, $17 \%$ for IHD, $12 \%$ for chronic obstructive pulmonary disease, and $11 \%$ for stroke. We then applied these percentages to the disease-specific numbers of deaths to estimate the burden of work-related disease.

An estimated total of roughly 1810 deaths from diseases and accidents occurred in Finland in 1996 (employed workforce 2.1 million) that can be ascribed to occupational factors, acting either independently or jointly with other risk factors (table 1). Eighty-six percent of the decedents were men. Of the total work-related mortality, malignant neoplasms and diseases of the circulatory system accounted for $46 \%$ and $31 \%$, respectively. IHD was a leading cause of death (26\%), and its prime risk factor was shift work or work involving stress. Malignant neoplasms of the bronchus and lung accounted for $25 \%$ of all the work-related fatalities, and half of these cancers were induced by exposure to asbestos dust. Other major causes of death were chronic obstructive pulmonary disease $(6 \%)$ due to exposure to various dusts, stroke (5\%) resulting mainly from exposure to environmental tobacco smoke at work, and vascular dementia (5\%) in relation to occupational exposure to pesticides. Occupational accidents accounted for $4 \%$ of all fatal work-related injuries (diseases, accidents and violence); the annual accident rate was 3.6 per 100000 workers.

\section{Discussion}

\section{General approach}

We attempted to provide some useful data on the issue of work-related causes of death. Yet it is an elusive goal and a daunting task to estimate the fraction of mortality due to occupational factors. We anticipate that the general idea advanced in this paper and the specific points in the estimating process will receive intense criticism. Already in a premonitory commentary, an eminent epidemiologist expressed that he was at a loss regarding both the theoretical and applied relevance of this work at the outset (OS Miettinen, personal communication). Theory aside, it is easy to disagree in practice with the agents and occupations selected as being related to a specific cause of death, and even easier to disagree with the level of risk selected to represent each association. Nevertheless, we maintain that a careful and thorough analysis is called for, because many people believe that occupational exposures no longer pose any health problem. This vague impression is, however, based on scanty solid information; therefore original data would seem to be welcome. Those who disagree with our method and interpretation of the available information may substitute alternative attributable fractions and perhaps arrive at a more correct result based on newly produced data.

A referee of an earlier version of the manuscript pointed out a methodological concern with respect to the employed approach, namely, that the exposures or work conditions used to estimate the attributable fractions were mostly based on the RR results from a few selected studies rather than a weighing of the evidence from the entire literature by means of a meta-analysis. The possible limitation of basing the attributable fraction estimates on a few studies is that some of the excesses in attributable fractions may be due to chance, bias, or confounding. An impression of overestimated attributable fractions may be created by the illusion that all published risk estimates are equally reliable. Yet critical reviews show that it is the methodologically highquality studies that tend to produce a greater share of positive results rather than studies that are rated as being of poor quality. (See, eg, reference 155). On the other hand, the "quality scoring" of studies is a subjective scheme, and it can be misleading (246, 247). Instead of using quality scores as weights in a meta-analysis, we preferred to examine directly the influence of component issues of study informativeness (absence of bias, size of study, etc) on the results. The studies that we chose as a basis for the attributable fraction estimation were the most recently published and, in our opinion, best scientifically representative within the experience of relevant epidemiologic research conducted in Finland and in countries with similar industrial circumstances. 
Table 1. Estimated number of work-related fatalities in Finland in 1996 by causes of death.

\begin{tabular}{|c|c|c|c|}
\hline Cause of death & $\begin{array}{l}\text { Total number } \\
\text { of deaths a }\end{array}$ & $\begin{array}{l}\text { Estimated number of } \\
\text { work-related deaths }\end{array}$ & $\begin{array}{l}\text { Percentage of total } \\
\text { work-related mortality }\end{array}$ \\
\hline All causes & $49161^{b}$ & $\approx 1810$ & 100 \\
\hline Infectious and parasitic diseases ${ }^{c}$ & 21 & $\leq 2$ & $\leq 0.1$ \\
\hline Tuberculosis & 14 & $\leq 1$ & $\leq 0.1$ \\
\hline Pneumococcal disease & 7 & $\leq 1$ & $\leq 0.1$ \\
\hline Malignant neoplasms ${ }^{d}$ & 10005 & 839 & 46.3 \\
\hline Oral cavity & 73 & 1 & $\leq 0.1$ \\
\hline Pharynx & 38 & 1 & $\leq 0.1$ \\
\hline Esophagus & 187 & 7 & 0.4 \\
\hline Stomach & 666 & 54 & 3.0 \\
\hline Colon & 587 & 15 & 0.8 \\
\hline Rectum & 295 & 5 & 0.3 \\
\hline Liver and intrahepatic bile ducts & 314 & 14 & 0.7 \\
\hline Gall bladder & 106 & $\leq 1$ & $\leq 0.1$ \\
\hline Pancreas & 690 & 55 & 3.0 \\
\hline Nose and nasal sinuses & 18 & 2 & 0.1 \\
\hline Larynx & 38 & 3 & 0.2 \\
\hline Lung and bronchus & 1878 & 451 & 24.9 \\
\hline Bone & 17 & $\leq 1$ & $\leq 0.1$ \\
\hline Melanoma of skin & 114 & 3 & 0.2 \\
\hline Other malignant neoplasms of skin & 27 & 2 & 0.1 \\
\hline Mesothelioma (all sites) & 59 & 42 & 2.3 \\
\hline Breast & 777 & 13 & 0.7 \\
\hline Uterus (cervix uteri and corpus uteri) & 205 & 5 & 0.3 \\
\hline Ovary & 308 & 6 & 0.4 \\
\hline Prostate & 784 & 47 & 2.6 \\
\hline Kidney & 340 & 11 & 0.6 \\
\hline Urinary bladder & 220 & 23 & 1.3 \\
\hline Brain & 273 & 17 & 1.0 \\
\hline Hodgkin's disease & 23 & $\leq 1$ & $\leq 0.1$ \\
\hline Non-Hodgkin's lymphoma & 657 & 31 & 1.7 \\
\hline Leukemia & 286 & 31 & 1.7 \\
\hline Mental disorders ${ }^{d}$ & 2673 & 94 & 5.2 \\
\hline Vascular and unspecified dementia & 2358 & 92 & 5.1 \\
\hline Depressive episodes & 22 & 2 & 0.1 \\
\hline Nervous system diseases ${ }^{d}$ & 1249 & 39 & 2.2 \\
\hline Spinal muscular atrophy & 142 & $\leq 1$ & $\leq 0.1$ \\
\hline Parkinson's disease & 286 & 26 & 1.5 \\
\hline Alzheimer's disease & 499 & 12 & 0.6 \\
\hline Diseases of the circulatory system ${ }^{\mathrm{e}}$ & 4466 & 556 & 30.7 \\
\hline Ischemic heart disease & 2772 & 469 & 25.9 \\
\hline Cerebrovascular disease & 817 & 87 & 4.8 \\
\hline Diseases of the respiratory system ${ }^{d}$ & 4197 & 171 & 9.4 \\
\hline Pneumonia & 65 & $\leq 1$ & $\leq 0.1$ \\
\hline Chronic obstructive pulmonary disease & 999 & 117 & 6.4 \\
\hline Asthma & 97 & 18 & 1.0 \\
\hline Pneumoconiosis ${ }^{f}$ & 19 & 19 & 1.0 \\
\hline Cryptogenic fibrosing alveolitis & 107 & 16 & 0.9 \\
\hline Diseases of the digestive system ${ }^{c}$ & 694 & 15 & 0.8 \\
\hline Gastric and duodenal ulcer & 51 & 15 & 0.8 \\
\hline Diseases of the genitourinary system ${ }^{d}$ & 1128 & 15 & 0.8 \\
\hline Chronic renal failure and nephritic syndrome & 563 & 15 & 0.8 \\
\hline Accidents and violent incidents & 2588 & 82 & 4.5 \\
\hline Accidents 9 & 1406 & 76 & 4.2 \\
\hline Homecide and injuries ${ }^{h}$ & 170 & 2 & 0.1 \\
\hline Suicides ${ }^{i}$ & 1012 & 4 & 0.2 \\
\hline
\end{tabular}

a Includes deaths in the relevant age range as specified in the given footnotes.

b Deaths at all ages.

c Includes only deaths between the ages of 25 and 64 years.

d Includes deaths at ages $\geq 25$ years.

e Includes all deaths between the ages of 25 and 59 years and a limited number of deaths in the range 60 to 74 years.

${ }^{f}$ There were only deaths from asbestosis, silicosis, and farmer's lung.

9 Includes only deaths between the ages of 15 and 64 years.

${ }^{\mathrm{h}}$ Includes deaths at ages of $\geq 15$ years.

i Includes only deaths between the ages of 20 and 64 years. 
Furthermore, the results of these studies were corroborated by other research. By and large, the RR estimates that we used were consistent with those summarized in several editorials, review articles, meta-analyses, and pooled analyses; we refer to the Data and Methods section. Thus it is improbable that many of the associations included in the analysis would not be causal or that the figures produced would be gross overestimates.

Although meta-analysis has become an important part of epidemiologic research, mainly for reconciling previously conducted studies that display inconsistent results, the use of this type of quantitative summary of published data is still controversial $(246,248,249)$. Meta-analysis is mainly used for summarizing the evidence in a situation when the risk is small but may have important implications for public health, such as the association of passive smoking with lung cancer and IHD. However, this approach is nearly impossible to follow in the case of many associations because of the vast number of studies that would have to be assessed. Moreover, meta-analyses from published data are, in gener$\mathrm{al}$, insufficient for calculations of reliable estimates since published estimates are based on heterogeneous populations, different study designs, and mainly different statistical models (250). A pooled analysis using individual original data would yield a more reliable estimate. For the criteria of strength of association and dose-response, meta-analysis provides precise quantitative estimates, but the causal relevance of these estimates remains a matter of judgment (251).

In situations in which different studies gave qualitatively discordant estimates of RR values (eg, an RR for a specific risk factor above 1 and another below 1), we rejected a conclusion of consistency and excluded the ambiguous hazards in order not to overestimate their risk. It may also well be that the summary attributable fraction for each disease is approximately correct because of the balancing of over- and underestimates. Another way around this problem of the credibility of the analysis would be to give lower or higher estimates of the attributable fractions based on a more conservative or liberal estimate of risk. This is exactly what we tried to accomplish with a sensitivity analysis for the main causes of work-related mortality (ie, lung cancer and IHD, presented later in the discussion). Yet another approach would be to consider only the most certain hazards in the attributable fraction estimation. For workrelated cancer, a Nordic study (252) provided attributable fraction estimates for agents that are carcinogenic in humans (group 1), as documented in the IARC monographs, and excluded cancers only suspected to be related to occupational exposures (such as those of the colon, prostate, and stomach). However, the decisions as to which associations to consider and which are definitely causal were, in the end, based on a subjective evaluation, even though it may have been a collective one. [Compare the IARC evaluations of carcinogenic risks (37).] The relative importance of the various exposures is presented in the appendix in terms of the attributable fractions. From these figures it is easy to compute and judge the approximate effect of including or excluding a particular hazard from the summary estimate of the attributable fraction.

\section{Methodological limitations of the estimates}

\section{Causality of the exposure-disease relation}

Causality cannot be inferred until any potential confounder that may explain the association has been ruled out with reasonable confidence. As Miettinen (20) has stated: "In nonexperimental epidemiologic research it would usually be pretentious to offer any specific estimate of the etiologic fraction attributable to a given marker of increased risk - as if confounding by extraneous factors were well under control. Instead, it would be prudent to think in terms of the etiologic fraction related to the marker - with certain, though not all, confounding factors under control [p 325-326]". Other researchers have proposed that calculating attributable fractions may be justified even if causality has not been demonstrated to a high degree of certainty (253-255). Through the estimation of attributable fractions, epidemiologists can recognize the potential reduction in disease incidence and mortality that could be attained by the elimination of the risk factors, were they later proved to be causal.

In 1981, Siemiatycki (39) launched an exposurebased case-referent monitoring system in Canada to discover carcinogens in the occupational environment. $\mathrm{He}$ and his co-workers estimated attributable fractions using three different methods. The first was based on identified carcinogens as judged by IARC, group 1 (carcinogenic to humans) and group 2A (probably carcinogenic to humans) (37). This method gave much lower estimates than the second one, which was based on statistically significant associations in the Canadian data. The third method was not based on any list of identified high-risk substances of occupations; instead it regressed the risk on a "dirtiness scale" of occupations. Our method was intermediate. We did not restrict ourselves to a predefined list of carcinogens and high-risk occupations. Rather, we also included some RR estimates for agents that belong to IARC group 2B (possible human carcinogen) and suspected agents that, in recent epidemiologic studies, have been causally implicated with cancer in humans, irrespective of their appearance on the IARC list of work-related carcinogens. For example, ionizing radiation had not been evaluated by IARC when this work started, but it is now a recognized human carcinogen (256). To be able to proceed 
with the analysis, we made plenty of assumptions, some of which were strong and may not have been convincingly defensible but were nevertheless upheld because of a lack of data to indicate otherwise. As already mentioned, the decision on which diseases were regarded as having an occupational etiologic component was reached as a result of our assessment of the strength and the consistency of the epidemiologic evidence, among other criteria. The causality of the relation between a specific disease and an occupational risk factor can be judged for certain causes to be definite when based on a large consistent body of evidence. For other causes, the causality may be only probable or suggestive, especially if the inference relies on a small series of moderate-sized, though high-quality, studies.

Based on our present knowledge, specific and reasonably unbiased estimates of RR for exposure-disease relations can be obtained from a number of well-designed and well-conducted epidemiologic studies. However, many of the agents showed relatively weak relations with the diseases studied (typically RR values in the range of 1.2-2.0). Thus it can be questioned whether sufficient epidemiologic evidence can ever be collected to provide an unambiguous judgment of causality. It can be argued, however, that it is important to interpret such small risk increments as "real" if the diseases are common, and, hence, the absolute risks are high. Thus it may be prudent policy to act in the interest of public health in the face of marginal evidence. In practical terms, the evaluation of whether residual bias persists in small associations is a matter of judgment. Shapiro (257) gives a counterpoint, "However, neither importance nor prudence nor judgement is a criterion of scientific validity. As a matter of good science, these considerations cannot be invoked as if they constitute bolstering evidence, in conjunction with low-magnitude associations, to justify causal inferences [p 945]". Shapiro defined an association to be of relatively low magnitude if an RR estimate is less than 2.0. To safeguard against bias in the evaluation of very low-magnitude associations, we did not consider RR values of $<1.2$ (except for the association of chronic obstructive pulmonary disease with environmental tobacco smoke).

\section{Application of the risk ratio estimates}

Two decades ago Doll \& Peto (258) cautioned, "If estimates of the current proportion of cancers attributable to occupational factors are to be made, it seems unwise to try to make them by estimating the number of workers that have been exposed to some agent and 'estimating' their excess relative risk of cancer. Even if deliberate bias is avoided, the data bearing on the likely magnitude of the excess risk are in most instances so unreliable (especially for the large numbers of less heavily exposed) that substantial errors are probable, unless the estimate of relative risk derives from direct epidemiological observation of a strictly representative random sample of the workers to whose future it will be applied [p 124]".

Since then several informative epidemiologic studies have produced valid RR estimates, which can be applied to estimate reliably the number of deaths that occurred in the Finnish population in a recent year as a result of past occupational exposures during preceding years. Our estimates apply to a certain year (ie, 1996) so that a general picture of the overall burden of workrelated mortality can be envisioned. In the future, these estimates will change to some extent. However, given the difficulties of anticipating changes in the workforce, as well as changes in exposure distributions, changes in the proportion of workers exposed to different agents over the years, and the like, we made no attempt to assess how current occupational exposures would predict the risk of future deaths. Such a prediction would require making some rather precarious assumptions. As the ability to make credible assumptions improves, a forecast of the effects of the current occupational exposures may become more viable. Be that as it may, the approach followed in our limited attempt will hopefully have some use for other occupational health researchers.

Extrapolation of a research finding depends on the generality of the assumed cause-effect relation. In situations in which the RR can be thought of as a biological constant that would not be restricted to particular (spatiotemporal) circumstances (259), we can use an estimate of this constant as derived from some previously studied population and combine it with the exposure prevalence of the Finnish population in order to calculate the attributable fraction.

In international terms, the quality of the epidemiologic data from medical registrations and surveys in the Nordic countries is high. For example, the Nordic national cancer registers rely on reporting from multiple sources, and they achieve close to $100 \%$ coverage (252). In particular, the Finnish Cancer Registry (260) has collaborated with the Finnish Institute of Occupational Health in conducting outstanding epidemiologic studies on occupational cancer.

We tried to choose cohort studies that represented samples of workers similar to the employed population to which the RR estimate was applied and thus ensure that substantial errors in the attributable fraction estimates were unlikely. Optimally, the similarity should hold with respect to both the level and duration of exposure, but in practice these properties could not always be guaranteed. When the risk estimates were extrapolated to the whole Finnish population, it was possible to obtain fairly precise national enumerations of people 
who have been occupationally exposed to specific agents and also quantitative estimates of exposure levels for particular time periods with the aid of FINJEM (14). Thereby we could obtain valid population-based estimates of the excess risk of work-related mortality. For example, in the estimation of the attributable fraction for nasal cancer, we applied the RR estimate of 2.4 for nickel exposure, taken from a Nordic case-referent study (261). In that study, the cases were derived from national registration systems, rather than from the corresponding greater RR estimate of 8.7 from a smaller cohort study of nickel refinery workers (43). In the case of lung cancer, the attributable fraction for lead exposure was based on the experience of the cohort of 20 000 workers who were biologically monitored for the concentration of lead in their blood. A yearly mean blood lead level of $\geq 0.8 \mu \mathrm{mol} / \mathrm{l}$ was used as the definition of occupational cumulative exposure. We did not expand the exposed population to all the 56000 employees who were possibly exposed to lead in their work (ie, at least $5 \%$ of the occupation was exposed to an annual mean level of $0.3 \mu \mathrm{mol} / 1$ of lead). The annual mean nonoccupational exposure originating mainly from the engine exhausts of vehicles using leaded gasoline as fuel usually does not exceed $0.3 \mu \mathrm{mol} / \mathrm{l}$.

Many of the case-referent studies that we selected as the scientific basis for this estimation were population-based and served a large study area. Case-referent studies in the general population may be subject to recall bias that can bias risk estimates. To avoid such biases, we paid special attention to the means by which exposure to a suspected hazard was ascertained for the cases and referents. For example, in the case of lung cancer, exposure to asbestos was objectively measured in the Finnish study (49) as pulmonary fiber concentrations. However, the accuracy of information given by the relatives of the referents on smoking-years may have been less than that given by the lung cancer patients in their personal interviews. Moreover, a complete adjustment for smoking could not be done because there were only two nonsmokers among the cases and smoking habits were not known for all the referents. Yet it is unlikely that these methodological inaccuracies would appreciably distort the risk estimates associated with past exposure to asbestos. As for the other occupational risk factors of lung cancer, the assessment of exposures in the German study (51) was based on a job history, an exposure checklist for known and suspected carcinogens, and job-specific questionnaires. Given the comprehensive and systematic method of inquiry, it is unlikely that the acquisition of exposure information would have been asymmetric between the cases and their referents. Regarding other associations studied by the casereferent design, we scrutinized the descriptions of the method of exposure ascertainment in the published reports. According to our judgment, there was no reason to suspect that the definition of exposure would be on a higher level among the cases than among the referents.

\section{Selection of specific exposure-disease associations}

In previous studies (3-5) estimating the national burden of disease, a lack of disease-specific attributable fractions has led to the assignment of somewhat arbitrarily defined point estimates and ranges of attributable fractions for major disease categories. This assignment was done on the basis of the available literature and relying on "established" estimates from similar countries. We conducted a nonsystematic literature review of occupationally induced cancers, cardiovascular diseases, respiratory diseases, and other major causes of death. [A systematic search of databases would have been an insurmountable task. For example, a search for only one disease, pancreatic cancer, and job titles, industrial branches, and occupational exposures, produced 1902 references, of which the 365 most relevant papers were accepted (111).] The starting point for the selection of studies was our quest for Finnish epidemiologic investigations. Of the references that were used as the basis of the attributable fraction calculations, half were studies conducted in Finland. We specifically included also minor causes of death (eg, tuberculosis and pneumonia) in order to indicate that the spectrum of workrelated mortality is wider than what is generally recognized. The only deaths from work-related diseases that are identifiable in Finnish official statistics are those which receive compensation under the workers' compensation system, that is, virtually only cases of mesothelioma, asbestos-induced lung cancer, and pneumoconiosis. The specificity comprised also exposures. Thus we evaluated the overall evidence based on specific exposure-disease relations that had been adjusted for confounding factors.

\section{Comparability of the level of exposure in the source (base)} population providing the risk ratio estimate and in the Finnish target population

To ensure the comparability of exposure levels in the source and target populations we chose:

- cohort studies representing exposure levels similar to those prevalent in the particular target populations to which the risk ratio (RR) estimates were applied

- case-referent studies whose referents were drawn by representative sampling of the source populations from which the cases were derived

- record-linkage studies based on national data on mortality risk or disease incidence, population census statistics on job-title or branch of industry, and job-exposure information defining the level of exposure in a specific job or industry.

Scand J Work Environ Health 2001, vol 27, no 3 
A possible reason for overestimating attributable fractions would be the inclusion of unsubstantiated or poorly substantiated associations. To be on the conservative side, we excluded a large number of associations that were not supported by similar observations in other studies. For example, a multiple risk factor study from Canada (106) suggested that prostate cancer was associated with formaldehyde exposure. But there are cohort studies that do not show significant evidence of this association (262). It seems unlikely that this association would be missed among these heavily exposed cohorts. Another similar exclusion was the association between asbestos exposure and stomach cancer [a reanalysis of the data of Kauppinen et al (14)]. Although asbestos has been listed as a recognized or probable carcinogen for gastrointestinal cancer (39), this positive finding was probably generated by chance because an earlier Finnish cohort study failed to find evidence supporting the link (57). A further example of an exclusion was formaldehyde in relation to cancer of the colon [a reanalysis of the data of Partanen et al (108)]. Given the lack of conclusive data demonstrating that cell proliferation and tissue damage occur in humans exposed to formaldehyde (262), it is difficult to postulate a mechanism that could explain the way in which exposure to formaldehyde could cause tumors in the large intestine.

Admittedly, a few of the included associations involving minor occupational hazards are new and based on results from well-conducted studies that alone do not provide a substantial body of evidence. Two novel studies furnish examples of such associations, exposure to welding fumes in the etiology of lobar pneumonia (263) and the link between passive smoking and pneumococcal infection (264). These results were nevertheless accepted because they bear evidence of the breadth of the occupational health problem area.

\section{Incidence versus mortality}

In estimating mortality risk from incidence data, we assumed that the incidence RR values were similar to the respective mortality RR values. For lung cancer, which is the most common work-related cancer, this comparability assumption would seem to be reasonably tenable because the malignant tumor is highly fatal. A Finnish cohort study (265) on cancer incidence and mortality among asbestos sprayers and asbestosis and silicosis patients provides empirical evidence. In the follow-up, the estimates of the standardized incidence ratios and standardized mortality ratios for all cancers and lung cancer were very similar. This observation indicates that, for diseases with a high case fatality rate, both incidence and mortality are reliable and interchangeable measures of the frequency of work-related cancer.
According to a Nordic study (252), the proportions of incident lung cancers that could be avoided in Finland, if carcinogenic exposures in the workplaces were eliminated, would be $13 \%$ for men and $<1 \%$ for women. Our attributable fraction estimates for lung cancer mortality were $29 \%$ for men and $5 \%$ for women. This discrepancy is principally due to the different approaches in the two studies. The Nordic study reported numbers of cancers that are "convincingly" linked with known exposure to carcinogens in the workplace as documented in the IARC monographs (IARC group 1). Our estimates are also "evidence-based", but we have also included relations in which the evidence pointing to a causal link between occupational exposure and cancer has not yet been established definitely — the link may be probable or only possible. Our attributable fraction estimates are therefore to be interpreted as the total proportion of cancers potentially caused by workplace carcinogens.

Another reason for the different attributable fraction estimates lies in the occurrence of cancer among women. As noted by Nordic scholars (252), “. . . it is likely that we have underestimated the numbers of workplacerelated cancers among women [p 77]"; they estimated that fewer than 25 cancers occur annually among women in all the five Nordic countries combined. Using newly conducted studies $(126,132,134)$, we have estimated that, in Finland alone, 24 women succumb to breast cancer and cancers of the genital organs. [Of the deaths recorded in the United States in 1978, Doll \& Peto (258) classified cancers of the female breast and genital organs as not known to be produced by work-related causes.]

The lower attributable fraction estimates in the Nordic study (252), as compared with our estimates, may also result from two methodological problems. First, the calculations in the Nordic study were based on the assumption that the RR for each cancer associated with any occupational category is equal for men and women. However, empirical studies show that the genderspecific risk can differ. Women may be more susceptible to the inception of some cancers (such as liver cancer), or their work may entail different exposure patterns within the same occupation $(108,137)$. We thus decided to apply separate RR estimates to men and women whenever reliable data were available. Second, the Nordic study used equation 1 in all the computations of attributable fraction. This formula is only strictly valid for cohort data with an unadjusted RR estimate. Substituting an adjusted RR estimate in equation 1 will, in general, produce biased estimates of attributable fraction (22).

For some other sites of cancer, such as the prostate and bladder, risks of morbidity and mortality may differ vastly, however. In a Swedish cohort study of chimney- 
sweeps, there was an appreciable increase in the incidence of bladder cancer, without any increase in mortality (73). As noted by the researchers, this discrepancy may be chance generated, given the low mortality of bladder cancer. Alternatively, it is possible that sweeps receive more intense screening for cancer than the general population, thus increasing the detection of common tumors such as those of the prostate and bladder. This possibility seems unlikely, however, since the incidence of cancer was followed from the early year 1958 until 1987. A third possibility is that the bladder cancer seen in this cohort may have a different natural history than that of the general population because of exposure to a complex mixture produced by the combustion of coal, coke, oil, and wood.

The studies on shift work and the risk of IHD used both incidence and mortality data $(30,34)$. The Helsinki Heart Study (30) did not analyze the data on men separately for nonfatal IHD and fatal IHD. Therefore we applied the RR for total incident IHD. The Nurses' Health Study (34) on shift work did analyze the data on women according to the disease outcome. The RR values for nonfatal IHD and fatal IHD were of the same order of magnitude: $\approx 1.2$ and $\approx 1.4$, respectively. We applied the mortality RR estimate. Similarly, there was no apparent difference in the magnitude of the association of passive smoking with nonfatal IHD events when compared with the association with fatal IHD end points (34).

For some cause-effect relations, however, the comparability assumption may not hold. In a Finnish followup study (186), for example, exposure to carbon disulfide worsened the prognosis of IHD in addition to increasing its incidence. In other words, when the IHD outcome changed from the milder manifestations to the more severe ones, the RR increased consistently: 1.4 for "coronary" electrocardiographic abnormalities, 2.2 for angina pectoris, 3.7 for nonfatal infarction, and 4.8 for fatal infarction (186). In this case, the effect of using an incidence RR in place of a mortality RR would have resulted in an underestimation of the risk. In the present assessment, cardiovascular disease due to chemical exposure was not attributed to carbon disulfide because the exposure has been eliminated in Finland (266).

The accuracy of information on disease incidence and cause of death differs between different sources. For example, the diagnosis and site of tumors recorded by the Finnish Cancer Registry are more reliable than the respective information available in the Finnish Register of Hospital Discharges maintained by the National Research and Development Centre for Welfare and Health and the Causes of Death Register kept by Statistics Finland (267). Incidence and mortality rates may not be comparable also for other reasons. For instance, the Register of Occupational Diseases kept by the Finnish In- stitute of Occupational Health reports an average of 10 incident cases of tuberculosis per year among medical and social workers. Even if the fatality rate of tuberculosis in the working age category is about 5\% (268), work-related tuberculosis may not claim any lives at all because of the ease of access to medical treatment among health care personnel. As another example, Parkinson's disease will probably be listed as the underlying cause of death in only the most severe cases and for those deceased who did not concurrently suffer from other fatal diseases, such as cancer or IHD (269). The same situation applies to Alzheimer's disease and vascular dementia.

Social class may affect the attributable fractions based on incidence ratios and mortality ratios. Exposures causing work-related cancer are the most common in occupations of the lowest social classes. In general, the survival of cancer patients in Finland is best among those in the highest social classes (270). This would mean that morbidity-based attributable fractions slightly overestimate work-related cancer mortality. Nevertheless, survival from lung cancer does not display any significant differences according to social class in Finland (270); that is, the comparability assumption seems to be tenable at least for the most important type of work-related cancer.

For IHD, access to the most efficient care, coronary bypass surgery, is better among those in the highest social class (271). In Finland, the Myocardial Infarction Register Study (272) has shown that those in the lowest social class have higher mortality rates from myocardial infarction than those in the highest or middle social class, and the differences are not fully explained by differences in the incidence rate of myocardial infarction. In England, in the Whitehall Study (273), socioeconomic status measured by employment grade was inversely associated with IHD mortality in civil servants with and without prevalent IHD at the beginning of the study. Exposure to some of the causative factors, for instance, shift work and noise, are more common in occupations of the lowest social classes, while the situation may not be the same for exposure to work strain. However, it is difficult to quantitate the impact that these effects may have on our attributable fraction estimates. In the Helsinki Heart Study (30) over 70\% of the participants were blue-collar workers. Consequently, the RR of IHD (incidence and mortality combined) due to shift work was similar for all shift workers and for blue-collar shift workers.

A recent Finnish register study (205) on socioeconomic inequalities in cardiovascular mortality found that the elimination of unfavorable work conditions (including work stress, shift work, and noise) would have reduced the portion of cardiovascular deaths and myocardial infarctions by about the same magnitude. However, 
the effect of income was strong in that mortality in the lowest income category was about twice as high as in the reference category.

\section{Relevant age range}

This study provides an overall approximate estimate of work-related mortality at a national level, the first of its kind in Finland. The main cause-specific contributions to total work-related mortality are due to IHD and lung cancer. When it is considered that these causes of death are common in the general population, especially in older age groups, it is crucial to decide on the vulnerable age range that the study encompasses. Presumably most of the work-related diseases that are potentially fatal are latent for some years from the start of occupational exposure. Thus the starting age was set at 25 years, except for accidents and violent incidents, for which we included all reported fatalities. More importantly, the exclusion of the age category of $\geq 65$ years for cancer would result in a marked underestimate of the total number of work-related fatalities because so many cancers do not manifest themselves until retirement. Those over 65 years of age have had time to experience longer latency and exposure to workplace carcinogens. It is also plausible that occupational risk and stress factors of IHD and cerebrovascular disease can carry over their adverse effects to retirement age (ie, beyond the age of 59 years), with their effects decreasing with increasing age. As for other diseases of chronic etiology, work-related respiratory diseases may even take decades to develop. Similarly, vascular dementia and neurological diseases that are probably caused by occupational exposure to pesticides may occur even in the oldest age groups (T Erkinjuntti, personal communication).

\section{Finnish job-exposure matrix}

Although FINJEM (14) has many advantageous features (such as providing the numbers of exposed workers in Finland by agent, occupation, and level of exposure for several calendar periods), the general exposure information system also has weaknesses. FINJEM was developed for exposure assessment in large register-based studies. While the number of major chemical, physical, and microbiological agents and the like is large $(\mathrm{N}=74)$, the selection is not wide enough to cover many of the more specific agents investigated for job-related hazards in epidemiologic studies. By comparison, the job-exposure matrix of the Montreal cancer mortality study (274) used a checklist of 293 workplace chemicals, including both known and suspected carcinogens, as well as substances that had not been previously evaluated for carcinogeneity. FINJEM is by no means error-free, since it is based on the subjective judgment of chemists, industrial hygienists, and other experts concerning occu- pational exposures in different jobs. The system is constructed by averaging across jobs that shared the same occupation. It follows that employees having the same job title may actually be subjected to quite different levels and durations of exposure. Some degree of exposure misclassification is inevitable in spite of the efforts made to attenuate its various sources. The efforts included accurate definitions of agents, exposures, and occupations. The definition covered inclusions and exclusions, minimum criteria of exposure, and routes of chemical exposure. Some factors, such as worktime arrangements and work strain were assessed directly using interview survey data. Furthermore, occupational classes were divided into more homogeneous subgroups according to exposure variability. Soundness was strived for in FINJEM by having the best available experts of the Finnish Institute of Occupational Health carry out the exposure assessment. Relevant background information was also used to enhance the validity of the resulting estimates. In addition, the experts documented their inferences and confidence in the estimates in FINJEM, and this documentation enabled the identification of unreliable estimates and their reassessment. Even then other occupational factors and nonoccupational confounders such as socioeconomic status may bias the matrix data. Despite these limitations, FINJEM is a useful translator of occupational title information into quantitative agent-specific data.

\section{Interpretation of attributable fractions}

The correct interpretation of attributable fractions is important. The population attributable fraction is the fraction of all disease cases (exposed and unexposed) that would not have occurred if exposure had not taken place (6). In other words, attributable fraction is the expected percentage of cases that are preventable by eliminating exposure from the population. These interpretations assume (275) (i) a causal relation between exposure and disease (ie, biases are absent), (ii) the attainment of the unexposed disease risk among the formerly exposed following the elimination of the exposures, and (iii) independence of the considered risk factors from other factors that affect the disease risk.

Consider, for example, our attributable fraction estimate of $6 \%$ for cerebrovascular disease due to exposure to environmental tobacco smoke. This percentage would seem to suggest that $6 \%$ fewer deaths (exposed and unexposed) would have occurred in the Finnish population if no one had been exposed to environmental tobacco smoke. This interpretation assumes that the absence of exposure to environmental tobacco smoke would not affect the number of persons at risk (6). However, this assumption does not hold completely in practice because eliminating environmental tobacco 
smoke will prevent deaths from other (competing) causes such as IHD, lung cancer, and respiratory diseases. Therefore the population at risk of cardiovascular death would expand.

It may appear counterintuitive that a set of conventional attributable fractions can sum up to a total equaling more than $100 \%$. This possibility follows from the "multicausal" model under which a case of disease can be prevented by eliminating any one of the necessary causal factors. The alternative notion of an "average attributable fraction" (276) for single factors does sum up to their combined attributable fraction. The attributable fraction estimates may give an overoptimistic view of the preventive effect for two reasons. First, deaths from a given cause cannot be prevented, but only postponed or transferred to another cause of death. For example, a fatal coronary infarction may be postponed by a few years if a person is relieved from work involving exposure to carbon monoxide. However, if the person is susceptible to IHD infarction, the infarction will not be preventable, although the manifestation may be milder. That is, in case of a disease with a multifactorial etiology, only the elimination of a necessary cause will prevent the disease incidence effectively. Second, it may not be possible to remove exposure to a risk factor completely but only partially. In this situation, a more general measure that the attributable fraction, namely, the "potential impact fraction" $(277,278)$, can be estimated. This measure is defined as the fractional reduction of the disease load that would result from shifting the current exposure distribution to a lower level.

Although the confidence interval of the attributable fraction is often wide, the point estimate is the most likely value of the attributable fraction parameter compatible with the observed data. We displayed the collection of exposure-specific point estimates of the attributable fractions primarily to allow for the inspection of their relative magnitudes by disease category and gender. The precise absolute magnitude of the specific point estimates was of secondary concern. In the absence of bias, however, the composite attributable fraction is a more precise estimate than its component attributable fraction estimates. The same interpretation holds for the specific point estimates of the number of deaths.

\section{Occupational burden of disease}

Increasingly diseases (in addition to pneumoconiosis, mesothelioma, and asbestos-induced lung cancer) are being recognized as causes of job-related deaths. These diseases include some malignant neoplasms caused by exposure to agents other than asbestos (eg, lung cancer due to exposure to radon), IHD, and chronic obstructive pulmonary disease. Although several occupations and industries have previously been associated with job hazards (279), the emphasis in this work has been on the specific agents associated with the disease risk in the workplace.

\section{Cancers}

Exposure to most of the agents that have been judged to cause cancer in humans can occur in the workplace (280). Previously it has been estimated that less than 5\% of cancer deaths (and at most 15\%) among men and $1 \%$ of cancer deaths among women (and no more than 5\%) can be attributed to occupational factors (258). This apparent discrepancy is related to the insufficient highquality information available on human carcinogens, as well as to the fact that most workers have minimal exposure to potentially carcinogenic agents (substances or processes) in the workplace. The estimated number of cancer deaths due to work-related exposures in New York State constituted $10 \%$ of all cancer deaths (2). An updated estimate of the fraction of all cancer deaths that are caused in the United States by work-related exposures ranged from $6 \%$ to $10 \%$ (3). Unlike this estimate, our estimate of work-related cancers included environmental tobacco smoke as a risk factor and resulted in an overall attributable fraction estimate of $8 \%$ (14\% for men and $2 \%$ for women). A Nordic study (252) estimated that, in Finland, $8 \%$ of the newly diagnosed cancers of the studied sites were "convincingly" related to workplace exposures.

Lung cancer. The attributable fraction for work-related lung cancers assigned for men in previous studies has varied from $10 \%$ to $33 \%$ (3), depending on the definition of occupational exposures and other methodological constraints. Applying our attributable fraction estimate of $29 \%$ to the 1480 lung cancer deaths among men in Finland in 1996 yielded about 430 deaths among men from lung cancer caused by occupational agents. These deaths from lung cancer represented $8 \%$ of all cancer deaths among Finnish men in 1996.

Most of the lung cancer deaths assumed to be due to occupational exposure in the present study are related to asbestos. The attributable fraction estimate of $14 \%$ (95\% CI 6-19\%) for asbestos among men in Finland was extrapolated using the attributable fraction estimate of $19 \%$ (95\% CI 8-26\%) from the greater Helsinki area and comparing incidence rates of reported asbestos-related malignancies in the Helsinki area with those in all of Finland. This proportion is lower than the corresponding estimate obtained in Norway (50), or 23\%. However, the Norwegian results on asbestos may not be applicable to Finland because the area in which the study was conducted is more industrialized than the average for the country. In the German studies $(51,54)$ the corresponding attributable fraction estimate was $8-9 \%$ for 
asbestos-related lung cancers among men. Although Jöckel et al (51) claimed that their estimate of risk was one of the highest in hospital-based (or populationbased) case-referent studies described in the literature, most of the methodologically valid studies from definite occupational asbestos exposure have produced attributable fraction estimates in the range of $10-20 \%$ (281). Our estimate is well within this range.

A Nordic study (252) derived asbestos-related cancer estimates indirectly, for example, by counting four excess cases of lung cancer for each pleural mesothelioma in excess of the expected number. However, the method hinged on the incredible assumption that the mesothelioma incidence among women reflected a background rate totally unrelated to past occupational exposure to asbestos. Thus this method underestimates asbestos-related cancer incidence among both women and men (the attributable fraction estimate being $4 \%$ for lung cancer among men).

Smoking affects the total lung cancer risk but does not detract from the asbestos-related risk. On the contrary, the combined effect of asbestos exposure and smoking on lung cancer risk is multiplicative (28). In a Finnish study (49), all the exposed men with lung cancer were smokers. Therefore, it was not possible to model for either the separate effects of asbestos and smoking or for their joint effect. Accordingly, the estimated attributable fraction of $14 \%$ for lung cancer has to be interpreted as the proportion of lung cancers that would not have been observed if asbestos exposure and its interaction with tobacco smoke had been absent. In a Norwegian study (50), the attributable fractions due to the independent effects of smoking and asbestos exposure were $61 \%$ and $1 \%$, respectively, and $22 \%$ for their combined effect. This finding implies that the hypothetically preventable proportion of all the cases is $23 \%$ by the elimination of asbestos alone $(1 \%+22 \%)$ and $83 \%$ $(61 \%+22 \%)$ for smoking alone. Note that the sum of the percentages exceeds $100 \%$. The reason for this discrepancy is that cases caused by the joint action of asbestos and smoking can be prevented by the removal of either risk factor, but each disease event can be prevented only once.

Incidentally, the proportion of lung cancers due to asbestos exposure and preventable by removal of the carcinogen is different from that used in some compensation schemes. These schemes quantify separately the attributability of lung cancer to asbestos, smoking, and their interaction, which is regarded as a third independent risk factor. This apportionment is accomplished by distributing the attributability of the interaction effect between the primary causes and weighting the component attributable fractions to sum up to $100 \%$ (282).

Smoking is likely to be responsible for an overwhelming proportion of lung cancer deaths, about $85 \%$
(283), in the sense of probability of causation. Exposures to asbestos and radon are the major work-related causes of lung cancer. Therefore, it would seem that the share of lung cancer deaths allotted to the other workrelated causes is marginal. Even though more than 95\% of the persons with lung cancer are active smokers, it does not, of course, follow that all smokers develop lung cancer. In fact, only a tiny proportion of smokers dies from lung cancer. Nor does it mean that occupational exposures do not contribute substantially to lung cancer mortality. Many lung cancer cases involve persons whose disease is probably the joint effect of smoking and exposure to asbestos, arsenic, and the like.

The attributable fractions for the population burden of lung cancer due to environmental tobacco smoke presume that the "unexposed" persons have not been exposed to environmental tobacco smoke. Wald \& Ritchie (284) have shown that, in fact, the "unexposed" subjects have, on the average, $8.5 \mathrm{ng} / \mathrm{ml}$ of cotinine in their urine. From this finding, it follows that the observed RR of, say, 1.3 is an underestimate of the true adverse effect of environmental tobacco smoke on "exposed" persons. The correct measure of the effect of environmental tobacco smoke on "exposed" persons would be the ratio of the lung cancer mortality risk of "exposed" persons to the risk of truly unexposed persons. Robins (285) used the data collected by Wald \& Ritchie (284) on the levels of urinary cotinine in "exposed" and "unexposed" persons to estimate the true RR by applying the nonlinear multistage model of cancer risk to the data on active smokers. Robins assumed that the excess RR of a nonsmoker is proportional to the lifetime dose of environmental tobacco smoke. On the basis of the empirical observation, Robins further assumed that the concentration of cotinine in the urine of passive smokers is about three times that of nonsmokers with no exposure to environmental tobacco smoke. These two assumptions imply that the estimated true RR for "exposed" persons is 1.54 , and for "unexposed" persons the true RR is 1.18 . [Note that $1.54 / 1.18=1.3$ and $(1.54-1) /(1.18-1)=$ 3.] Using these estimates, Robins estimated that about 6470 lung cancer deaths in the United States among lifelong nonsmokers per year from passive smoking. The average over eight studies yielded a mean estimate of 5000 (SD 2400) deaths (286). In 1988, this mean estimate was 3.6 (SD 1.7)\% of all lung cancer deaths in the United States. When extrapolated to the total number of lung cancer deaths in the age category of $\geq 25$ years in Finland in 1996 (ie, 1878 deaths), the proportion yields 68 (SD 32) deaths from environmental tobacco smoke. Furthermore, using a phenomenological model, Repace \& Lawley (286) estimated that the proportion of lung cancer deaths due to environmental tobacco smoke derived from the exposure at work is about $50 \%$. Three other reviewed studies, which explicitly estimated 
the workplace contribution to lung cancer risk, suggested that the proportion is at least half of the risk (286). Applied to the Finnish statistics, the $50 \%$ estimate gives 34 (95\% CI 2-66) lung cancer deaths from passive smoking at work, comparable with the 43 deaths per year based on Robins' estimate. Given the disparity in the various risk assessment methodologies for lung cancer induced by environmental tobacco, the estimated numbers of death are approximately of the same order of size.

Only a small proportion of nonsmokers is currently exposed in Finland to levels of environmental tobacco smoke that can cause lung cancer. Given this fact, it can be predicted that only a few passive smokers who are exposed currently to environmental tobacco smoke at work would succumb from lung cancer in Finland annually in the future (T Kauppinen, personal communication). This risk assessment is in apparent disagreement with our estimate of about 52 lung cancer deaths in 1996 attributable to past higher levels of exposure to environmental tobacco smoke in the workplace. Risk assessment serves the purpose of standard setting, whereas our estimates can be used, for example, for deciding on the allocation of resources for etiologic research on workrelated diseases. The 52 are the cases of lung cancer that would not have been observed if people had not been exposed to levels of environmental tobacco smoke that can cause lung cancer. This number would be even greater if environmental tobacco smoke acts jointly with other carcinogens, for example, environmental radon exposure that is prevalent in certain regions of Finland.

Mesothelioma. The number of deaths due to mesothelioma attributable to occupational exposure can also be roughly estimated from the number of lung cancer deaths. Exposure to asbestos accounts for about 50\% of all cases of lung cancer attributable to occupational agents (50). [According to our estimation based on the attributable fraction method, this proportion was 47\%.] On the other hand, in Finland four cases of asbestosattributable lung cancer occur for each asbestos-attributable case of mesothelioma (60). This ratio is greater than in most countries and is due to the wide use of anthophyllite asbestos in Finland in the past. Modern data indicate that the ratio of recorded asbestos-related lung cancer to mesothelioma is lower than in the historical cohorts, 1.6:1 in Britain (287) based on cancer mortality data and 1:1 in Germany (288) based on a compensation system. If the assumed figures are applied to the 451 work-related lung cancer deaths (table 1), it can be estimated that 56 deaths from mesothelioma (men and women) would be expected to be attributable to asbestos exposure. This number is $33 \%$ greater than the 42 cases in table 1 and nearly equals the total number of 59 for mesotheliomas (asbestos-related and nonasbes- tos-related). The discrepancy probably derives from the underdiagnosing of mesothelioma as the underlying cause of death.

\section{Circulatory diseases}

Most occupational health studies have focused on the study of pneumoconiosis and cancers, and only a few have addressed circulatory diseases. Circulatory diseases nevertheless comprise a larger share of all job-related deaths than is generally acknowledged, $31 \%$ when all risk factors were included and $26 \%$ when environmental tobacco smoke was excluded. Our attributable fraction estimate for the occupational burden of circulatory disease deaths was $12 \%$. The corresponding preferred estimate (or informed guess) in a novel study from the United States was 15\% (18). In spite of the similar attributable fraction estimates, there is a striking disparity between the Finnish Register of Occupational Diseases and the Census of Fatal Occupational Injuries in the United States (289). The register of the Finnish Institute of Occupational Health does not include incident cases of circulatory disease except for a few cases of hand and arm vibration syndrome. Neither are deaths recorded. Whereas the bulk (85\%) of the job-related diseases causing death according to the United States census were diseases of the circulatory system. Within the circulatory category, IHD claimed the highest percentage, $71 \%$ of all job-related diseases (289). In Finland, circulatory diseases are responsible for $49 \%$ of all disease deaths (nonjob-related and job-related). In part, this discrepancy is a result of the different views of stress created by jobs. In a number of states in the United States, workers' compensation is awarded automatically to police officers and firefighters who have a heart attack, regardless of whether or not they were working at the time (but not during retirement), because work in these professions is regarded inherently stressful (289). The advocates of the "job-strain" hypothesis hold the view that work conditions can generate stress, which in turn can lead to or exacerbate circulatory disease (290, 291).

Ischemic heart disease. Shift work and work strain were regarded as two of the most important risk factors of IHD. There are several putative pathways for the effect of shift work on IHD risk. [See, especially references 30 and 177.] Shift work that causes loss of sleep may have a direct effect on the risk of IHD by desynchronizing the circadian pattern. Shift workers have also been shown to have elevated levels of serum triglycerides $(292,293)$. This trend may indicate that shift work is associated with metabolic effects, which, in turn, may increase the risk of IHD. Chronic strain may act as a causal link in the indirect relation between shift work 
and IHD. On the other hand, work strain may exert an independent effect on the risk of IHD. The strain-related biological mediating mechanism may function either by raising blood pressure and increasing the risk of hypertension (294) or by decreasing fibrinolytic activity (295) and predisposing to thrombosis. If the arteriosclerotic growth inside the coronary arteries is discontinuous as a result of the coaction of low-density cholester$\mathrm{ol}$ and fibriolytic factors, then the effects of shift work could carry over far into the retirement age (L Tenkanen, personal communication).

We are not aware of any studies on the risk of arteriosclerotic disease among retired shift workers. In a study (16) of workers exposed to carbon monoxide in the United States, the risk of death from arteriosclerotic heart disease was elevated after 60 years of age. For persons 65 years of age at death the risk ratio was 2.5- to 5.5fold. However, after being away from work for 5 years, the mortality risk of the exposed workers declined and started to approach that of the general population. The data in the Census of Fatal Occupational Injuries in the United States (289) also suggest that the job-related circulatory-disease link should be extended to concern retired people as well. Although deaths due to illness among retirees are largely ignored, $12 \%$ of the IHD deaths nevertheless occurred in the age category of $\geq 65$ years. Thus, although the hypothesis on the long-term effect of work stress on the risk of cardiovascular disease has not been proved, there is new empirical evidence to support it (296).

The RR estimate of 1.30 that we used as the basis of the attributable fraction calculation for IHD induced by environmental tobacco smoke may seem high when compared with the RR of 1.78 for active smoking of 20 cigarettes a day (191). This result is, however, probable because many of the possible agents in environmental tobacco smoke (eg, carbon monoxide) that may cause IHD are in the vapor phase (297); they are therefore deposited more completely in the lung and are harder to clear than particle deposits (298). The toxins must be cleared into the body fluids, where they can circulate to distant sites, such as the heart or the brain (298).

There is also a methodological reason why the risk of IHD due to passive smoking seems to be high when compared with the risk of active smoking. In fact, the two risk estimates may not be directly comparable (299). For studies of active smoking, the reference group includes all nonsmokers, those with and without exposure to environmental tobacco smoke, whereas for studies of involuntary smoking, nonsmokers with higher levels of exposure to environmental tobacco smoke are compared with nonsmokers with lower levels of exposure to environmental tobacco smoke (299). This incomparability of the reference categories has the effect of attenuating the relative risk of IHD in association with active smoking.

Cerebrovascular stroke. The association between active smoking and stroke has been demonstrated in many studies and is likely to be causal. The Auckland study (207) is one of the few large population-based case-referent studies to investigate the relation between passive smoking and the risk of stroke. After adjustment for known risk factors for stroke, such as high blood pressure, diabetes, and heart disease, the study suggested that nonsmokers who have been exposed to environmental tobacco smoke have an $82 \%$ (95\% CI 34-149\%) increased risk of stroke. The size of the RR estimate may seem excessive. Actually, it is much smaller than the RR of 4.1 (95\% CI 3.0-5.6) observed for active smokers. The stroke risk increased further for active smokers (RR 6.3, 95\% CI 4.5-8.9) when those who had been exposed to environmental tobacco smoke were excluded from the nonsmoking reference group (207). The researchers concluded that the finding of an independent increased risk of stroke in association with exposure to environmental tobacco smoke provides support for current efforts to reduce the prevalence of passive smoking and strengthens public health arguments against smoking.

\section{Total mortality}

The size of the work-related death toll (ie, about 1800) can be put into perspective by comparing it with other causes of death. In Finland, in 1996, altogether 1247 persons died by suicide, 593 died of diabetes, and 345 died of poisonings due to the abuse of alcohol. Even a very low estimate of 500 deaths would imply a significant occupational health problem. This number is about as large as the annual number of deaths from traffic and transportation accidents in Finland. If our estimates would prove to be accurate, work-related diseases, especially circulatory diseases and other nonasbestos-related diseases, are responsible for more deaths than what has been previously recognized and reported.

The two problems of occupational health statistics - unwillingness to recognize occupational causes of injuries or health problems and failure to report them even when recognized - are common in both developed and developing countries. Reliable information for most developing countries is scarce, mainly because of serious limitations in the diagnosis of occupational illnesses and in the reporting systems. Even in developed countries, the reporting systems are sometimes fragmentary. The problems have their historical background in workers' demand for protection and preventive measures or compensation and their employers seeking to 
deny or reduce their liability for work-related diseases and injuries. This conflict has greatly affected statistical reporting. As a result, the burden of disease due to occupational exposures is frequently underestimated. In Australia, for example, there was an estimated total of about 2000 deaths in 1996 attributed to occupational exposures (300). This figure is of about the same magnitude as our estimate for Finland, in spite of the fact that the population of Australia is 3.6-fold that of Finland's.

The magnitude of the attributable fraction estimate naturally depends on the chosen age ranges. Given our age-interval specifications, the estimated percentage of deaths attributed to work-related diseases as a fraction of deaths from all diseases (work-related and work-unrelated) in the relevant age categories became $6.7 \%$. This percentage can be compared with the estimated attributable fraction range of 6.2-9.7\% (3) attributed in the United States to selected causes of death (cancer, cardiovascular and cerebrovascular disease, chronic respiratory disease, nervous system disorders, renal disorders, and pneumoconiosis) in the age category of $\geq 25$ years, except for circulatory diseases, which included only deaths between the ages 25 and 64 years. Leigh et al (3) assumed a 5-10\% range for the percentage of deaths due to circulatory disease, which they later regarded as too conservative and therefore revised to 5$20 \%$ (18). This revision raises the upper limit of their range estimate for total work-related mortality to $11 \%$. For the same selected causes our corresponding estimate would be $9.4 \%$.

Health issues are also relevant from an economic point of view. It has been estimated that the costs incurred by premature work-related deaths in Finland in 1991 totaled $3.2 \%$ of the gross national product (301). This percentage is higher than those in the other Nordic countries (Denmark 2.2\%, Sweden 2.4\%, and Norway $1.7 \%$ ) (301), mainly due to the higher occurrence of circulatory diseases in Finland. The distribution of total economic costs by cause of death demonstrated that the greatest losses were due to circulatory diseases $(50 \%)$, cancer $(20 \%)$, respiratory diseases $(7 \%)$, and accidents (9\%) (302). These figures underscore the fact that the costs resulting from circulatory diseases represent a major share of the total costs of work-related diseases and an important drain on national health economics.

\section{Sensitivity analysis}

Given the aforementioned methodological constraints, it is important to underline the uncertainty pertaining to the use of attributable fraction point estimates. One way of assessing the effect of uncertainty in the attributable fraction estimates is sensitivity analysis. Sensitivity analysis is a quantitative extension of the qualitative conjecture that characterizes any thorough discussion of study results (303). Morrell et al (5) adopted an approach that provided the likely lowest and likely highest attributable fractions. These fractions give an indication of the ranges in which the numbers of deaths in the employed population due to occupational risk factors probably lie. However, Morrell et al (5) did not support these ranges with empirical data. In the sensitivity analysis by Leigh et al (3), the ranges relied on national survey data. As shown later in the discussion, sensitivity analysis calls for improving the precision of epidemiologic data in connection with the estimation of attributable fractions, for instance, by means of a pooled analysis of two or more studies.

\section{Lung cancer risk due to asbestos exposure}

Our approach to dealing with the problem of the uncertainty of estimates was to depict attributable fraction as a function of RR and the proportion of exposed cases. Thus, in the case of asbestos and lung cancer (49), the procedure is as follows. Suppose that we know with certitude that $35 \%$ of the lung cancer cases were exposed to asbestos. We can then use this prevalence together with an RR estimate to yield a corresponding estimate of the attributable fraction.

Figure 1 shows the point and interval estimates of attributable fraction as projections from the "spline" surface (304) at the intersections of the estimated values of the RR values and the prevalence of asbestos exposure among disease cases. Consider a reduction in the asbestos exposure prevalence among cases from the observed value of $35 \%$ in the Helsinki metropolitan area (49) to the extrapolated value of $25 \%$ in Finland at large, and to a lower value of $15 \%$. These reductions would result in a decrease in the attributable fraction from the point estimate of $19 \%$ to $14 \%$, and to $8 \%$. This result is reassuring from the preventive point of view. But the effect of imprecision on the attributable fraction is marked because the size of the study population was rather small in terms of the number of incident cases of lung cancer (113 cases). The 95\% CI for RR ranging from 1.3 to 3.9 around the point estimate of 2.3 corresponds to an attributable fraction interval of $8-26 \%$ for all of Finland. With this range of attributable fractions, the estimated number of lung cancer deaths due to asbestos among men varied from about 85 to 273 around the point estimate of 208 .

This analysis indicates that the attributable fraction estimate is sensitive to the exposure prevalence or the risk ratio when these sources are not known with great precision. This uncertainty is reflected in a wide interval estimate for the attributable fraction, and this wide interval estimate, in turn, translates to widely separate lower and upper limits for the estimated number of 


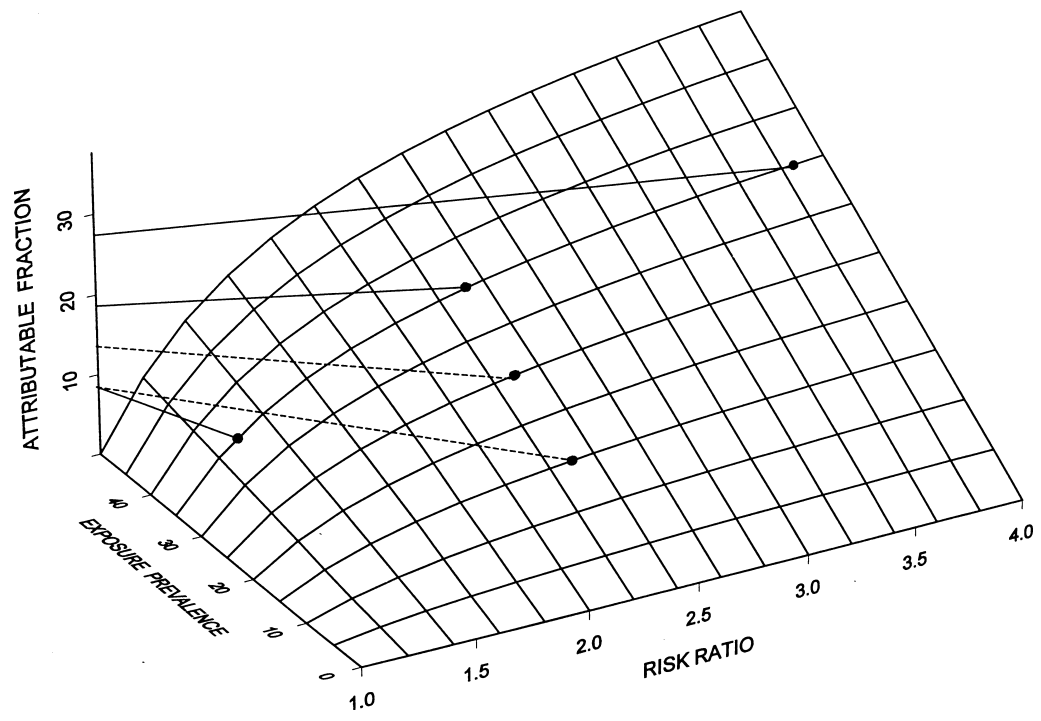

Figure 1. Effect of risk ratio and exposure prevalence (\%) assumptions on the attributable fraction (AF) (\%) for lung cancer deaths among men due to occupational exposure to asbestos, as estimated from a Finnish case-referent study (49). [solid lines = AF projections using the point and confidence interval estimates of the risk ratio and a fixed exposure prevalence (35\%), broken lines = AF projections using exposure prevalences of $25 \%$ and $15 \%$ and a fixed point risk ratio estimate of 2.3]
Table 2. Effect of the assumptions of attributable fraction, age range, and disease risk after retirement on the estimated total number of work-related deaths from ischemic heart disease (codes I21-I25 of the International Classification of Diseases, 10th revision) in Finland.

\begin{tabular}{lccc}
\hline & \multicolumn{3}{c}{ Age range } \\
\cline { 2 - 4 } Attributable fraction & $\begin{array}{l}25-74 \\
\text { years }\end{array}$ & $\begin{array}{l}25-69 \\
\text { years }\end{array}$ & $\begin{array}{l}25-64 \\
\text { years }\end{array}$ \\
\hline Unreduced risk after retirement & & & \\
$10 \%$ & 500 & 315 & 183 \\
$15 \%$ & 750 & 472 & 274 \\
$20 \%$ & 1000 & 629 & 366 \\
Reduced risk after retirement & & & \\
$10 \%$ & 277 & 231 & 165 \\
$15 \%$ & 416 & 346 & 247 \\
$20 \%$ & 554 & 462 & 330 \\
\hline
\end{tabular}

a Risk reduced by $25 \%, 50 \%$, and $75 \%$ in the age categories of $60-64$ years, $65-69$ years, and $70-74$ years, respectively.

deaths. The same formal inference applies to other exposure-disease relations.

\section{Risk of ischemic heart disease due to shift work and other stress factors}

The RR for IHD among male shift workers, when compared with day workers, was 1.38 with a $95 \%$ CI of $1.01-1.89$ (30). These estimates convert to the estimates of attributable fraction (according to equation 3) as follows: point estimate $10.7 \%$ and interval estimate $0.4-18.3 \%$. The corresponding upper and lower limits of deaths among men due to the shift work effect alone then are 8 and 405. In the interpretation of this result, it is inappropriate to treat all the values of RR in the confidence interval as if they were equally plausible. Even in the very wide interval, the point estimate of 237 deaths is the number that makes the observed data most likely. Had we not imposed the linearly decreasing trend on the IHD risk in the age categories between $60-74$ years, the death toll would have been about $70 \%$ heavier. Conversely, if we had assumed that the population at risk was halved when it ages 5 years, then the IHD deaths would have been reduced by a quarter. A restriction of the IHD deaths to the 25- to 60-year age range would have more than halved the estimated number. Some authors have also extrapolated the attributable fractions of IHD and stroke to some additional cardiovascular disease entities, or even to total cardiovascular mortality (18). We did not find enough specific evidence for this approach, which would have raised the number of work-related cardiovascular deaths by as much as $20 \%$.

The estimated total number of work-related IHD deaths depends on assumptions involving which ICD codes to include, which ages apply, and which attributable fraction percentages are appropriate. The significance of the included ICD codes is pronounced. For example, the addition of aortic aneurysm (ICD-10, code I71) to the list of included circulatory diseases would have increased the number of deaths by about 100 . The choice of the percentage attributable is also important. In table 2 the percentages - $10 \%, 15 \%$, and $20 \%-$ refer to the percentages of all the IHD deaths (men and women) we alternatively assumed to be caused by jobrelated factors. By definition, the $20 \%$ assumption provides numbers twice the size of those of the $10 \%$ assumption. The numbers of deaths range from a low of 165 to a high of 1000 (ie, a 6-fold difference). Our preferred estimate was based on an attributable fraction of $17 \%$ and a decreasing portion of the ICD I21-I25 deaths at ages 60 through 74 years. Use of these data yielded 469 deaths due to shift work (or work strain) and other risk factors. 


\section{From national estimates to global estimates}

Existing Finnish statistics on fatal occupational accidents are readily available and reliable, and these figures were used by us (a total of 76 accidents). But a reliable national estimate of fatal work-related diseases should not be based on data from official statistics because the only deaths from work-related diseases that are identifiable in the compulsory reporting sources are those compensated under the workers' compensation system (9) or the farmers' insurance system (10). In 1996, only 76 fatalities from occupational diseases were reported in these statistics ( 74 due to asbestos and 2 due to organic dusts). Thus the ratio of fatal occupational diseases to fatal occupational accidents was 76:76=1. But this ratio estimate is inaccurate given that the reported number of fatal diseases is an underestimate of the true number. Moreover, it is imprecise because the number of fatal-disease end points is small. We chose the attributable fraction method for estimating the number of deaths attributable to work-related diseases. In this study, the disease:accident fatality ratio was about $(1810-876): 76=23$, which is in stark contrast to the aforementioned ratio of unity. The discrepancy is due to the fact that diseases such as work-related IHD and cancer due to exposures other than asbestos are not covered by official statistics.

Thus precautions are needed in the interpretation of these figures and in the extrapolation based on them. For example, Takala (305) used the occupational disease:accident fatality ratio of 0.96 obtained from the official statistics of Finland in 1990-1994 to estimate the number of fatal work-related diseases in the world. His global annual estimate was 325000 fatalities from work-related diseases. As the author remarked, this estimate does not cover such workrelated diseases as those of the circulatory system. In contrast, our ratio estimate of 23 would yield about 7.6 million fatalities when based on the estimated number of occupational accidents in the world (ie, 335 000) (305). If deaths from diseases of the circulatory system were not counted, the ratio would be about 16 , and the global burden of mortality from work-related diseases would still be as high as 5.2 million. Takala (306) gave another estimate of the global work-related disease mortality based on the attributable fractions applied in a study in the United States (3), that is, 990000 deaths. The global number for work-related-disease mortality can also be estimated crudely by multiplying the total number of disease deaths in table 1 by the ratio of the world population to that of Finland, namely, 1100. This calculation would yield about 2 million work-related disease deaths per year in the world as an estimate. However, this figure is surely an underestimate because the Finnish occupational mortality rates are more favo- rable than those prevailing in many developing countries.

Another example of invalid extrapolation would be the estimation of the number of fatal injuries (accidents and diseases) in Australia based on the Finnish injury rate. The rate of fatal occupational injuries (work-related diseases and accidents), based on the official statistics of Finland for $1996(9,10)$, was 7.2 per 100000 workers. An estimate of the corresponding annual rate in Australia was 35.2 per 100000 (305, 307). The fivefold difference in the rates probably derives from the different standards of occupational health and safety in the two countries, and these differences influence strongly the injury rates. Therefore, applying the Finnish rate to the Australian population would result in a gross underestimation of the burden of occupational fatalities, and the result would be even worse if it were applied to populations of world regions in developing economies. On the other hand, estimating the number of fatal injuries in the world solely on the basis of linear extrapolation of the Australian rate [Takala's (305) estimate was 843299 ] is problematic because the extrapolation is targeted at a highly heterogeneous global population.

Global estimates of the burden of disease due to occupational factors have been based on the incidence rates of occupational disease in Finland by Leigh et al (1), who applied twice the Finnish rates for the developing regions of the world. However, the rationale for the method was not characterized, so it is unlikely that the token rates would be uniformly applicable. Therefore, as the authors reminded, "Local estimates, particularly at the subnational and national levels, would be a valuable contribution to the further development of the process [p 630]".

It is evident that the distribution of exposures contributing to our Finnish estimate differs drastically from the exposure circumstances in many other countries, especially in developing countries. For example, two nested case-referent studies, based on an international register of workers exposed to phenoxy herbicides, chlorophenols, and dioxins, showed an increased risk for soft-tissue sarcoma (308). But these pesticides, in particular 2,3,7,8-tetrachlorodibenzo-p-dioxin (TCDD), have not been used as widely in Finland as in many other countries. Accordingly, the absence of Finnish attributable fraction estimates for the link between phenoxy herbicides and their contaminants should not be taken as evidence of an absence of an excess risk. The availability, sources, and quality of information also vary from country to country. Therefore any attempt of straightforward extrapolation of our estimates to other countries or regions of the world at a different level of industrial development with different socioeconomic standards would be treacherous. Instead, local estimation 
of the work-related disease load should start with a careful examination of existing information sources and a thorough literature search to identify the most reliable study base. When the necessary data are not available, representative surveys may be needed to obtain estimates of disease rates and the sizes of employed populations.

\section{Prevention of work-related diseases}

Knowledge of the role of exposure to occupational factors in inducing morbid events is crucial to the prevention of disease. Most work-related illnesses are preventable. For instance, all illnesses and deaths related to asbestos are entirely avoidable. In Finland, many regulatory measures have been undertaken to prevent the adverse outcomes of hazardous substances: all asbestos usage has been banned; hygienic standards for occupational exposures have been set for arsenic, cadmium, chromates, carbon disulfide, nickel, and organic solvents; lead-exposed workers are being biologically monitored; and the like. However, as Vineis (309) has remarked, the sufficient evidence that is needed before preventive action is undertaken is "a matter of political decision, not only of scientific evaluation, and it depends on the circumstances [p 447]". Moreover, the overall health impact on the population has to be considered.

Consider, for example, congenital malformations in relation to reproductive hazards in the workplace (310). An early Finnish register-based case-referent study found an association between the occurrence of congenital defects of the central nervous system after mothers' exposure to organic solvents during the first trimester of pregnancy (311). This tentative observation has been corroborated in an up-to-date meta-analysis of retrospective studies (312). A new Canadian prospective cohort study (313) confirmed the strong significant association and concluded that it is prudent to minimize women's occupational exposure to organic solvents during pregnancy. This step is important because occupational exposure limits are not usually based on reproductive health effects. In Finland, legislation on the protection of the reproductive health of working men and women, as well as of pregnant women, has been in effect since 1991 (314). According to the law on special maternity

\section{Uncertainty of the mortality estimates}

Debating whether the actual number of work-related deaths per year in Finland due to hazardous substances or environments is nearly 2000 or only 1000 is missing the point, unless one truly feels that the 1000 annual deaths are acceptable. leave, female workers who are exposed to certain chemical, physical, or biological agents that are considered harmful to the fetus are entitled to special maternity leave and benefits. The main cause of the leave has been exposure to organic solvents. On the other hand, in many cases the worktasks of a pregnant woman can be modified or she can be transferred to another job. Because of these effective measures to reduce exposure to reproductive toxic agents, we excluded congenital defects from our mortality analysis. In the European Union, the classification of "toxic to reproduction" has not only been widened to encompass structural defects, but now includes functional deficits as well (315).

A more current example concerns the health risks attributable to exposure to environmental tobacco smoke at work (316). In 2000, an amendment of the Tobacco Control Act came into force in Finland. It stipulates that environmental tobacco smoke is a carcinogenic substance. Hence the Finnish Institute of Occupational Health will officially register all employees who are significantly exposed to environmental tobacco smoke along with employees exposed to other carcinogenic substances or processes in their work. The estimated average number of employed passive smokers in the country in 1998-2000 was 167000 . Consequently, the potential preventive impact on the population is considerable. In 1994 the Finnish Tobacco Control Act had already banned smoking in workplaces other than restaurants. When the new law becomes fully effective in 2003, places free of environmental tobacco smoke must be allocated for nonsmoking customers in Finnish restaurants and cafés, and bar areas must be free of tobacco smoke. Preventive measures that effectively reduce lung cancer induced by environmental tobacco smoke will also be powerful means of reducing the high burden of heart attack, stroke, and respiratory diseases worldwide.

\section{Concluding remarks}

We restricted our analysis to the most severe health outcome of harmful exposures, death. An analysis covering total work-related morbidity, as well as consequent losses in work ability and quality of life, would bring in additional important (nonfatal) disease entities and add to the case load of the diseases already included in our study. This addition would, however, further increase the methodological difficulties and demands for adequate epidemiologic data. Such an analysis would probably reveal that recognized risks represent just the tip of the iceberg. Our estimate of approximately 1800 work-related fatalities annually already indicates that there is no reason to believe that occupational factors no longer cause harm. Although methodological improvements may be achieved in 
future studies, preventive efforts should not be impeded by the uncertainties of the current estimate.

The new constitution of Finland, which became effective in March 2000, requires that public authorities ensure the protection of the workforce. This noble obligation has not been fulfilled, however, because so many fatalities are still annually caused in Finland by exposure to factors associated with employment. Of course, not all occupational deaths are avoidable. Fatal disease incidents and accidents do occur in spite of legislative rules and other efforts made to prevent them. In consideration of our results, however, it would be unjust to claim that everything that is reasonably possible has been done to protect workers' health and safety. We conclude that the burden of work-related mortality in Finland is considerably heavier than what has been generally recognized and reported.

\section{Acknowledgments}

We thank Sven Hernberg for reviewing the entire manuscript and for his valuable comments and suggestions for editorial improvements; the anonymous referees for their constructive criticisms; Timo Erkinjuntti, Pirjo Heikkilä, Mikko Härmä, Raija Kalimo, Timo Kauppinen, Tage S Kristensen, Maritta S Jaakkola, Hannu Laaksovirta, Olli S Miettinen, Bo Netterstøm, Tuula Nurminen, Timo Partanen, Julian Peto, Eero Pukkala, Vesa Riihimäki, Veikko Salomaa, Leena Tenkanen, Antti Tossavainen, Simo Virtanen, and Stephen S Walter for valuable consultative advice in their particular fields of expertise; Per Gustavsson, Kirsti HusgafvelPursiainen, Riitta-Sisko Koskela, Eeva Kuosma, James Leigh, J Paul Leigh, Pekka Nuorti, Anneli Ojajärvi, Ilmari Pyykkö, Lauri Tammilehto, Kaisa Vasama-Neuvonen, and Elisabete Weiderpass for providing additional information and references; and Terttu Kaustia for the English language revision.

\section{References}

1. Leigh J, Macaskill P, Kuosma E, Mandryk J. Global burden of disease and injury due to occupational factors. Epidemiology 1999;10:626-31.

2. Markowitz SB, Fisher E, Fachs MC, Shapiro J, Landrigan PJ. Occupational disease in New York State: a comprehensive examination. Am J Ind Med 1998;16:417-35.

3. Leigh JP, Markowitz SB, Fahs M, Shin C, Landrigan PJ. Occupational injury and illness in the United States. Estimates of costs, morbidity, and mortality. Arch Intern Med 1997; 157:1557-68.
4. Kraut A. Estimates of the extent of morbidity and mortality due to occupational diseases in Canada. Am J Ind Med 1994; 25:267-78.

5. Morrell S, Kerr C, Driscoll T, Taylor R, Salkeld G, Corbett S. Best estimate of the magnitude of mortality due to occupational exposure to hazardous substances. Occup Environ Med 1998;55:634-41.

6. Rothman KJ, Greenland S. Modern epidemiology. 2nd ed. New York (NY): Lippincott-Raven, 1997.

7. World Health Organization (WHO). International statistical classification of diseases and health related problems, 10th revision; vol 1-3. Geneva: WHO, 1992.

8. Statistics Finland. Causes of death 1996. Helsinki: Statistics Finland, 1999. Health 1998:3

9. Federation of Finnish Insurance Companies. Fatal work accidents 1996. Helsinki: Federation of Finnish Insurance Companies, 2000. (World Wide Web address: http:/www.vakes.fi/ svk/)

10. Farmers' Social Insurance Institution. Accidents at work and occupational diseases in farmers in 1996. Helsinki: Farmers' Social Insurance Institution, 1999.

11. Karjalainen A, Aalto L, Jolanki R, Keskinen H, Savela A. Occupational diseases in Finland in 1996: new cases of occupational diseases reported to the Finnish Register of Occupational Diseases. Helsinki: Finnish Institute of Occupational Health, 1998.

12. Kolari R. Occupational mobility in Finland 1970/1975. Helsinki: Central Statistical Office of Finland, 1983. Studies no 97.

13. Statistics Finland. Occupation and socio-economic status: population census 1990, vol 8. Helsinki: Statistics Finland, 1993.

14. Kauppinen T, Toikkanen J, Pukkala E. From cross-tabulations to multipurpose exposure information systems: a new job-exposure matrix. Am J Ind Med 1998;33:409-17.

15. Lehto A-M, Sutela H. Finnish quality of worklife survey. Helsinki: Statistics Finland, 1998. Labour market, 1998:12.

16. Stern FB, Halperin WE, Hornung RW, Ringenburg VL, McCammon CS. Heart disease mortality among bridge and tunnel officers exposed to carbon monoxide. Am J Epidemiol 1988; 128:1276-88.

17. Steenland K. Risk assessment for heart disease and workplace environmental tobacco smoke exposure among nonsmokers. Environ Health Perspect 1999;107 suppl 6:85963.

18. Leigh JP, Schnall P. Costs of occupational circulatory disease. In: Schnall PL, Belkic KL, Landbergis PA, Baker DB, editors. The workplace and cardiovascular disease. Philadelphia (PA): Hanley \& Belfus Inc, 2000:257-67. Occupational medicine: state of the art reviews, vol 15.

19. Levin ML. The occurrence of lung cancer in man. Acta Unio Internationalis Contra Cancrum 1953;9:531-41.

20. Miettinen OS. Proportion of disease caused or prevented by a given exposure, trait or intervention. Am J Epidemiol 1974;99:325-32.

21. Greenland S, Morgenstern H. Morgenstern corrects a conceptual error. Am J Public Health 1983;73:703—4.

22. Greenland S. Bias in methods for deriving standardized mortality ratio and attributable fraction estimates. Stat Med 1984;3:131-41.

23. Walter SD. The distribution of Levin's measure of attributable risk. Biometrika 1975;62:371—4.

24. Brüske-Hohlfeld I, Möhner M, Ahrens W, Pohabeln H, Heinrich J, Kreuzer M, et al. Lung cancer risk in male workers 
occupationally exposed to diesel motor emissions in Germany. Am J Ind Med 1999;36:405-14.

25. Greenland S, Drescher K. Maximum likelihood estimation of the attributable traction from logistic models. Biometrics 1993;49:865-72.

26. Hubbard R, Lewis S, Richards K, Johnston I, Britton J. Occupational exposure to metal or wood dust and aetiology of cryptogenic fibrosing alveolitis. Lancet 1996;347(8997): 284-9.

27. Shy CM, Mundt KA. Interaction: an epidemiological perspectice for risk assessment. In: Fan AM, Chang LW, editors. Toxicology and risk assessment. Principles, methods, and applications. New York (NY): Marcel Deccer, Inc, 1996: 329-51.

28. Lee PN. Relation between exposure to asbestos and smoking jointly and the risk of lung cancer. Occup Environ Med 2001; 58:145-53.

29. Järup L, Pershagen G. Arsenic exposure, smoking, and lung cancer in smelter workers - a case-control study. Am J Epidemiol 1991;134:545-51.

30. Tenkanen L, Sjöblom T, Kalimo R, Alikoski T, Härmä M. Shift work, occupation and coronary heart disease over 6 years of follow-up in the Helsinki Heart Study. Scand J Work Environ Health 1997;23:257-65.

31. Cox DR. Regression models and life-tables (with discussion). JR Stat Soc 1972;34:187-220. Series B.

32. Kalimo R, Toppila S. Työuupumus Suomen työikäisellä väestöllä [Fatigue at work in the Finnish population of working age]. Helsinki: Finnish Institute of Occupational Health, 1997.

33. Lehto A-M, Sutela H. Tehokas, tehokkaampi, uupunut: työolosuhdetutkimuksen tuloksia 1977-1997 [Efficient, more efficient, burnout: results of a survey on work conditions 1977_1997]. Helsinki: Statistics Finland, 1998. Työmarkkinat 1998:12.

34. Kawachi I, Colditz GA, Stampher MJ, Willett WC, Manson JE, Speizer FE, et al. Prospective study of shift work and risk of coronary heart disease in women. Circulation 1995; 92:3178-82.

35. Cox LA Jr. Probability of causation and the attributable proportion of risk. Risk Anal 1984;4:221-30.

36. Greenland S, Robins JM. Conceptual problems in the definition and interpretation of attributable fractions. Am J Epidemiol 1988;128:1185-97.

37. International Agency for Research on Cancer (IARC). IARC monographs on the evaluation of carcinogenic risks to humans, vol 1-77. Lyon: IARC, 1972-2000.

38. Boffetta P, Kogevinas M, Simonato L, Wilbourn J, Saracci R. Current perspectives on occupational cancer risks. Occup Environ Health 1995;1:315-25.

39. Siemiatycki J, editor. Risk factors for cancer in the workplace. Boca Raton (FL): CRC Press, 1991.

40. Andersen A, Barlow L, Engeland A, Kjærheim K, Lynge E, Pukkala E. Work-related cancer in the Nordic countries. Scand J Work Environ Health 1999;25 suppl 2:1-116.

41. International Agency for Research on Cancer (IARC). Some naturally occurring substances: food items and constituents, heterocyclic aromatic amines and mycotoxins. Lyon: IARC, 1993. IARC monographs on the evaluation of carcinogetic risks to humans, vol 56.

42. International Agency for Research on Cancer (IARC). Occupational exposures of hairdressers and barbers and personal use of hair colourants, some hair dyes, cosmetic colourants, industrial dyestaffs and aromatic amines. Lyon, France:
IARC, 1993. IARC monographs on the evaluation of carcinogetic risks to humans, volume 57.

43. Anttila A, Pukkala E, Aitio A, Rantanen T, Karjalainen S. Update of cancer incidence among workers at a copper/ nickel smelter and nickel refinery. Int Arch Occup Environ Health 1998;71:245-50.

44. Ahlman K, Koskela R-S, Kuikka P, Koponen M, Annanmäki M. Mortality among sulfide ore miners. Am J Ind Med 1991;19:603-17.

45. Pukkala E, Nokso-Koivisto P, Roponen P. Changing cancer risk pattern among Finnish hairdressers. Int Arch Occup Environ Health 1992;64:39—-42.

46. Anttila A, Heikkilä P, Pukkala E, Nykyri E, Kauppinen T, Hernberg S, et al. Excess lung cancer among workers exposed to lead. Scand J Work Environ Health 1995;21:460 9.

47. Koskela R-S, Klockars M, Laurent H, Holopainen M. Silica dust exposure and lung cancer. Scand J Work Environ Health 1994;20:407-16.

48. Elinder C-G, Kjellström T, Hogstedt C, Andersson K, Spång G. Cancer mortality of cadmium workers. Br J Ind Med 1985;42:651-5.

49. Karjalainen A, Anttila S, Vanhala E, Vainio H. Asbestos exposure and the risk of lung cancer in a general urban population. Scand J Work Environ Health 1994;20:243-50.

50. Kjuus H, Skjærven R, Langård S, Lien JT, Aamodt T. A case-referent study of lung cancer, occupational exposures and smoking: I Comparison of title-based and exposurebased occupational information. Scand J Work Environ Health 1986;12:193-202.

51. Jöckel K-H, Ahrens W, Jahn I, Pohlabeln H, Bolm-Audorff U. Occupational risk factors for lung-cancer: a case control study in West Germany. Int J Epidemiol 1998;27:549—60.

52. Jöckel K-H, Ahrens W, Pohlabeln H, Bolm-Audorff U, Müller KM. Lung cancer risk and welding: results from a case-control study in Germany. Am J Ind Med 1998; 33:313-20.

53. Jahn I, Ahrens W, Brüske-Hohlfeld I, Kreuzer M, Möhner M, Pohlabeln $\mathrm{H}$, et al. Occupational risk factors for lung cancer in women: results of a case-control study in Germany. Am J Ind Med 1999;36:90—100.

54. Brüske-Hohlfeld I, Möhner M, Pohlabehn H, Ahrens W, Bolm-Audorff U, Kreienbrock L, et al. Occupational lung cancer risk for men in Germany: results from a pooled casecontrol study. Am J Epidemiol 2000;151:384—95.

55. Kreuzer M, Krauss M, Kreienbrock L, Jöckel K-H, Wichmann H-E. Environmental tobacco smoke and lung-cancer: a case-control study in Germany. Am J Epidemiol 2000; 151:241-50

56. Droste JHJ, Weyler JJ, van Meerbeeck JP, Vermeire PA, van Sprundel MP. Occupational risk factors of lung cancer: a hospital based case-control study. Occup Environ Med 1999;56:322-7.

57. Nurminen M. A study of the mortality of workers in an antophyllite asbestos factory in Finland. Work Environ Health 1972;9:112-8.

58. Steenland K, Loomis D, Shy C, Simonsen N. Review of occupational lung carcinogens. Am J Ind Med 1996;29:47490.

59. Karjalainen A, Vanhala E, Karhunen PJ, Lalu K, Penttilä A, Tossavainen A. Asbestos exposure and pulmonary fiber concentrations of 300 Finnish urban men. Scand J Work Environ Health 1994;20:34-41.

60. Karjalainen A, Pukkala E, Mattson K, Huuskonen MS. 
Improved reporting of asbestos-related occupational cancers in Finland. In: Chiyotani K, Hosoda Y, Aizawa Y, editors. Advances in prevention of occupational respiratory diseases. Amsterdam: Elsevier Science, 1998:66-74.

61. International Agency for Research on Cancer (IARC). Manmade mineral fibers and radon. Lyon: IARC, 1988. IARC monographs on the evaluation of carcinogenic risks to humans, vol 43.

62. Sosiaaali- ja terveysministeriö. Radonin terveysvaikutukset [The health effects of radon]. Helsinki: Sosiaaali- ja terveysministeriö, 1998.

63. Kauppinen T, Toikkanen J, Pedersen D, Young R, Ahrens $\mathrm{W}$, Boffetta $\mathrm{P}$, et al. Occupational exposure to carcinogens in the European Union. Occup Environ Med 2000;57:10-18.

64. International Agency for Research on Cancer (IARC). Silica, some silcates, coal dust and para-aramid fibrils. Lyon: IARC, 1997. IARC monographs on the evaluation of carcinogenic risks to humans, vol 68 .

65. Partanen T, Pukkala E, Vainio, H, Kurppa K, Koskinen H. Increased incidence of lung and skin cancer in Finnish silicotics. J Occup Med 1994;36:616-22.

66. Partanen T, Jaakkola J, Tossavainen A. Silica, silicosis and cancer in Finland. Scand J Work Environ Health 1995;21 suppl 2:84-6.

67. Collins JJ, Acquavella JF. Review and meta-analysis of studies of acrylonitrile workers. Scand J Work Environ Health 1998;24 suppl 2:71-80.

68. Coggon D, Cole P. Acrylonitrile and human cancer - an overview. Scand J Work Environ Health 1998;24 suppl 2: $81-82$.

69. Järup L, Nordberg G. Cancer. In: Järup L, editor, Berglund M, Elinder CG, Nordberg G, Vahter M. Health effects of cadmium exposure - a review of the literature and a risk estimate. Scand J Work Environ Health 1998;24 suppl 1:346.

70. International Committee on Nickel Carcinogenis in Man. Report of the International Committee on Nickel Carcinogenis in Man. Scand J Work Environ Health 1990;16:1—82.

71. International Agency for Research on Cancer (IARC). Diesel and gasoline engine exhausts and some nitroarenes. Lyon: IARC, 1989. IARC monographs on the evaluation of carcinogenic risks to humans, vol 46.

72. Gustavsson P, Jakobsson R, Nyberg F, Pershagen G, Järup L, Scheele P. Occupational exposure and lung cancer risk: a population-based case-referent study in Sweden. Am J Epidemiol 2000;52:32-40.

73. Evanoff BA, Gustavsson P, Hogstedt C. Mortality and incidence of cancer in a cohort of Swedish chimney sweeps: an extended follow up study. Br J Ind Med 1993;50:450—9.

74. Fu H, Boffetta P. Cancer and occupational exposure to inorganic lead compounds: a meta-analysis of published data. Occup Environ Med 1995;52:73-81.

75. Steenland K, Boffetta P. Lead and cancer in humans: where are we now? Am J Ind Med 2000;38:295-9.

76. Vainio H. Lead and cancer - association or causation? [editoriall Scand J Work Environ Health 1997;23:1-3.

77. Danielsen TE, Langård S, Andersen A, Knudsen $\emptyset$. Incidence of cancer among welders of mild steel and other shipyard workers. Br J Ind Med 1993;50:1097-103.

78. Sjögren B, Hansen KS Kjuus H, Persson P-G. Exposure to stainless steel welding fumes and lung cancer: a meta-analysis. Occup Environ Med 1994;51:335-6.

79. Pukkala E, Saarni H. Cancer incidence among Finnish seafarers, 1967-92. Cancer Causes Control 1996;7:231—9.
80. Pershagen G. Passive smoking and lung cancer. In: Samet JM, editor. Epidemiology of lung cancer. New York (NY): Marcel Decker Inc, 1994:109_30.

81. United States (US) Environmental Protection Agency. Respiratory health effects of passive smoking: lung cancer and other disorders. Washington (DC): US Environmental Protection Agency, 1992.

82. United States Occupational Safety and Health Administration. Indoor air quality. Fed Reg 1994;59:15968-16039.

83. Hackshaw AK, Law MR, Wald NJ. The accumulated evidence on lung cancer and environmental tobacco smoke. Br Med J 1997;315:980—8.

84. Wells JA. Lung cancer from passive smoking at work. Am J Public Health 1998;88:1025—9.

85. Brown KG. Lung cancer and environmental tobacco smoke: occupational risk to nonsmokers. Environ Health Perspect 1999;107 suppl 6:885-90.

86. Reynolds P. Epidemiologic evidence for workplace ETS as a risk factor for lung cancer among nonsmokers: specific risk estimates. Environ Health Perspect 1999;107 suppl 6:86572.

87. Boffetta P, Agudo A, Ahrens W, Benhamou E, Benhamou S, Darby SC, et al. Multicenter case-control study of exposure to environmental tobacco smoke and lung cancer in Europe. JNCI 1998;90:1040—50.

88. Fontham ET, Correa P, Reynolds P, Wu-Williams A, Buffler PA, Greenberg S, et al. Environmental tobacco smoke and lung cancer in nonsmoking women: a multicenter study. J Am Med Assoc 1994;271:1752-9.

89. Cardenas VM, Thun MJ, Austin H, Lally CA, Clark WS, Greenberg RS, et al. Environmental tobacco smoke and lung cancer mortality in the American Cancer Society's Cancer Prevention Study II. Cancer Causes Control 1997;8:57-64.

90. Kreuzer M, Boffetta P, Whitley E, Ahrens W, Gaborieau V, Heinrich $\mathrm{J}$, et al. Gender differences in lung cancer risk by smoking: a multicentre case-control study in Germany and Italy. Br J Cancer 2000;82:227-33.

91. Correa P, Pickle LW, Fontham E, Lin Y, Haenszel W. Passive smoking and lung cancer. Lancet 1983;2(8350):595-7.

92. Nomura AMY, Kolonel LN. Prostate cancer: a current perspective. Epidemiol Rev 1991;13:200-27.

93. Pienta KJ, Esper PS. Risk factors for prostate cancer. Ann Intern Med 1993;118:793-803.

94. Giovannucci E. Epidemiologic characteristics of prostate cancer. Cancer 1995;75:1766-77.

95. Van der Gulden JWJ. Metal workers and repairmen at risk for prostate cancer: a review. Prostate 1997;30:107-16.

96. Blair A, Hoar Zahm S, Pearce NF, Heineman EF, Fraumeni JF Jr. Clues to cancer etiology from studies of farmers. Scand J Work Environ Health 1992;18:209-15.

97. Van der Gulden JWJ, Vogelzang PFJ. Farmers at risk for prostate cancer. Br J Urol 1996;77:6-14.

98. Keller-Byrne JE, Khuder SA, Schaub EA. Meta-analyses of prostate cancer and farming. Am J Ind Med 1997;31:580-6.

99. Acquavella J, Olsen G, Cole P, Ireland B, Kaneene J, Schuman S, et al. Cancer among farmers: a meta-analysis. Ann Epidemiol 1998;8:64-74.

100. Band PR, Le ND, Fang R, Threlfall WJ, Gallagher RP. Identification of occupational cancer risks in British Columbia. J Occup Environ Med 1999;41:233-47.

101. Parker AS, Cerhan JR, Putnam SD, Cantor KP, Lynch CF. A cohort study of farming and risk of prostate cancer in Iowa. Epidemiology 1999;10:452-5.

102. Sharma-Wagner S, Chokkalingam AP, Malker HSR, Stone 
BJ, McLaughlin JK, Hsing AW. Occupation and prostate cancer risk in Sweden. J Occup Environ Med 2000;42:51725 .

103. Morrison H, Sawitz D, Semenciw R, Hulka B, Mao Y, Morison D, et al. Farming and prostate cancer mortality. Am J Epidemiol 1993;137:270-80.

104. Goldsmith D, Smith A, McMichael A. A case-control study of prostate cancer within a cohort of rubber and tire workers. J Occup Med 1980;19(22):533—41.

105. Hagmar N, Bellander T, Andersson C, Andersson C, Lindén $\mathrm{K}$, Attewall $\mathrm{R}$, et al. Cancer morbidity in nitrate fertilizer workers. Int Arch Occup Environ Health 1991;63:63-7.

106. Aronson KJ, Siemiatycki J, Dewar R, Gérin M. Occupational risk factors for prostate cancer: results from a case-control study in Montréal, Québec, Canada. Am J Epidemiol 1996;143:363-73.

107. Gold EB, Goldin SB. Epidemiology and risk factors for pancreatic cancer. Surg Oncol Clin N Am 1998;7:67-91.

108. Partanen T, Kauppinen T, Degert R, Moneta G, Mearelli I, Ojajärvi A, et al. Pancreatic cancer in industrial branches and occupations in Finland. Am J Ind Med 1994;25:851—66.

109. Kauppinen T, Partanen T, Degerth R, Ojajärvi A. Pancreatic cancer and occupational factors. Epidemiology 1995;6:498502.

110. Alguecil J, Kauppinen T, Porta M, Partanen T, Malats N, Kogevinas M, et al. Risk of pancreatic cancer and occupational exposures in Spain. Ann Occup Hyg 2000;44:391403.

111. Ojajärvi IA, Partanen TJ, Ahlbom A, Boffetta P, Hakulinen $\mathrm{T}$, Jourenkova $\mathrm{N}$, et al. Occupational exposures and pancreatic cancer: a meta-analysis. Occup Environ Med 2000; $57: 316-24$.

112. Cocco P, Ward MH. Occupational exposures and gastric cancer aetiology. Eur J Gastroenterol Hepatol 1994;6:1089— 96.

113. Parent M-É, Siemiatycki J, Fritschi L. Occupational exposures and gastric cancer. Epidemiology 1997;9:48-55.

114. Liddell FDK, Thomas DC, Gibbs GW, McDonald JC. Fibre exposure and mortality from pneumoconiosis, respiratory and abdominal malignancies in chrysotile production in Quebec, 1926-75. Ann Acad Med Singapore 1984;13:340—4.

115. Gerhardsson de Verdier M, Plato N, Steineck G, Peters JM. Occupational exposures and cancer of the colon and rectum. Am J Ind Med 1992;22:291-303.

116. Ekström AM, Eriksson M, Hansson LE, Lindgren A, Signorello LB, Nyren O, et al. Occupational exposures and risk of gastric cancer in a population-based case-control study. Cancer Res 1999;59:5932-7.

117. Chow WH, McLaughlin JK, Malker HS, Weiner JA, Ericsson JL, Stone BJ, et al. Occupation and stomach cancer in a cohort of Swedish men. Am J Ind Med 1994;26:511-20.

118. Cocco P, Palli D, Buiatti E, Cipriani F, DeCarli A, Manca P, et al. Occupational exposures as risk factors for gastric cancer. Cancer Causes Control 1994;5:241-8.

119. Chow WH, Malker HS, Hsing AW, McLaughlin JK, Weiner JA, Stone BJ, et al. Occupational risks for colon cancer in Sweden. J Occup Med 1994;36:647-51.

120. Tomatis L, Aitio A, Day NE, Heseltine E, Kaldor J, Miller $\mathrm{AB}$, et al, editors. Cancer: causes, occurrence and control. Lyon: International Agency for Research on Cancer, 1990. IARC scientific publications, no 100 .

121. Tola S. Occupational cancer of the urinary bladder. J Toxicol Environ Health 1980;6:1253-60.

122.t'Mannetje A, Kogevinas M, Chang-Claude J, Cordier S,
Gonzales CA, Hours M, et al. Occupation and bladder cancer in European women. Cancer Causes Control 1999;10:20917.

123. Pesch B, Haerting J, Ranft U, Klimpel A, Oelschlägel B, Schill W, et al. Occupational risk factors for urothelial carcinoma: agent-specific results from a case-control study in Germany. Int J Epidemiol 2000;29:238—47.

124. Goldberg M, Labrèche M. Occupational risk factors for female breast cancer: a review. Occup Environ Med 1996; 53:145-56.

125. Sankila R, Karjalainen S, Läärä E, Pukkala E, Teppo L. Cancer risk among health care personnel in Finland, 19711980. Scand J Work Environ Health 1990;16:252-7.

126. Weiderpass E, Pukkala E, Kauppinen T, Mutanen P, Paakkulainen $\mathrm{H}$, Vasama-Neuvonen $\mathrm{K}$, et al. Breast cancer and occupational exposures in women in Finland. Am J Ind Med 1999;36:48-53.

127. Pukkala E, Auvinen A, Wahlberg. Incidence of cancer among Finnish airline cabin attendants, 1967-92. Br Med J 1995;311:649-52.

128. Welp EA, Weiderpass E, Boffetta P, Vainio H, VasamaNeuvonen K, Petralia S, et al. Environmental risk factors of breast cancer. Scand J Work Environ Health 1998;24:3-7.

129. Committee on the Biological Effects of Ionizing Radiation, National Research Council. Health effects of exposure to low levels of ionizing radiation. Washington (DC): US National Academy Press, 1990.

130. Shen N, Weiderpass, Anttila A, Goldberg M, Vasama-Neuvonen $\mathrm{K}$, Boffetta $\mathrm{P}$, et al. Epidemiology of occupational and environmental risk factors related to ovarian cancer. Scand J Work Environ Health 1998;24:175-82.

131. Pukkala E. Cancer risk by social class and occupation: a survey of 109000 cancer cases among Finns of working age. Basel: Karger, 1995:307-12. Contributions to epidemiology and biostatistics, no 7.

132. Vasama-Neuvonen K. Pukkala E, Paakkulainen H, Mutanen P, Weiderpass E, Boffetta P, et al. Ovarian cancer and occupational exposures in Finland. Am J Ind Med 1999;36:839.

133. Anttila A, Pukkala E, Sallmén, Hernberg S, Hemminki K. Cancer incidence among Finnish workers exposed to halogenated hydrocarbons. J Occup Environ Med 1995;37:797806.

134. Weiderpass E, Pukkala E, Vasama-Neuvonen K, Kauppinen T, Paakkulainen H, Boffetta P, et al. Occupational exposures and cancers of the endometrium and cervix uteri in Finland. Am J Ind Med 2001. In press.

135. Moradi T, Weiderpass E, Signorello LB, Persson I, Nyren O, Adami HO. Physical activity and postmenopausal cancer risk (Sweden). Cancer Causes Control 2000;11:829-37.

136. Khuder SA, Mutgi AB, Schaub EA, Tano BDK. Meta-analysis of Hodgkin's disease among farmers. Scand J Work Environ Health 1999;25:436-441.

137. Pukkala E, Notkola V. Cancer incidence among Finnish farmers, 1979-93. Cancer Causes Control 1997;8:25-33.

138. Hardell L, Eriksson M. A case-control study of non-Hodgkin lymphoma and exposure to pesticides. Cancer Causes Control 1999;85:1353-60.

139. Partanen T, Kauppinen T, Luukkonen R, Hakulinen T, Pukkala E. Malignant lymphomas and leukemias, and exposures in the wood industry: an industry-based case-referent study. Int Arch Occup Environ Health 1993;64:593-6.

140. National Institute of Environmental Health Sciences (NIEHS). NIEHS report on health effects from exposure to 
power-line frequency electric and magnetic fields. Research Triangle Park (NC): National Institutes of Health, 1999. NIH publication, no $99-4493$.

141. Kheifets L, Afifi AA, Buffler P, Zhang Z, Matkin C. Occupational electric and magnetic field exposure and leukemia. J Occup Environ Health 1997;39:1074-91.

142. Feychting M, Forssén U, Floderus B. Occupational and residential magnetic field exposure and leukemia and central nervous system tumors. Epidemiology 1997;8:384-9.

143. Harvard Center for Cancer Prevention, Harvard School of Public Health. Harvard report on cancer prevention; vol 1 (Causes of human cancer: occupation). Cancer Causes Control 1996;7:S19-S22.

144. Scotto J. Skin (nonmelanoma). In: National Institutes of Health, National Cancer Institute. Cancer rates and risks. Internet address: http://rex.nci.nih.gov/NCI_Pub_Interface/ raterisk/risks188.html.

145. Fraser MC, Hartge P. Melanoma of the skin. In: National Institutes of Health, National Cancer Institute. Cancer rates and risks. Internet address: http://rex.nci.nih.gov/ NCI_Pub_Interface/raterisk/risks 163.html.

146. Band PR, Spinelli JJ, Ng VT, Moody J, Gallagher RP. Mortality and cancer incidence in a cohort of commercial airline pilots. Aviat Space Environ Med 1990;61:299-302.

147. Band PR, Le ND, Fang, R, Deschamps M, Coldman AJ, Gallagher RP, et al. Cohort study of Air Canada pilots: mortality, cancer incidence, and leukemia risk. Am J Epidemiol 1996;143:137-43.

148. Grayson Jk, Lyons TJ. Cancer incidence in United States Air Force aircrew, 1975-89. Aviat Space Environ Med 1996; 67:101-4.

149. Rafnsson V, Hrafnkelsson J, Tulinius H. Incidence of cancer among commercial airline pilots. Occup Environ Med 1999;57:175-9.

150. Haldorsen T, Reitan JB, Tveten U. Cancer incidence among Norwegian airline pilots. Scand J Work Environ Health 2000;26:106-11.

151. Blettner M, Grosche B, Zeeb H. Occupational cancer risk in pilots and flight attendants: current epidemiological knowledge. Radiat Environ Biophys 1998;37:75—80.

152. Uvarov EB, Isaacs A. The Penguin dictionary of science. London: Penguin Books, 1993.

153. Leigh JP, Miller TR. Job-related diseases and occupations within a large workers' compensation data set. Am J Ind Med 1998;33:197-211.

154. Kristensen TS. Challenges for research and prevention in relation to work and cardiovascular diseases. Scand J Work Environ Health 1999;25:550-7.

155. Olsen O, Kristensen TS. Impact of work environment on cardiovascular diseases in Denmark. J Epidemiol Community Health 1991;45:4-10.

156. Kristensen TS. Cardiovascular diseases and the work environment: a critical review of the epidemiologic literature on nonchemical factors. Scand J Work Environ Health 1989; 15:165-79.

157. Belkic K, Schnall P, Landbergis P, Baker D. The workplace and cardivascular health: conclusions and thoughts for a future agenda. In: Schnall PL, Belkic K, Landbergis PA, Baker $\mathrm{D}$, editors. The workplace and cardiovascular disease. Philadelphia (PA): Hanley \& Belfus, Inc, 2000:213-22. Occupational medicine: state of the art reviews, vol 15.

158. Johnson JV, Hall EM. Job strain, work place social support, and cardiovascular disease: a cross-sectional study of a random sample of the Swedish working population. Am J Public
Health 1988;78:1336-42.

159. Schnall P, Landsbergis P, Baker D. Job strain and cardiovascular disease. Annu Rev Public Health 1994;15;381-411.

160. Landbergis PA, Schnall PL, Warren K, Pickering TG, Schwartz JE. Association between ambulatory blood pressure and alternative formulations of job strain. Scand J Work Environ Health 1994;20:349-63.

161. Theorell T, Tsutsumi A, Hallqvist J, Reuterwall C, Fredlund $\mathrm{P}$, Emlund N, et al. Decision latitude, job strain and myocardial infarction. Am J Public Health 1998;88:382-8.

162. Kristensen TS, Kornitzer M, Alfredsson L. Social factors, stress, and cardiovascular disease prevention. Bryssel: The European Heart Network, 1998.

163. Hemingway H, Marmot M. Psychosocial factors in the aetiology and prognosis of coronary heart disease: systematic review of prospective cohort studies. BMJ 1999;318:14607.

164. Belkic K, Landbergis P, Schnall P, Baker D, Theorell T, Siegrist J, et al. Psychosocial factors: review of the empirical data among men. In: Schnall PL, Belkic K, Landbergis PA, Baker D, editors. The workplace and cardiovascular disease. Philadelphia (PA): Hanley \& Belfus Inc, 2000:24-40. Occupational medicine: state of the art reviews, vol 15.

165. Brisson C. Women, work and CVD. In: Schnall PL, Belkic $\mathrm{K}$, Landbergis PA, Baker D, editors. The workplace and cardiovascular disease. Philadelphia (PA): Hanley \& Belfus Inc, 2000:49-57. Occupational medicine: state of the art reviews, vol 15 .

166. Morikawa Y, Nakagawa H, Miura K, Ishizaki M, Tabata M, Nishijo M, et al. Relationship between shift work and onset of hypertension in a cohort of manual workers. Scand J Work Environ Health 1999;25:100-4.

167. Frankenhauser M, Johansson G. Stress at work psychobiological and psychosocial aspects. Int Rev Appl Psychol 1986;35:287-99.

168. Schnall PL, Pieper C, Schwartz JE, Karasek RA, Schlussel Y, Devereux RB, et al. The relationship between job strain, workplace diastolic blood pressure, and left ventricular mass index: results of a case-control study. J Am Med Assoc 1990;263:1929-35.

169. Levi L, Frankenhaeuser M, Gardell B. Report on work stress related to social structures, and processes. In: Elliott GR, Eisdorfer C. Stress and human health. New York (NY): Springer, 1982:119—46.

170. Siegrist J, Peter R. Job stressors and coping characteristics in work-related disease: issues of validity. Work Stress 1994;8:130—40.

171. Jousilahti P, Vartiaianen E, Tuomilehto J, Puska P. Occupation, fibrinogen, and heart disease [letter]. Lancet 1997; 349(9650):506.

172. Härmä MI, Ilmarinen JE. Towards the 24-hour society new approaches for aging shift workers? Scand J Work Environ Health 1999;25:610-5.

173. Kalimo R, Toppinen S. Työuupumus Suomen työikäisellä väestöllä [Burnout in the Finnish population of working age]. Helsinki: Finnish Institute of Occupational Health, 1997.

174. Åkerstedt T, Knutsson A. Cardiovascular disease and shift work [editorial]. Scand J Work Environ Health 1997; 23:241-2.

175. Tuchsen F, Andersen O, Guiseppe C, Filakti H, Marmot MG. Occupation and ischemic heart disease in the European Community: a comparative study of occupations at potential high risk. Am J Ind Med 1996;30:407-14.

176. Bøggild H, Knutsson A. Shift work, risk factors and 
cardiovascular disease. Scand J Work Environ Health 1999;25:85-99.

177. Tenkanen L, Sjöblom T, Härmä M. Joint effect of shift work and adverse life-style factors on the risk of coronary heart disease. Scand J Work Environ Health 1998;24:351-7.

178. Bøggild H, Suadicani P, Hein HO, Gyntelberg F. Shift work, social class, and ischaemic heart disease in middle aged and elderly men: a 22 year follow up in the Copenhagen male study. Occup Environ Med 1999;56:640—5.

179. Knutsson A, Hallquist J, Reuterwall K, Theorell T, Åkerstedt T. Shiftwork and myocardial infarction: a case-control study. Occup Environ Med 1999;56:46-50.

180. Berglund B, Lindvall T, editors. Community noise. In: University of Stockholm and the Karolinska Institute. Archives of the Center for Sensory Research; vol 2. Stockholm: University of Stockholm and the Karolinska Institute, 1995:1195.

181. Ising H, Babisch W, Kruppa B, Lindthammer A, Wiens D. Subjective worknoise: a major risk factor in myocardial infarction. Soz Praventivmed 1997;42(4):216-22.

182. Passchier-Vermeer W. Noise and health. The Hague: Health Council of the Netherlands, 1993. Publication no A93/02E.

183. Passchier-Vermeer W, Passchier WF. Noise exposure and public health. Environ Health Perspect 2000;108 suppl $1: 123-31$.

184. Babisch W, Ising H, Gallacher JE, Sweetnam PM, Elwood PC. Traffic noise and cardiovascular risk: the Caerphilly and Speedwell studies, third phase -10 year follow up. Arch Environ Health 1999;54:210-6.

185. Murphy LR. Job dimensions associated with severe disability due to cardiovascular disease. J Clin Epidemiol 1991; 44:155-66.

186. Tolonen M, Hernberg S, Nurminen M, Tiitola K. A followup study of coronary heart disease in viscose rayon workers exposed to carbon disulphide. Br J Ind Med1975;32:1-10.

187. Hogstedt C. Dynamite occupational exposure and health effects [dissertation]. Linköping (Sweden): Linköping University hospital, 1980.

188. Kristensen TS. Cardiovascular diseases and the work environment. A critical review of the epidemiologic literature on chemical factors. Scand J Work Environ Health 1989; 15:245-64.

189. Nurminen M, Hernberg S. Effects of intervention on the cardiovascular mortality of workers exposed to carbon disulphide: a 15-year follow-up. Br J Ind Med 1985;42:32-5.

190. Repace JL, Jinot J, Bayard S, Emmons K, Hammond SK. Air nicotine and saliva cotine as indicators of workplace passive smoking exposure and risk. Risk Anal 1998;18:71—83.

191. Law MR, Morris JK, Wald NJ. Environmental tobacco smoke exposure and ischaemic heart disease: an evaluation of the evidence. Br Med J 1997;315:973-80.

192. Gross AJ. The risk of coronary heart disease and environmental tobacco smoke. Environmetrics 1998;9:197-210.

193. Ellison L, Morrison H. Coronary heart disease and environmental tobacco smoke: a rejoinder to Gross. Environmetrics 1998;9:211-2.

194. Brown KS. The risk of coronary heart disease and environmental tobacco smoke: a rejoinder to Gross. Environmetrics 1998;9:213-21.

195. Gross AJ. "The risk of coronary heart disease in non-smokers exposed to environmental tobacco smoke" revisited: response to Ellison and Morrison and to Brown. Environmetrics 1998;9:223-7.

196. Brown KS. The risk of coronary heart disease in non-smok- ers exposed to environmental tobacco smoke: reply to Gross's response. Environmetrics 1998;9:229—33.

197. Thun M, Henley J, Apicella L. Epidemiologic studies of fatal and nonfatal cardiovascular disease and ETS exposure from spousal smoking. Environ Health Perspect 1999;107 suppl 6:841-6.

198. Wells AJ. Heart disease from passive smoking in the workplace. J Am Coll Cardiol 1998;31:1-9.

199. He Y, Lam TH, Li LS, Du RY, Jia GL, Huang JY, et al. Passive smoking at work as a risk factor for coronary heart disease in Chinese women who have never smoked. BMJ 1994;308:380—4.

200. Kawachi I, Colditz GA, Speizer FE, Manson JE, Stampfer MJ, Willet WC, et al. A prospective study of passive smoking and coronary heart disease. Circulation 1997;95:2374—9.

201. Kawachi I, Colditz GA. Workplace exposure to passive smoking and risk of cardiovascular disease: summary of epidemiologic studies. Environ Health Perspect 1999;107 suppl 6:847-51.

202. Koskela R-S. Cardiovascular diseases among foundry workers exposed to carbon monoxide. Scand J Work Environ Health 1994;20:286-93.

203. Koskela R-S. Mutanen P, Sorsa J-A, Klockars M. Predicticve factors of ischemic heart disease mortality among foundry workers exposed to carbon monoxide. Am J Epidemiol 2000;152:628-32.

204. Hansen ES. Mortality from cancer and ischemic heart disease in Danish chimney sweeps: a 5 year follow-up. Am J Epidemiol 1983;117:160—4.

205. Virtanen SV, Notkola V. Socio-economic inequalities in cardiovascular mortality and the role of work: a register study of Finnish Men. Am J Epidemiol. In press.

206. Donnan GA, McNeil JJ, Adena MA, Doyle AE, O’Malley $\mathrm{HM}$, Neill GC. Smoking as a risk factor for cerebral ischemia. Lancet 1989;2(8668):923.

207. Bonita R, Duncan J, Truelsen T, Jackson RT, Beagelhole R. Passive smoking as well as active smoking increases the risk of acute stroke. Tob Control 1999;8:156-60.

208. Repace JL, Lowrey AH. Indoor pollution, tobacco smoke, and public health. Science 1980;208:464-72.

209. Hammond SK, Sorensen G, Youngstrom R, Ockene JK. Occupational exposure to environmental tobacco smoke. J Am Med Assoc 1995;274:956-60.

210. Skoog I. Status of risk factors for vascular dementia. Neuroepidemiology 1998;17:2-9.

211. Persson G, Skoog I. A prospective population study of psychosocial risk factors for late-onset dementia. Int J Geriatr Psychiatry 1996;11:15-22.

212. Mortel KF, Meyer JS, Herod B, Thornby J. Education and occupation as risk factors for dementias of the Alzheimer and ischemic vascular types. Dementia 1995;6:55-62.

213. Hachinski V. Preventable senility: a call for action against the vascular dementias. Lancet 1992;340(8820):645-8.

214. Ostbye T, Hill G, Steenhuis R. Mortality in elderly Canadians with and without dementia: a 5-year follow-up. Neurology 1999;53:521-6.

215. Lindsay J, Hébert R, Rockwood K. The Canadian study of health and aging. Risk factors for vascular dementia. Stroke 1997;28:526-30.

216. Gorell JM, Johnson CC, Rybicki BA, Peterson EL, Richardson RJ. The risk of Parkinson's disease with exposure to pesticides, farming, well water, and rural living. Neurology 1998;50:1346-50.

217. Fall PA, Fredrikson M, Axelson O, Granerus AK. Nutritional 
and occupational factors influencing the risk of Parkinson's disease: a case-control study in southeastern Sweden. Mov Disord 1999;14:28-37.

218. The Canadian study of health and aging: risk factors for Alzheimer's disease in Canada. Neurology 1994;44:207380.

219. Sobel E, Danipour Z, Sulkava R, Erkinjuntti T, Wikström J, Henderson VW, et al. Occupations with exposure to electromagnetic fields: a possible risk factor for Atzheimer's disease. Am J Epidemiol 1995;142:515-24.

220. Feychting M, Pedersen NL, Svedberg P, Floderus B, Gatz M. Dementia and occupational exposure to magnetic fields. Scand J Work Environ Health 1998;24:46-53.

221. Sawitz DA, Checkoway H, Loomis DP. Magnetic field exposure and neurodegenerative disease mortality among electric utility workers. Epidemiology 1998;9:398-404.

222. Welp E, Kogevinas M, Andersen A, Bellander T, Biocca M, Coggon D, et al. Exposure to styrene and mortality from nervous system diseases and mental disorders. Am J Epidemiol 1996;144:623-33.

223. Littorin ME, Fehling C, Attewell RG, Skerfving S. Focal epilepsy and exposure to organic solvents: a case-referent study. J Occup Med 1988;30:805-8.

224. Jacobsen M, Baelum J, Bonde JP. Temporal epileptic seizures and occupational exposure to solvents. Occup Environ Med 1994;51:429-30.

225. Becklake MR. Occupational exposures and chronic airways disease. In: Rom W, editor. Environmental and and occupational medicine. Boston (MA): Little Brown \& Co Inc, 1992:453-63.

226. Kogevinas M, Antó JM, Sunyer J, Tobias A, Kromhout H, Burney $\mathrm{P}$, et al. Occupational asthma in Europe and other industrialised areas: a population-based study. Lancet 1999;353(9166):1750—4.

227. Becklake MR. Occupational exposures: exposure for a causal association with chronic obstructive pulmonary disease. Am Rev Respir Dis 1989;140:S85—91.

228. Notkola VJ, Husman KRH, Laukkanen VJ. Mortality among male farmers in Finland during 1979-1983. Scand J Work Environ Health 1987;13:124-8.

229. Kauffmann F, Drouet D, Lellouch J, Brille D. Occupational exposure and 12-year spirometric changes among Paris area workers. Br J Ind Med 1982;39:211-32.

230. Isoaho R, Puolijoki H, Huhti E, Kivelä S-L, Laippala P, Tala E. Prevalence of chronic obstructive pulmonary disease in elderly Finns. Respir Med 1994;88:571—80.

231. Hunting KL, Welch LS. Occupational exposure to dust and lung disease among sheet metal workers. Br J Ind Med 1993;50:432-42.

232. Euler GL, Abbey DE, Magie AR, Hodgkin JE. Chronic obstructive pulmonary disease symptom effects of long-term cumulative exposure to ambient levels of total suspended particulates and sulfur dioxide in California Seventh-Day Adventist residents. Arch Environ Med 1987;42:213-22.

233. White JR, Froeb HF, Kulic JA. Respiratory illness in nonsmokers chronically exposed to tobacco smoke in the work place. Chest 1991;100:39—43.

234. Leuenberger P, Schwartz J, Ackerman-Liebrich U, Blaser K, Bolognini G, Bongard JP, et al. Passive smoking exposure in adults and chronic respiratory symptoms (SAPALDIA Study): Swiss study on air pollution and lung diseases in adults, SAPALDIA team. Am J Respir Crit Care Med 1994;150:1222-8.

235. Jaakkola MS, Jaakkola JJK, Becklake MR, Ernst P. Effect of passive smoking on the development of respiratory symptoms in young adults: an 8-year longitudinal study. J Clin Epidemiol 1996;49:581—6.

236. Venables KM, Chan-Yeung M. Occupational asthma. Lancet 1997;349(9063):1456-69.

237. Karjalainen A, Kurppa K, Virtanen S, Keskinen H, Nordman $\mathrm{H}$. Incidence of occupational asthma by occupation and industry in Finland. Am J Ind Med 2000;37:451—8.

238. Blanc P, Torén K. How much adult asthma can be attributed to occupational factors? Am J Med 1999;107:580-7.

239. Isoaho R, Puolijoki H, Huhti E, Kivel S-L, Tala E. Prevalence of asthma in elderly Finns. J Clin Epidemiol 1994; 47:1109-18.

240. Leino T, Tammilehto L, Paakkulainen H, Orjala H, Nordman $\mathrm{H}$. Occurrence of asthma and chronic bronchitis among female hairdressers. J Occup Environ Med 1997;39:534-9.

241. Torén K, Hörte L-G. Asthma mortality and occupation in Sweden 1981-1992. Am J Ind Med 1997;31:678-81.

242. Torén K, Balder B, Brisman J, Lindholm N, Lowhagen O, Palmqvist $\mathrm{M}$, et al. The risk of athma in relation to occupational exposures: a case-control study from a Swedish city. Eur Respir J 1999;13:469—501.

243. Greer JR, Abbey DE, Burchette RJ. Asthma related to occupational and ambient air pollutants in nonsmokers. J Occup Med 1993;35:909-15.

244. Flodin U, Jönsson P, Ziegler J, Axelson O. An epidemiologic study of bronchial asthma and smoking. Epidemiology 1995;6:503-5.

245. Weiss ST, Utell MJ, Samet JM. Environmental tobacco smoke exposure and asthma in adults. Environ Health Perspect 1999;107 suppl 6:891-5.

246. Greenland S. A critical look at some popular meta-analytic methods. Am J Epidemiol 1994;140:290—6.

247. Greenland S. Quality scores are useless and potentially misleading. Am J Epidemiol 1994;140:300—1.

248. Thompson SG, Pocock SJ. Can meta-analyses be trusted? Lancet 1991;338(8775):1127-30.

249. Shapiro S. Meta-analysis/Shmeta-analysis. Am J Epidemiol 1994;140:771.

250. Blettner M, Sauerbrei W, Schlehofer B, Scheuchenpflug T, Freidenreich C. Traditional reviews, meta-analyses and pooled analyses in epidemiology. Int J Epidemiol 1999; 28:1-9.

251. Weed DL. Interpreting epidemiological evidence: how metaanalysis and causal inference methods are related. Int J Epidemiol 2000;29:387-90.

252. Dreyer L, Andersen A, Pukkala E. Occupation. In: Olsen JH, Andersen A, Dreyer L, Pukkala E, Tryggvadottir L, Gerhardsson de Verdier M, et al, editors. Avoidable cancers in the Nordic countries. Acta Pathol Micobiol Immunol Scand Suppl 1997;105 suppl 76:68-79.

253. Walter SD: Attributable risk in practice. Am J Epidemiol 1998;148:411-3.

254. Wilson PD, Loffredo CA, Correa-Villaseñor A, Ferencz C. Attributable fraction for cardiac malformations. Am J Epidemiol 1998;148:414-23.

255. Benichou J, Chow W-H, McLaughlin JK, Mandel JS, Fraumeni JF. Population attributable risk of renal cell cancer in Minnesota. Am J Epidemiol 1998;148:424-30.

256. International Agency for Research on Cancer (IARC). Ionizing radiation, part 1: $\mathrm{X}$ - and gamma $(\mathrm{g})$-radiation. Lyon: IARC, 2000. IARC monographs on the evaluation of carcinogenic risks to humans, vol 75 .

257. Shapiro S. Bias in the evaluation of low-magnitude 
associations: an empirical perspective. Am J Epidemiol 2000; 151:939-45.

258. Doll R, Peto R. The causes of cancer: quantitative estimates of avoidable risks of cancer in the United States today. JNCI 1981;66:1196-308

259. Walter SD. Calculation of attributable risks from epidemiologic data. Int J Epidemiol 1978;7:175-82.

260. Teppo L, Hakulinen T. Finnish Cancer Registry — producing statistics and doing research. In: Alho J, editor. Statistics, registers, and science. Helsinki: Statistics Finland, 1999: $225-40$.

261. Hernberg S, Westerholm P, Schultz-Larsen K, Degerth R, Kuosma E, Englund A, et al. Nasal and sinonasal cancer: connnection with occupational exposures in Denmark, Finland and Sweden. Scand J Work Environ Health 1983; 9:315-26.

262. International Agency for Research on Cancer (IARC). Wood dust and formaldehyde. Lyon: IARC, 1995. IARC monographs on the evaluation of carcinogenic risks to humans, vol 62.

263. Coggon D, Inskip H, Winter P, Pannett B. Lobar pneumonia: an occupational disease in welders. Lancet 1994;344 (8914):41-3.

264. Nuorti JP, Butler JC, Farley MM, Harrison LH, McGeer A, Kolczak MS, et al. Cigarette smoking and invasive pneumococcal disease. New Engl J Med 2000;342:681—9.

265. Oksa P, Pukkala E, Karjalainen A, Ojajärvi A, Huuskonen MS. Cancer incidence and mortalily among asbestos sprayers and in asbestosis and silicosis patients. Am J Ind Med 1997;31:693-8.

266. Nurminen M. Survival experience of a cohort of carbon disuphide exposed workers from a 8-year prospective follow-up period. Int J Epidemiol 1976;5:179—85.

267. Teppo L, Pukkala E, Lehtonen M. Data quality and quality control of a population-based cancer registry. Experience in Finland. Acta Oncol 1994;33:365—9.

268. National Public Health Institute. Register of infectious diseases. Helsinki: National Public Health Institute, 1998.

269. Ritz B, Yu F. Parkinson's disease mortality and pesticide exposure in California 1984-1994. Int J Epidemiol 2000; 29:323-9.

270. Auvinen A, Karjalainen S, Pukkala E. Social class and cancer patient survival in Finland. Am J Epidemiol 1995;142:1089_ 1102.

271. Keskimäki I, Koskinen S, Salinto M, Aro S. Socioeconomic and gender inequities in access to coronary artery bypass grafting in Finland. Eur J Public Health 1997;7:392-7.

272. Salomaa V, Niemelä M, Miettinen H, Ketonen M, ImmonenRäihä P, Koskinen S, et al. Relationship of socioeconomic status to the incidence and prehospital, 28-day, and 1-year mortality rates of acute coronary events in the FINMONICA Myocardial Infarction Register Study. Circulation 2000; 101:1913-8.

273. Hemingway H, Shipley M, Macfarlane P, Marmot M. Impact of socioeconomic status on coronary mortality in people with symptoms, electrocardiographic abnormalities, both or neither: the original Whitehall study 25 year follow up. J Epidemiol Community Health 2000;54:510-6.

274. Weston TL, Aronson KJ, Siemiatycki J, Howe GR, Nadon L. Cancer mortality among males in relation to exposures assessed through a job-exposure matrix. Int J Occup Environ Health 2000;6:194-202.

275. Rockhill B, Newman, Weinberg C. Use and misuse of population attributable fractions. Am J Public Health 1998;
88:15-9.

276. Eide GE, Gefeller O. Sequential and average attributable fractions as aids in the selection of preventive strategies. J Clin Epidemiol 1995;48:645-55.

277. Morgenstern H, Bursic ES. A method for using epidemiologic data to estimate the potential impact of an intervention on the health status of a target population. J Community Health 1982;7:292-309.

278. Murray CJ, Lopez AD. On the comparable quantification of health risk: lessons from the Global Burden of Disease Study. Epidemiology 1999;10:594-605.

279. Leigh JP. Causes of death in the workplace. Westpoint (CT): Quarum Books, 1995.

280. Tomatis L. The contribution of the IARC monographs program to the identification of cancer risk factors. Ann NY Acad Sci 1988;534:31-8.

281. Albin M, Magnani C, Krstev S, Rapiti E, Shefer I. Asbestos and cancer: an overview of current trends in Europe. Environ Health Perspect 1999;107 suppl 2: 289-98.

282. Leigh J, Berry G, de Klerck NH, Henderson DW. Asbestosrelated lung cancer: apportionment of causation and damages to asbestos and tobacco smoke. In: Peters GA, Peters BJ, editors. Asbestos pathogenesis and litigation: sourcebook on asbestos diseases, vol 13. Charlottesville (VA): Michie, 1996:141-66.

283. United States Surgeon General. The health consequences of smoking: smoking and cancer. Washington (DC): United States Department of Health and Human Services, 1982 DHHS publication no 82-50179.

284. Wald NJ, Ritchie C. Validation of studies on lung cancer in nonsmokers married to smokers. Lancet 1984;1(8385):1067.

285. Robins J. Risk assessment - exposure to environmental tobacco smoke and lung cancer. In: Environmental tobacco smoke - measuring exposures and assessing health effects: appendix D. Washington (DC): National Academy Press, 1986.

286. Repace JL, Lowley AH. Risk assessment methodologies for passive smoking-induced lung cancer. Risk Anal 1990; 10:27-37.

287. Peto J, Dacarli A, La Vecchia C, Levi F, Negri E. The European mesothelioma epidemic. Br J Cancer 1999;79: 666-72.

288. Butz M. Beruflich verursachte Krebserkrankungen: Eine Darstellung der im Zeitraum 1978 bis 1997 anerkannten Berufskrankheiten [Occupationally induced cancers: a description of cancers recognized between 1978 and 1997 by the industrial Berufsgenossenschaften as occupational diseases]. Mackenhein: Druck Center Mackenheim, 1999.

289. Leigh JP, Miller TR. Occupational illnesses within two national data sets. Int J Occup Environ Health 1998;4:99-113.

290. Karasek R, Theorell T. Healthy work: stress, productivity, and the reconstruction of working life. New York (NY): Basic Books, 1990.

291. Johnson JR, Steward W, Hall EM, Fredlund P, Theorell T. Long-term psychosocial work environment and cardiovascular mortality among Swedish men. Am J Public Health 1996;86:324-31.

292. Knutsson A, Åkerstedt T, Jonsson B. Prevalence of risk factors for coronary artery disease among day and shift workers. Scand J Work Environ Health 1988;14:317-21.

293. Romon M, Nuttens MC, Fievet C, Pot P, Bard JN, Furon D, et al. Increased triglyceride levels in shift workers. Am J Med 1992;93:259-62.

294. Schnall PL, Schwartz JE, Landbergis PA, Warren K, Pickering 
TG. A longitudinal study of job strain and ambulatory blood pressure: results from a 3-year follow-up. Psychosom Med 1998;60:697-706.

295. Räikkönen K, Lassila R, Keltikangas-Järvinen L, Hautanen A. Association of chronic stress with plasminogen activator inhibitor-l in healthy middle-aged men. Arterioscler Thromb Vasc Biol 1996;16:363 - 7.

296. Landbergis PA, Schnall PL, Schwartz JE Warren K, Pickering TG. Job strain, hypertension, and cardiocvascular disease: empirical evidence, methodological issues, and recommendations for future research. In: Sauter SL, Murphy LR, editors. Organizational risk factors for job stress. Washington (DC): American Psychological Association, 1995:97112.

297. Wells AJ. An estimate of adult mortality in the United States from passive smoking: a response to criticism. Environ Int 1991;17:382-5.

298. Wells AJ. Passive smoking and coronary heart disease [letter]. New Engl J Med 1999;341:697-8.

299. Wu-Williams A, Samet J. Environmental tobacco smoke: exposure relationships in epidemiologic studies. Risk Anal 1990;10:39-48.

300. Mathers C, Vos T, Stevenson C. The burden of disease and injury in Australia. Camberra (ACT): Australian Institute of Health and Welfare, 1999. AIHW Cat no PHE-17. (http:// www.aihw.gov.au/publications/health/bdia/.)

301. Ahonen G. The costs of occupational accidents and diseases in the Nordic countries. Helsinki: Nordic Institute for Advanced Training in Occupational Health Nordic (NIVA), 1994. Institute for Advanced Training in Occupational Health, report no 1994:3.

302. Hansen SM. Arbejdsmiljø og samfundsøkonomi - en metode til konsekvensberegning [Work environment and society economics - a method for counting the consequences]. Køpenhavn: Nordisk Ministerråd, 1993. Nord 1993:22.

303. Geeenland S. Basic methods for sensitivity analysis of biases. Int J Epidemiol 1996;25:1107-16.

304. Venables WN, Ripley BD. Modern applied statistics with SPLUS. New York (NY): Springer, 1997.

305. Takala J. Global estimates of fatal occupational accidents. Epidemiology 1999;10:640—6.

306. Takala J. Indicators of death, disability and disease at work. Asian-Pacific newsl occup health safety 2000;7:4-8.

307. National Occupational Safety and Health Commission. Trends over recent years. Sydney (NSW, Australia): National Occupational Safety and Health Commission, 1997. Australian occupational health and safety, statistics bulletin no 1 .

308. Kogevinas M, Kauppinen T, Winkelmann R, Becher H, Bertazzi PA, Bueno-de-Mesquita B, et al. Soft tissue sarcoma and non-Hodgkin's lymphoma in workers exposed to phenoxy herbicides, chlorophenols, and dioxins: two nested case-control studies. Epidemiology 1995:6:396-402.

309. Vineis P. Evidence-based primary prevention? [commentary]. Scand J Work Environ Health 2000;26:443—8.

310. Sever LE. Congenital malformations related to occupational reproductive hazards. In: Gold EB, Lasley BL, Schenker MB. Reproductive hazards. Philadelphia (PA): Hanley \& Belfus Inc, 1994:471—94. Occupational medicine: state of the art review, vol 9.

311. Holmberg PC, Nurminen M. Congenital defects of the nervous system and occupational factors during pregnancy. Am J Ind Med 1981;1:167-6.

312. McMartin KI, Chu M, Kopecky E, Einarson TR, Koren G. Pregnancy outcome following maternal organic solvent ex- posure: a meta-analysis of epidemiologic studies. Am J Indust Med 1998;34:288-92.

313. Khattak S, K-Moghtader G, McMartin K, Barrera M, Kennedy D, Koren G. Pregnancy outcome following gestational exposure to organic solvents. J Am Med Assoc 1999;281:1106-9.

314. Taskinen HK, Olsen J, Bach B. Experiences in developing legislation protecting reproductive health. J Occup Environ Med 1995;37:974-9.

315. Sullivan FM. The European Community directive on the classification and labelling of chemicals for reproductive toxicity. J Occup Environ Med 1995;37:966-9.

316. Jaakkola MS, Samet JM. Summary: workshop on health risks attributable to ETS exposure in the workplace. Environ Health Perspect 1999 suppl 6;107:823-7.

317. Gustavsson P, Jakobsson R, Johansson H, Lewin F, Norell S, Rutkvist L-E. Occupational exposures and squamous cell carcinoma of the oral cavity, pharynx, larynx, and oesophagus: a case-control study in Sweden. Occup Environ Med 1998;55:393-400.

318. Anttila A, Pukkala E, Riala R, Sallmén M, Hemminki K. Cancer incidence among Finnish workers exposed to aromatic hydrocarbons. Int Arch Occup Environ Health 1998; 71:187-93.

319. Kauppinen T, Riala R, Seitsamo J, Hernberg S. Primary liver cancer and occupational exposure. Scand J Work Environ Health 1992;18:18-25.

320. Hernberg S, Kauppinen T, Riala R, Korkala M-L, Asikainen $\mathrm{U}$. Increased risk for primary liver cancer among women exposed to solvents. Scand J Work Environ Health 1988; $14: 356-65$.

321.t'Mannetje A, Kogevinas M, Luce D, Demers PA, Bégin D, Bolm-Audorff U, et al. Sinonasal cancer, occupation, and tobacco smoking in European women and men. Am J Ind Med 1999;36:101-7.

322. Fritschi L, Siemiatycki J. Melanoma and occupation: results of a case-control study. Occup Environ Med 1996;53:16873.

323. Spirtas R, Heineman EF, Bernstein L, Beebe GW, Keehn RJ, Stark A, et al. Malignant mesothelioma: attributable risk of asbestos exposure. Occup Environ Med 1994;51:804-11.

324. Yates DH, Corrin B, Stidolph PN, Browne K. Malignant mesothelioma in south east England: clinicopathological experience of 272 cases. Thorax 1997;52:507-12.

325. Pukkala E. Cancer incidence among Finnish oil refinery workers, 1971-1994. J Occup Environ Med 1998;40:6759.

326. Parent M-É, Hua Y, Siemiatycki J. Occupational risk factors for renal cell carcinoma in Montreal. Am J Ind Med 2000;38:609-18.

327. Partanen T, Heikkilä P, Hernberg S, Kauppinen T, Moneta G, Ojajärvi A. Renal cell cancer and occupational exposure to chemical agents. Scand J Work Environ Health 1991; 17:231-9.

328. Mandel JS, McLaughlin JK, Schlehofer B, Mellemgaard A, Helmert U, Lindblad P, et al. International renal-cell cancer study, IV: occupation. Int J Cancer 1995;61:601-5.

329. Pesch B, Haerting J, Ranft U, Klimpel A, Oelschlägel B, Schill W, et al. Occupational risk factors for renal cell carcinoma: agent-specific results from a case-control study in Germany. Int J Epidemiol 2000;29:1014-24.

330. Tola S, Tenho M, Korkala M-L, Järvinen E. Cancer of the urinary bladder in Finland. Int Arch Environ Health 1980;46:43-51. 
331. Thomas TL, Fontham ETH, Norman SA, Stemhagen A, Hoover RN. Occupational risk factors for brain tumors: a casereferent death-certificate analysis. Scand J Work Environ Health $1986 ; 12: 121-7$.

332. Anttila A, Heikkilä P, Nykyri E, Kauppinen T, Pukkala E, Hernberg S, et al. J. Risk of nervous system cancer among workers exposed to lead. J Occup Environ Med 1996; 38:131-6.

333. Niedhammer I, Goldberg M, Leclerc A, Bugel I, David S. Psychosocial factors at work and subsequent depressive symptoms in the Gazel cohort. Scand J Work Environ Health 1998;24:197-205.

334. Sawitz DA, Loomis DP, Tse C-KJ. Electrical occupations and neurodeneratice disease: analysis of the US mortality data. Arch Environ Health 1998;53:71-4.

335. Checkoway H, Nelson LM. Epidemiologic approaches to the study of Parkinson's disease etiology. Epidemiology 1999;10;327-36.
336. Coggon D, Inskip H, Winter P, Pannett B. Lobar pneumonia: an occupational disease in welders. Lancet 1994;344 (8914):41-3.

337. Tüchsen F, Jeppesen HJ, Bach E. Employment status, nondaytime work and gastric ulcer in men. Int $\mathrm{J}$ Epidemiol 1994;23:365-70.

338. Nuyts GD, van Viem E, de Leersnijder D, Haese PCD, Elseviers MM, De Broe ME. New occupational risk factors for chronic renal failure. Lancet 1995;346(8966):7-11.

339. Isotalus N, Saarela KL. Väkivaltatapaturmat Suomessa [Violent accidents in Finland]. Työ ja ihminen 1999;13:137-49.

340. Rimpelä AH, Nurminen MM, Pulkkinen PO, Rimpelä MK, Valkonen T. Mortality of doctors: do doctors benefit from their medical knowledge? Lancet 1987; 1(8524):84—6

Received for publication: 31 August 2000 


\section{Appendix}

\section{Attributable fraction estimates of mortality in the Finnish population}

\begin{tabular}{|c|c|c|c|c|c|c|}
\hline \multirow[t]{2}{*}{ Cause of death a } & \multicolumn{3}{|c|}{$\begin{array}{l}\text { Attributable } \\
\text { fraction }{ }^{\circ}(\%)\end{array}$} & \multirow{2}{*}{$\begin{array}{l}\text { Potentially implicated } \\
\text { exposure or work } \\
\text { environment c }\end{array}$} & \multirow[t]{2}{*}{ Study design and data analysis } & \multirow[t]{2}{*}{$\begin{array}{l}\text { Primary source of } \\
\text { quantitative estimate }{ }^{e}\end{array}$} \\
\hline & Total & Men & Women & & & \\
\hline $\begin{array}{l}\text { Total deaths } \\
\text { (all codes) }\end{array}$ & 6.7 & 10.2 & 2.1 & & & \\
\hline $\begin{array}{l}\text { Infectious diseases } \\
\text { (all } A \text { and } B \text { codes) }\end{array}$ & 8.8 & 4.8 & 32.5 & & & \\
\hline $\begin{array}{l}\text { Tuberculosis } \\
\text { (A15-A18, B90) }\end{array}$ & 6.0 & 0.6 & $\approx 75$ & $\begin{array}{l}\text { Health and social } \\
\text { worker (infection) }\end{array}$ & Based on register data & $\begin{array}{l}\text { Karjalainen et al, 1998, } \\
\text { Finland (11); National } \\
\text { Public Health Institute, } \\
\text { 1998, Finland (268) }\end{array}$ \\
\hline $\begin{array}{l}\text { Pneumococcal } \\
\text { disease (A40.3) }\end{array}$ & 14.3 & 15.6 & 10.9 & $\begin{array}{l}\text { Environmental tobacco } \\
\text { smoke }\end{array}$ & $\begin{array}{l}\text { Adjusted for age, gender, race, level of } \\
\text { education, chronic illness, study site, and status } \\
\text { of children in the houshold }\end{array}$ & $\begin{array}{l}\text { Nuorti et al, 2000, United } \\
\text { States (264) }\end{array}$ \\
\hline $\begin{array}{l}\text { Malignant neoplasms, } \\
\text { by site or type (all C } \\
\text { codes) }\end{array}$ & 8.4 & 13.8 & 2.2 & & & \\
\hline \multirow{3}{*}{$\begin{array}{l}\text { Oral cavity } \\
\text { (C01-C06) }\end{array}$} & 0.8 & 1.2 & 0.3 & Combined risk factors & & . \\
\hline & & 0.3 & 0.0 & $\begin{array}{l}\text { Polycyclic aromatic } \\
\text { hydrocarbons (high level } \\
\text { of exposure) }\end{array}$ & $\begin{array}{l}\text { Restricted to men; adjusted for age, geographic } \\
\text { region, and alcohol and tobacco consumption }\end{array}$ & $\begin{array}{l}\text { Gustavsson et al, } 1998, \\
\text { Sweden (317) }\end{array}$ \\
\hline & & 0.9 & 0.3 & Hydrocarbon solvents & $\begin{array}{l}\text { Restricted to men; adjusted for age and social } \\
\text { class }\end{array}$ & $\begin{array}{l}\text { Kauppinen et al, } 1998, \\
\text { Finland (14) }\end{array}$ \\
\hline \multirow[t]{3}{*}{ Pharynx (C09-C14) } & 1.9 & 2.0 & 0.5 & Combined risk factors & . & . \\
\hline & & 1.1 & 0.2 & $\begin{array}{l}\text { Welding fumes (metal } \\
\text { dust, irritant gases, } \\
\text { polycyclic aromatic } \\
\text { hydrocarbons) }\end{array}$ & $\begin{array}{l}\text { Restricted to men; adjusted for age, geo- } \\
\text { graphical region, and alcohol and tobacco } \\
\text { consumption }\end{array}$ & $\begin{array}{l}\text { Gustavsson et al, } 1998, \\
\text { Sweden (317) }\end{array}$ \\
\hline & & 0.9 & 0.3 & Hydrocarbon solvents & $\begin{array}{l}\text { Restricted to men; adjusted for age and social } \\
\text { class }\end{array}$ & $\begin{array}{l}\text { Kauppinen et al, 1998, } \\
\text { Finland (14) }\end{array}$ \\
\hline \multirow[t]{3}{*}{ Esophagus (C15) } & 3.6 & 6.4 & 0.2 & Combined risk factors & . & . \\
\hline & & 6.1 & 0.1 & $\begin{array}{l}\text { Polycyclic aromatic } \\
\text { hydrocarbons }\end{array}$ & $\begin{array}{l}\text { Restricted to men; adjusted for age, geo- } \\
\text { graphical region, and alcohol and tobacco } \\
\text { consumption }\end{array}$ & $\begin{array}{l}\text { Gustavsson et al, 1998, } \\
\text { Sweden (317) }\end{array}$ \\
\hline & & 0.3 & 0.1 & Hydrocarbon solvents & $\begin{array}{l}\text { Restricted to men; adjusted for age and social } \\
\text { class. }\end{array}$ & $\begin{array}{l}\text { Kauppinen et al, } 1998, \\
\text { Finland (14) }\end{array}$ \\
\hline Stomach (C16) & 8.0 & 10.3 & 5.4 & $\begin{array}{l}\text { Farming and rearing of } \\
\text { live stock (grain dust, } \\
\text { animal contact, herbi- } \\
\text { cides, diesel fuels) }\end{array}$ & $\begin{array}{l}\text { Restricted to decedents; adjusted for age, } \\
\text { gender, cigarette smoking in the } 1960 \mathrm{~s} \text {, alcohol } \\
\text { consumption in the } 1960 \text { s, and diabetes }\end{array}$ & $\begin{array}{l}\text { Partanen et al, 1994, } \\
\text { Finland (108) }\end{array}$ \\
\hline \multirow[t]{3}{*}{ Colon (C18) } & 2.5 & 5.6 & 0.0 & Combined risk factors & . & . \\
\hline & & 2.3 & 0.0 & Asbestos & $\begin{array}{l}\text { Restricted to decedents; adjusted for age, } \\
\text { gender, cigarette smoking in the } 1960 \text { s, alcohol } \\
\text { consumption in the1960s, and diabetes }\end{array}$ & $\begin{array}{l}\text { Kauppinen et al, } 1995, \\
\text { Finland (109) }\end{array}$ \\
\hline & & 3.4 & 0.0 & $\begin{array}{l}\text { Welding and soldering } \\
\text { fumes and gases } \\
\text { (polycyclic aromatic } \\
\text { hydrocarbons and other } \\
\text { combustion products) }\end{array}$ & $\begin{array}{l}\text { Restricted to decedents; adjusted for age, } \\
\text { gender, cigarette smoking in the } 1960 \mathrm{~s} \text {, alcohol } \\
\text { consumption in the1960s, and diabetes }\end{array}$ & $\begin{array}{l}\text { Kauppinen et al, 1995, } \\
\text { Finland (109) }\end{array}$ \\
\hline
\end{tabular}




\begin{tabular}{|c|c|c|c|c|c|c|}
\hline \multirow[t]{2}{*}{ Cause of death a } & \multicolumn{3}{|c|}{$\begin{array}{l}\text { Attributable } \\
\text { fraction }{ }^{b}(\%)\end{array}$} & \multirow{2}{*}{$\begin{array}{l}\text { Potentially implicated } \\
\text { exposure or work } \\
\text { environment }{ }^{c}\end{array}$} & \multirow[t]{2}{*}{ Study design and data analysis ${ }^{d}$} & \multirow[t]{2}{*}{$\begin{array}{l}\text { Primary source of } \\
\text { quantitative estimate }\end{array}$} \\
\hline & Total & Men & Women & & & \\
\hline \multirow[t]{3}{*}{ Rectum (C20) } & 1.7 & 3.1 & 0.1 & Combined risk factors & . & . \\
\hline & & 2.9 & 0.0 & Asbestos & $\begin{array}{l}\text { Restricted to decedents; adjusted for age, } \\
\text { gender, cigarette smoking in the } 1960 \mathrm{~s} \text {, alcohol } \\
\text { consumption in the } 1960 \text { s, and diabetes }\end{array}$ & $\begin{array}{l}\text { Kauppinen et al, 1995, } \\
\text { Finland (109) }\end{array}$ \\
\hline & & 0.2 & 0.1 & Styrene & $\begin{array}{l}\text { Standardized incidence ratios based on age-, } \\
\text { gender-, and period-specific incidence rates of } \\
\text { cancer in the general population }\end{array}$ & $\begin{array}{l}\text { Anttila et al, 1998, Finland } \\
(318)\end{array}$ \\
\hline \multirow{5}{*}{$\begin{array}{l}\text { Liver and intra- } \\
\text { hepatic bile ducts } \\
\text { (C22) }\end{array}$} & 4.3 & 3.5 & 5.3 & Combined risk factors & . & . \\
\hline & & 3.1 & 0.3 & $\begin{array}{l}\text { Inorganic dusts (mainly } \\
\text { silica) }\end{array}$ & $\begin{array}{l}\text { Frequency-matched for age and gender; } \\
\text { stratified by alcohol consumption; hepatitis B } \\
\text { infection and the use of oral contraceptives and } \\
\text { other hormone preparations were rare }\end{array}$ & $\begin{array}{l}\text { Kauppinen et al, 1992, } \\
\text { Finland (319) }\end{array}$ \\
\hline & & 0.0 & 2.1 & $\begin{array}{l}\text { Milk maids (aflatoxins } \\
\text { from crops used by the } \\
\text { livestock feed- } \\
\text { processing industry) }\end{array}$ & $\begin{array}{l}\text { Frequency-matched for age and gender; } \\
\text { stratified by alcohol consumption; hepatitis B } \\
\text { infection and the use of oral contraceptives and } \\
\text { other hormone preparations were rare }\end{array}$ & $\begin{array}{l}\text { Kauppinen et al, 1992, } \\
\text { Finland (319) }\end{array}$ \\
\hline & & . & 3.0 & $\begin{array}{l}\text { Chlorinated hydrocarbon } \\
\text { solvents }\end{array}$ & $\begin{array}{l}\text { Estimate for women; control for confounders } \\
\text { as in Kauppinen et al (319) }\end{array}$ & $\begin{array}{l}\text { Hernberg et al, } 1988, \\
\text { Finland }(320)\end{array}$ \\
\hline & & 0.4 & . & $\begin{array}{l}\text { Chlorinated hydrocarbon } \\
\text { solvents }\end{array}$ & $\begin{array}{l}\text { Estimate for men; adjusted for age and social } \\
\text { class }\end{array}$ & $\begin{array}{l}\text { Kauppinen et al, 1998, } \\
\text { Finland (14) }\end{array}$ \\
\hline Gallbladder (C23) & 0.1 & 0.2 & 0.4 & Hydrocarbon solvents & $\begin{array}{l}\text { Restricted to men; adjusted for age and social } \\
\text { class }\end{array}$ & $\begin{array}{l}\text { Kauppinen et al, } 1998, \\
\text { Finland (14) }\end{array}$ \\
\hline \multirow[t]{10}{*}{ Pancreas (C25) } & 8.0 & 13.4 & 3.5 & Combined risk factors & . & . \\
\hline & & . & . & Gardener & $\begin{array}{l}\text { Restricted to decedents; adjusted for age, } \\
\text { gender, cigarette smoking in the } 1960 \text { s, alcohol } \\
\text { consumption in the } 1960 \text { s, and diabetes }\end{array}$ & $\begin{array}{l}\text { Partanen et al, 1994, } \\
\text { Finland (108) }\end{array}$ \\
\hline & & . & . & $\begin{array}{l}\text { Transport inspectors } \\
\text { and supervisors } \\
\text { (polycyclic aromatic } \\
\text { hydrocarbons in engine } \\
\text { exhaust) }\end{array}$ & $\begin{array}{l}\text { Restricted to decedents; adjusted for age, } \\
\text { gender, cigarette smoking in the } 1960 \mathrm{~s} \text {, alcohol } \\
\text { consumption in the } 1960 \text { s, and diabetes }\end{array}$ & $\begin{array}{l}\text { Partanen et al, 1994, } \\
\text { Finland (108) }\end{array}$ \\
\hline & & $\cdot$ & $\cdot$ & $\begin{array}{l}\text { Warehousemen } \\
\text { (polycyclic aromatic } \\
\text { hydrocarbons) }\end{array}$ & $\begin{array}{l}\text { Restricted to decedents; adjusted for age, } \\
\text { gender, cigarette smoking in the } 1960 \text { s, alcohol } \\
\text { consumption in the } 1960 \text { s, and diabetes }\end{array}$ & $\begin{array}{l}\text { Partanen et al, 1994, } \\
\text { Finland (108) }\end{array}$ \\
\hline & & 2.1 & 0.4 & $\begin{array}{l}\text { Organic solvents } \\
\text { (including aliphatic and } \\
\text { aromatic hydrocarbons) }\end{array}$ & $\begin{array}{l}\text { Adjusted for age, gender, cigarette smoking in } \\
\text { the } 1960 \text { s, alcohol consumption in the } 1960 \mathrm{~s} \text {, } \\
\text { and diabetes }\end{array}$ & $\begin{array}{l}\text { Kauppinen et al, 1995, } \\
\text { Finland (109) }\end{array}$ \\
\hline & & 1.5 & 0.6 & $\begin{array}{l}\text { Inorganic dust } \\
\text { containing crystalline } \\
\text { silica }\end{array}$ & $\begin{array}{l}\text { Adjusted for age, gender, cigarette smoking in } \\
\text { the } 1960 \text { s, alcohol consumption in the } 1960 \text { s, } \\
\text { and diabetes }\end{array}$ & $\begin{array}{l}\text { Kauppinen et al, } 1995, \\
\text { Finland (109) }\end{array}$ \\
\hline & & 1.4 & 0.0 & $\begin{array}{l}\text { Rubber chemicals } \\
\text { including acrylonitrile }\end{array}$ & $\begin{array}{l}\text { Adjusted for age, gender, cigarette smoking in } \\
\text { the } 1960 \text { s, alcohol consumption in the } 1960 \mathrm{~s} \text {, } \\
\text { and diabetes }\end{array}$ & $\begin{array}{l}\text { Kauppinen et al, 1995, } \\
\text { Finland (109) }\end{array}$ \\
\hline & & 0.8 & 1.9 & Ionizing radiation & $\begin{array}{l}\text { Adjusted for age, gender, cigarette smoking in } \\
\text { the } 1960 \text { s, alcohol consumption in the } 1960 \text { s, } \\
\text { and diabetes }\end{array}$ & $\begin{array}{l}\text { Kauppinen et al, } 1995, \\
\text { Finland (109) }\end{array}$ \\
\hline & & 2.5 & 0.3 & $\begin{array}{l}\text { Pesticides (herbicides } \\
\text { and insecticides) }\end{array}$ & $\begin{array}{l}\text { Adjusted for age, gender, cigarette smoking in } \\
\text { the } 1960 \text { s, alcohol consumption in the } 1960 \mathrm{~s} \text {, } \\
\text { and diabetes }\end{array}$ & $\begin{array}{l}\text { Kauppinen et al, } 1995, \\
\text { Finland (109) }\end{array}$ \\
\hline & & 3.1 & 0.2 & Nickel & $\begin{array}{l}\text { Risk estimates from a meta-analysis; estimates } \\
\text { adjusted for at least known risk factors for } \\
\text { pancreatic cancer (age, gender, tobacco } \\
\text { smoking, and social class), if there was a } \\
\text { choice }\end{array}$ & $\begin{array}{l}\text { Ojajärvi et al, 2000, } \\
\text { international (111) }\end{array}$ \\
\hline
\end{tabular}




\begin{tabular}{|c|c|c|c|c|c|c|}
\hline \multirow[t]{2}{*}{ Cause of death a } & \multicolumn{3}{|c|}{$\begin{array}{l}\text { Attributable } \\
\text { fraction }{ }^{\mathrm{b}}(\%)\end{array}$} & \multirow{2}{*}{$\begin{array}{l}\text { Potentially implicated } \\
\text { exposure or work } \\
\text { environment }{ }^{c}\end{array}$} & \multirow[t]{2}{*}{ Study design and data analysis ${ }^{d}$} & \multirow[t]{2}{*}{$\begin{array}{l}\text { Primary source of } \\
\text { quantitative estimate }\end{array}$} \\
\hline & Total & Men & Women & & & \\
\hline $\begin{array}{l}\text { Pancreas } \\
\text { (continued) }\end{array}$ & & 2.8 & 0.1 & $\begin{array}{l}\text { Polycyclic aromatic } \\
\text { hydrocarbons }\end{array}$ & $\begin{array}{l}\text { Risk estimates from a meta-analysis; estimates } \\
\text { adjusted for at least known risk factors for } \\
\text { pancreatic cancer (age, gender, tobacco } \\
\text { smoking, and social class), if there was a choice }\end{array}$ & $\begin{array}{l}\text { Ojajärvi et al, } 2000, \\
\text { international (111) }\end{array}$ \\
\hline \multirow{4}{*}{$\begin{array}{l}\text { Nose and nasal } \\
\text { sinuses (C30-C31) }\end{array}$} & 12.5 & 24.0 & 6.7 & Combined risk factors & . & . \\
\hline & & 15.7 & 2.4 & $\begin{array}{l}\text { Hardwood dust or } \\
\text { softwood dust or both }\end{array}$ & $\begin{array}{l}\text { Matched for country, gender, age at diagnosis, } \\
\text { and survival status; confounding by exposure to } \\
\text { formaldehyde unlikely }\end{array}$ & $\begin{array}{l}\text { Hernberg et al, } 1983 \text {, } \\
\text { Denmark, Finland, Sweden } \\
(261)\end{array}$ \\
\hline & & 2.8 & 4.4 & $\begin{array}{l}\text { Leather dust (shoe and } \\
\text { boot manufacturing) }\end{array}$ & $\begin{array}{l}\text { Pooled analysis of data from } 8 \text { studies; adjusted } \\
\text { for age, gender, study center, and smoking } \\
\text { status, as well as for the remaining occupational } \\
\text { exposures examined }\end{array}$ & $\begin{array}{l}\text { t'Mannetje et al, 1999, } \\
\text { France, Germany, Italy, } \\
\text { Sweden, The Netherlands } \\
(321)\end{array}$ \\
\hline & & 7.3 & 0.0 & $\begin{array}{l}\text { Welding, flame-cutting } \\
\text { and soldering } \\
\text { (hexavalent chromium, } \\
\text { nickel) }\end{array}$ & $\begin{array}{l}\text { Pooled analysis of data from } 8 \text { studies; adjusted } \\
\text { for age, gender, study center, and smoking } \\
\text { status, as well as for the remaining occupational } \\
\text { exposures examined }\end{array}$ & $\begin{array}{l}\text { t'Mannetje et al, 1999, } \\
\text { France, Germany, Italy, } \\
\text { Sweden, The Netherlands } \\
(321)\end{array}$ \\
\hline \multirow[t]{3}{*}{ Larynx (C32) } & 9.1 & 9.3 & 0.5 & Combined risk factors & $\cdot$ & $\cdot$ \\
\hline & & 8.3 & 0.3 & Asbestos & $\begin{array}{l}\text { Adjusted for age, geographic region, and alcohol } \\
\text { and tobacco consumption }\end{array}$ & $\begin{array}{l}\text { Gustavsson et al, 1998, } \\
\text { Sweden (317) }\end{array}$ \\
\hline & & 1.1 & 0.2 & $\begin{array}{l}\text { Welding fumes (metal } \\
\text { dust, irritant gases, } \\
\text { polycyclic aromatic } \\
\text { hydrocarbons) }\end{array}$ & $\begin{array}{l}\text { Adjusted for age, geographic region, and alcohol } \\
\text { and tobacco consumption }\end{array}$ & $\begin{array}{l}\text { Gustavsson et al, 1998, } \\
\text { Sweden (317) }\end{array}$ \\
\hline \multirow{4}{*}{$\begin{array}{l}\text { Bronchus and } \\
\text { lung (C34) }\end{array}$} & 24.0 & 29.0 & 5.3 & Combined risk factors & $\cdot$ & $\cdot$ \\
\hline & & . & . & $\begin{array}{l}\text { Industries f: metal } \\
\text { production and } \\
\text { processing workers, } \\
\text { transportation workers } \\
\text { and freight handlers, } \\
\text { rubber and plastics } \\
\text { industry, engine and } \\
\text { vehicle construction, } \\
\text { installation }\end{array}$ & $\begin{array}{l}\text { Results for men; matched for age, gender, and } \\
\text { region of residence; adjusted for smoking and } \\
\text { asbestos exposure }\end{array}$ & $\begin{array}{l}\text { Jöckel et al, } 1998, \\
\text { Germany (51) }\end{array}$ \\
\hline & & . & . & $\begin{array}{l}\text { Industries f: chemical } \\
\text { and oil processing, } \\
\text { production of pottery } \\
\text { and glass, engine, } \\
\text { engine and vehicle } \\
\text { construction, paper, } \\
\text { wood, printing, cleaning } \\
\text { services, hairdressing, } \\
\text { housekeeping, and waste } \\
\text { disposal }\end{array}$ & $\begin{array}{l}\text { Results for women; matched for age, gender, } \\
\text { and region; adjusted for smoking and time } \\
\text { since quitting, asbestos, and education } \\
\end{array}$ & $\begin{array}{l}\text { Jahn et al, 1999, Germany } \\
\text { (53) }\end{array}$ \\
\hline & & . & . & $\begin{array}{l}\text { Occupations }{ }^{\mathrm{f}} \text { : metal } \\
\text { production and } \\
\text { processing worker } \\
\text { (polycyclic aromatic } \\
\text { hydrocarbons, } \\
\text { chromates, arsenic } \\
\text { compounds), transporta- } \\
\text { tion workers and freight } \\
\text { handlers (diesel engine } \\
\text { exhaust) }\end{array}$ & $\begin{array}{l}\text { Results for men; matched for age, gender, and } \\
\text { region of residence; adjusted for smoking and } \\
\text { asbestos exposure }\end{array}$ & $\begin{array}{l}\text { Jöckel et al, 1998, } \\
\text { Germany (51) }\end{array}$ \\
\hline
\end{tabular}




\begin{tabular}{|c|c|c|c|c|c|}
\hline \multirow[t]{2}{*}{ Cause of death a } & \multicolumn{2}{|c|}{$\begin{array}{l}\text { Attributable } \\
\text { fraction }^{\mathrm{b}}(\%)\end{array}$} & \multirow{2}{*}{$\begin{array}{l}\text { Potentially implicated } \\
\text { exposure or work } \\
\text { environment }{ }^{c}\end{array}$} & \multirow[t]{2}{*}{ Study design and data analysis ${ }^{d}$} & \multirow[t]{2}{*}{$\begin{array}{l}\text { Primary source of } \\
\text { quantitative estimate }\end{array}$} \\
\hline & Total & Women & & & \\
\hline
\end{tabular}

Bronchus and
lung (continued)
Occupations : ers (soldering fumes containing cadmiun and lead), stock clerks, etc (diesel engine exhaust), restaurant and hotel service workers, waitresses (environmental tobacco smokers), ceramic and pottery workers (arsenic, asbestos, lead, silica), laudry workers and dry cleaners (chlorinated solvents and other industrial solvents)

$\begin{array}{lll}14.0 & 0.6 & \begin{array}{l}\text { Asbestos (and its } \\ \text { synergistic joint action }\end{array}\end{array}$
with smoking)

Restricted to male surgical patients from a general urban population; reference subjects were deceased men from the same metropolitan area; adjusted for age and smoking

2.7 0.2 Crystalline silica (quartz Standardized mortality ratio dust)

\section{$2.5 \quad 0.1 \quad$ Diesel engine exhaust}

Matched for age, gender, and region; adjusted for smoking and asbestos

Matched for age, gender, and region; adjusted for smoking and asbestos

$0.5 \quad 0.1 \quad$ Welding fumes (mild Restricted to men; matched for age, gender, and steel welding, chromium region; adjusted for smoking and asbestos and nickel welders excluded)

Arsenic (and its synergistic joint action with smoking)

Cadmium

Nickel sulfate nitrosamines)
Matched for year of birth and survival time

Restricted to men; standardized mortality ratio estimates based on gender and calendar year specific rates in the whole population; confoun ing by nickel hydroxide possible

Adjusted for age, educational level, marital and socioeconomic status, smoking history, and other carcinogens under study

Restricted to men; matched for gender, year of birth, vital status, and, age at the end of followup

Restricted to men; matched for gender, year of birth, age at the end of follow-up, and vital status; adjusted for smoking, asbestos, chromates, cadmium, solvents, and gasoline

Standardized mortality ratio estimates based on national and regional cancer rates; silica dust and exhaust gases probably had co-carcinogenic or synergistic effects; smoking alone did not explain excess risk

Restricted to subjects who had not smoked more than 400 cigarettes in their lifetime: multicenter case-referent study; matched for age and gender; adjusted in addition for educational level, proportion of life spent in urban areas, occupational exposure to lung carcinogens, intake of vegetables, beta-carotene, total carotenoids, and retinol
Jahn et al, 1999, Germany (53)

Karialainen et al, 1994, Finland (49)

Koskela et al, 1994

Finland (47)

Brüske-Hohlfeld et al, 2000, Germany (54)

Brüske-Hohlfeld et al, 2000, Germany (54)

Jöckel et al. (52), 1998, Germany

Järup \& Pershagen, 1991, Sweden (29)

Elinder et al, 1985,

Sweden, United Kingdom, United States (48)

Droste et al, 2000,

Belgium (56)

Anttila et al, 1995, Finland

Anttila et al, 1998, Finland

Ahlman et al, 1991, Finland (44)

Boffetta et al, 1998 western European countries (87) 


\begin{tabular}{|c|c|c|c|c|c|c|}
\hline \multirow[t]{2}{*}{ Cause of death a } & \multicolumn{3}{|c|}{$\begin{array}{l}\text { Attributable } \\
\text { fraction }{ }^{\mathrm{b}}(\%)\end{array}$} & \multirow{2}{*}{$\begin{array}{l}\text { Potentially implicated } \\
\text { exposure or work } \\
\text { environment c }\end{array}$} & \multirow[t]{2}{*}{ Study design and data analysis ${ }^{d}$} & \multirow[t]{2}{*}{$\begin{array}{l}\text { Primary source of } \\
\text { quantitative estimate e }\end{array}$} \\
\hline & Total & Men & Women & & & \\
\hline $\begin{array}{l}\text { Bronchus and } \\
\text { lung (continued) }\end{array}$ & & 0.0 & 0.7 & $\begin{array}{l}\text { Hairdressing (hair dyes } \\
\text { and colorants) }\end{array}$ & Standardized incidence ratio estimates & $\begin{array}{l}\text { Pukkala et al, } 1992, \\
\text { Finland (45) }\end{array}$ \\
\hline Bone (C40-C41) & 0.6 & 0.6 & 0.6 & $\begin{array}{l}\text { Air carrier personnel } \\
\text { (ionizing radiation) }\end{array}$ & $\begin{array}{l}\text { Standardized incidence ratio estimates based on } \\
\text { national cancer incidences. }\end{array}$ & $\begin{array}{l}\text { Pukkala et al. (127), 1995, } \\
\text { Finland }\end{array}$ \\
\hline \multirow{4}{*}{$\begin{array}{l}\text { Skin melanoma } \\
\text { (C43) }\end{array}$} & 2.7 & 4.3 & 0.4 & Combined risk factors & & . \\
\hline & & 2.4 & 0.3 & $\begin{array}{l}\text { Warehouse clerks } \\
\text { (indoor work, diesel } \\
\text { engine exhaust) }\end{array}$ & Adjusted for age, years of schooling, and ethnicity & $\begin{array}{l}\text { Fritschi \& Siemiatycki, } \\
\text { 1996, Canada (322) }\end{array}$ \\
\hline & & 1.9 & 0.0 & $\begin{array}{l}\text { Seafarer's outdoor work } \\
\text { (repeated sunburns) }\end{array}$ & $\begin{array}{l}\text { Standardized incidence ratio based on national } \\
\text { cancer incidences }\end{array}$ & $\begin{array}{l}\text { Pukkala \& Saarni, } 1996, \\
\text { Finland (79) }\end{array}$ \\
\hline & & 0.1 & 0.1 & $\begin{array}{l}\text { Airline pilots' work } \\
\text { (cosmic radiation) }\end{array}$ & $\begin{array}{l}\text { Restricted to men; standardized incidence ratio } \\
\text { based on national cancer incidence; proportion of } \\
\text { current smokers among the pilots was similar to } \\
\text { that expected in the general polulation }\end{array}$ & $\begin{array}{l}\text { Haldorsen et al, } 2000 \text {, } \\
\text { Norway (150) }\end{array}$ \\
\hline $\begin{array}{l}\text { Skin non-melanoma } \\
\text { (C44) }\end{array}$ & 8.3 & 13.1 & 3.8 & $\begin{array}{l}\text { Ultraviolet radiation } \\
\text { (outdoor work) }\end{array}$ & $\begin{array}{l}\text { Standardized incidence ratio based on national } \\
\text { cancer incidences }\end{array}$ & $\begin{array}{l}\text { Pukkala \& Saarni, } 1996, \\
\text { Finland (79) }\end{array}$ \\
\hline \multirow[t]{2}{*}{$\begin{array}{l}\text { Mesothelioma (all } \\
\text { sites) (C45) }\end{array}$} & 71.3 & 90.0 & 25.0 & Asbestos & Case series study & $\begin{array}{l}\text { Spirtas et al, 1994, United } \\
\text { States (323) }\end{array}$ \\
\hline & & . & . & Asbestos & Case series study & $\begin{array}{l}\text { Yates et al, 1997, United } \\
\text { Kingdom (324) }\end{array}$ \\
\hline \multirow[t]{3}{*}{ Female breast (C50) } & 1.7 & $\cdot$ & 1.7 & Combined risk factors & & . \\
\hline & & $\cdot$ & 1.7 & Ionizing radiation & $\begin{array}{l}\text { Restricted to postmenopausal women; adjusted } \\
\text { for mean number of children, mean age at first } \\
\text { delivery, and turnover rate for each job title }\end{array}$ & $\begin{array}{l}\text { Weiderpass et al, } 1999, \\
\text { Finland (126) }\end{array}$ \\
\hline & & . & 0.1 & Hairdressing (hair dyes) & Standardized incidence ratio estimates & $\begin{array}{l}\text { Pukkala et al, } 1992, \\
\text { Finland (45) }\end{array}$ \\
\hline Cervix uteri (C53) & 5.9 & . & 5.9 & $\begin{array}{l}\text { Aromatic hydrocarbon } \\
\text { solvents (co-exposure } \\
\text { with aliphatic and } \\
\text { alicyclic, and chlorinated } \\
\text { hydrocarbons) }\end{array}$ & $\begin{array}{l}\text { Standardized for birth cohort, follow-up period, } \\
\text { and social status; adjusted for mean parity, } \\
\text { mean age at birth of first child, and turnover rate }\end{array}$ & $\begin{array}{l}\text { Weiderpass et al, 2001, } \\
\text { Finland (134) }\end{array}$ \\
\hline $\begin{array}{l}\text { Corpus uteri (endo- } \\
\text { metrium) (C54) }\end{array}$ & 1.1 & $\cdot$ & 1.1 & $\begin{array}{l}\text { Sedentary work } \\
\text { (industrial sewers, low } \\
\text { level of occupational } \\
\text { physical activity) }\end{array}$ & $\begin{array}{l}\text { Standardized for birth cohort, follow-up period, } \\
\text { and social status; adjusted for mean parity, mean } \\
\text { age at birth of first child, and turnover rate }\end{array}$ & $\begin{array}{l}\text { Weiderpass et al, 2001, } \\
\text { Finland (134) }\end{array}$ \\
\hline \multirow[t]{6}{*}{ Ovary (C56) } & 2.1 & . & 2.1 & Combined risk factors & . & . \\
\hline & & . & 0.7 & $\begin{array}{l}\text { Aromatic hydrocarbon } \\
\text { solvents (co-exposure } \\
\text { with aliphatic and } \\
\text { alicyclic, and chlori- } \\
\text { nated hydrocarbons) }\end{array}$ & $\begin{array}{l}\text { Stratified by birth cohort, follow-up period, and } \\
\text { socio economic status; adjusted for mean number } \\
\text { of children and turnover rate for each job title }\end{array}$ & $\begin{array}{l}\text { Vasama-Neuvonen et al, } \\
\text { 1999, Finland (132) }\end{array}$ \\
\hline & & . & 0.3 & $\begin{array}{l}\text { Asbestos (co-exposure } \\
\text { with silica dust and man- } \\
\text { made vitreous fibers) }\end{array}$ & $\begin{array}{l}\text { Stratified by birth cohort, follow-up period, and } \\
\text { - socio economic status; adjusted for mean number } \\
\text { of children and turnover rate for each job title }\end{array}$ & $\begin{array}{l}\text { Vasama-Neuvonen et al, } \\
\text { 1999, Finland (132) }\end{array}$ \\
\hline & & . & 0.4 & Leather dust & $\begin{array}{l}\text { Stratified by birth cohort, follow-up period, and } \\
\text { socio economic status; adjusted for mean number } \\
\text { of children and turnover rate for each job title }\end{array}$ & $\begin{array}{l}\text { Vasama-Neuvonen et al, } \\
\text { 1999, Finland (132) }\end{array}$ \\
\hline & & . & 0.4 & $\begin{array}{l}\text { Diesel or gasoline engine } \\
\text { exhaust }\end{array}$ & $\begin{array}{l}\text { Stratified by birth cohort, follow-up period, and } \\
\text { socio economic status; adjusted for mean number } \\
\text { of children and turnover rate for each job title }\end{array}$ & $\begin{array}{l}\text { Vasama-Neuvonen et al, } \\
\text { 1999, Finland (132) }\end{array}$ \\
\hline & & . & 0.3 & $\begin{array}{l}\text { Hairdressers (hair dyes } \\
\text { and colorants) }\end{array}$ & $\begin{array}{l}\text { Stratified by birth cohort, follow-up period, and } \\
\text { socio economic status; adjusted for mean number } \\
\text { of children and turnover rate for each job title }\end{array}$ & $\begin{array}{l}\text { Vasama-Neuvonen et al, } \\
\text { 1999, Finland (132) }\end{array}$ \\
\hline
\end{tabular}




\begin{tabular}{|c|c|c|c|c|c|c|}
\hline \multirow[t]{2}{*}{ Cause of death a } & \multicolumn{3}{|c|}{$\begin{array}{l}\text { Attributable } \\
\text { fraction }{ }^{b}(\%)\end{array}$} & \multirow{2}{*}{$\begin{array}{l}\text { Potentially implicated } \\
\text { exposure or work } \\
\text { environment }{ }^{c}\end{array}$} & \multirow[t]{2}{*}{ Study design and data analysis ${ }^{d}$} & \multirow[t]{2}{*}{$\begin{array}{l}\text { Primary source of } \\
\text { quantitative estimate e }\end{array}$} \\
\hline & Total & Men & Women & & & \\
\hline \multirow[t]{3}{*}{ Prostate (C61) } & & 6.0 & & Combined risk factors & . & . \\
\hline & & 3.5 & - & $\begin{array}{l}\text { Metal dust, especially } \\
\text { cadmium dust }\end{array}$ & $\begin{array}{l}\text { Adjusted for age, ethnicity, socioeconomic } \\
\text { status, Quatelet index, self versus proxy status } \\
\text { of the respondent, and core substances }\end{array}$ & $\begin{array}{l}\text { Aronsen et al, 1996, Canada } \\
\text { (106) }\end{array}$ \\
\hline & & 2.7 & . & Herbicides & $\begin{array}{l}\text { Adjusted for age, calendar period, and other } \\
\text { farm exposures. Income, education, ethnic } \\
\text { origin, and immigrant status examined as } \\
\text { potential confounders }\end{array}$ & $\begin{array}{l}\text { Morrison et al, } 1993 \\
\text { Canada (103) }\end{array}$ \\
\hline \multirow{12}{*}{$\begin{array}{l}\text { Kidney (renal cell } \\
\text { carcinoma) (C64- } \\
\text { C65) }\end{array}$} & 3.1 & 4.7 & 0.8 & Combined risk factors & $\cdot$ & $\cdot$ \\
\hline & & . & & $\begin{array}{l}\text { Oil refinery workers }{ }^{\dagger} \\
\text { (petroleum refining, } \\
\text { constituents of gas- } \\
\text { oline: benzene, etc) }\end{array}$ & $\begin{array}{l}\text { Standardized incidence ratio estimates based } \\
\text { on national cancer incidences; adjusted for } \\
\text { social class }\end{array}$ & $\begin{array}{l}\text { Pukkala, 1998, Finland } \\
\text { (325) }\end{array}$ \\
\hline & & . & & $\begin{array}{l}\text { Printers, } \\
\text { printing industry }{ }^{f}\end{array}$ & $\begin{array}{l}\text { Adjusted for age, cigarette-years, body mass } \\
\text { index, and respondent status (self versus } \\
\text { proxy); potential occupational confounders } \\
\text { were chosen independently for each substance } \\
\text { under study }\end{array}$ & $\begin{array}{l}\text { Parent et al, 2000, Canada } \\
(326)\end{array}$ \\
\hline & & & $\cdot$ & Aviation gasoline $^{f}$ & $\begin{array}{l}\text { Adjusted for age, cigarette-years, body mass } \\
\text { index, and respondent status (self versus } \\
\text { proxy); potential occupational confounders } \\
\text { were chosen independently for each substance } \\
\text { under study }\end{array}$ & $\begin{array}{l}\text { Parent et al, 2000, Canada } \\
(326)\end{array}$ \\
\hline & & $\cdot$ & & $\begin{array}{l}\text { Printing press operators } \\
\text { used gasoline as as a } \\
\text { cleaning agent }\end{array}$ & $\begin{array}{l}\text { Restricted to subjects with reported occupa- } \\
\text { tional history; matched for year of birth, } \\
\text { gender, and survival status at the time of data } \\
\text { collection; adjusted for smoking, obesity, and } \\
\text { coffee consumption }\end{array}$ & $\begin{array}{l}\text { Partanen et al, 1991, Finland } \\
(327)\end{array}$ \\
\hline & & $\cdot$ & $\cdot$ & $\begin{array}{l}\text { Nonchlorinated } \\
\text { hydrocarbon solvents }{ }^{\uparrow}\end{array}$ & $\begin{array}{l}\text { Restricted to subjects with reported occupa- } \\
\text { tional history; matched for year of birth, } \\
\text { gender, and survival status at the time of data } \\
\text { collection; adjusted for smoking, obesity, and } \\
\text { coffee consumption }\end{array}$ & $\begin{array}{l}\text { Partanen et al, 1991, Finland } \\
\text { (327) }\end{array}$ \\
\hline & & & & Iron and steel industry ${ }^{\dagger}$ & $\begin{array}{l}\text { Multicenter population-based case-referent } \\
\text { study }\end{array}$ & $\begin{array}{l}\text { Mandel et al, 1995, Austra- } \\
\text { lia, Denmark, Germany, } \\
\text { Sweden, United States } \\
\text { (328) }\end{array}$ \\
\hline & & . & · & Dry-cleaning solvents ${ }^{\dagger}$ & $\begin{array}{l}\text { Multicenter population-based case-referent } \\
\text { study }\end{array}$ & $\begin{array}{l}\text { Mandel et al, 1995, Austra- } \\
\text { lia, Denmark, Germany, } \\
\text { Sweden, United States } \\
\text { (328) }\end{array}$ \\
\hline & & . & . & $\begin{array}{l}\text { Gasoline and other } \\
\text { petroleum products }\end{array}$ & $\begin{array}{l}\text { Multicenter population-based case-referent } \\
\text { study }\end{array}$ & $\begin{array}{l}\text { Mandel et al, 1995, Austra- } \\
\text { lia, Denmark, Germany, } \\
\text { Sweden, United States } \\
\text { (328) }\end{array}$ \\
\hline & & 1.1 & 0.0 & $\begin{array}{l}\text { Gasoline (tetraethyl lead } \\
\text { used as additive) }\end{array}$ & $\begin{array}{l}\text { Multicenter population-based case-referent } \\
\text { study }\end{array}$ & $\begin{array}{l}\text { Mandel et al, 1995, Austra- } \\
\text { lia, Denmark, Germany, } \\
\text { Sweden, United States } \\
\text { (328) }\end{array}$ \\
\hline & & 0.4 & 0.2 & Solvents & $\begin{array}{l}\text { Matched for gender, age, and region; adjusted } \\
\text { for smoking }\end{array}$ & $\begin{array}{l}\text { Pesch et al, } 2000 \text { Germany } \\
\text { (329) }\end{array}$ \\
\hline & & 3.4 & 0.6 & $\begin{array}{l}\text { Heavy metals (cadmium } \\
\text { and lead) }\end{array}$ & $\begin{array}{l}\text { Matched for gender, age, and region; adjusted } \\
\text { for smoking }\end{array}$ & $\begin{array}{l}\text { Pesch et al, } 2000 \text { Germany } \\
\text { (329) }\end{array}$ \\
\hline
\end{tabular}




\begin{tabular}{|c|c|c|c|c|c|c|}
\hline \multirow[t]{2}{*}{ Cause of death a } & \multicolumn{3}{|c|}{$\begin{array}{l}\text { Attributable } \\
\text { fraction }{ }^{\mathrm{b}}(\%)\end{array}$} & \multirow{2}{*}{$\begin{array}{l}\text { Potentially implicated } \\
\text { exposure or work } \\
\text { environment }{ }^{c}\end{array}$} & \multirow[t]{2}{*}{ Study design and data analysis ${ }^{d}$} & \multirow[t]{2}{*}{$\begin{array}{l}\text { Primary source of } \\
\text { quantitative estimate } \mathrm{e}\end{array}$} \\
\hline & Total & Men & Women & & & \\
\hline \multirow{6}{*}{$\begin{array}{l}\text { Urinary bladder } \\
\text { (C67) }\end{array}$} & 10.3 & 14.2 & 0.7 & Combined risk factors & & \\
\hline & & 4.0 & 0.0 & $\begin{array}{l}\text { Textile dyes, paints, and } \\
\text { pigments (2-naphthyl- } \\
\text { amine) }\end{array}$ & Pair-matched for age, gender, and hospital & $\begin{array}{l}\text { Tola et al, 1980, Finland } \\
(330)\end{array}$ \\
\hline & & 5.4 & 0.0 & $\begin{array}{l}\text { Leather and rubber } \\
\text { (aromatic amines) }\end{array}$ & Pair-matched for age, gender, and hospital & $\begin{array}{l}\text { Tola et al, 1980, Finland } \\
(330)\end{array}$ \\
\hline & & 2.8 & 0.4 & Lead & $\begin{array}{l}\text { Restricted to men; matched for gender, year of } \\
\text { birth, age at the end of follow-up, and vital } \\
\text { status; adjusted for smoking and vital status }\end{array}$ & $\begin{array}{l}\text { Anttila et al, 1995, Finland } \\
\text { (43) }\end{array}$ \\
\hline & & 0.9 & 0.3 & $\begin{array}{l}\text { Chlorinated hydrocarbon } \\
\text { solvents }\end{array}$ & $\begin{array}{l}\text { Restricted to men; adjusted for age and social } \\
\text { class; the male population of Finland used as } \\
\text { the reference }\end{array}$ & $\begin{array}{l}\text { Kauppinen et al, 1998, } \\
\text { Finland (14) }\end{array}$ \\
\hline & & 1.9 & 0.0 & $\begin{array}{l}\text { Polycyclic aromatic } \\
\text { hydrocarbons }\end{array}$ & $\begin{array}{l}\text { Matched for age, gender, and region; adjusted } \\
\text { for smoking }\end{array}$ & $\begin{array}{l}\text { Pesch et al, } 2000 \text {, } \\
\text { Germany (329) }\end{array}$ \\
\hline \multirow[t]{4}{*}{ Brain (C71) } & 6.4 & 10.6 & 1.3 & Combined risk factors & . & · \\
\hline & & 6.8 & 0.1 & $\begin{array}{l}\text { Precision metal workers, } \\
\text { including machinists, } \\
\text { tool and die makers, and } \\
\text { sheet metal workers } \\
\text { (metal dusts and fumes, } \\
\text { lubricating oils, and } \\
\text { solvents) }\end{array}$ & $\begin{array}{l}\text { Restricted to men; adjusted for age at death and } \\
\text { marital status }\end{array}$ & $\begin{array}{l}\text { Thomas et al, 1986, United } \\
\text { States (331) }\end{array}$ \\
\hline & & 2.8 & 0.7 & Lead & $\begin{array}{l}\text { Restricted to men; matched for birth-year, age } \\
\text { at diagnosis, and vital status; adjusted for year } \\
\text { of first exposure measurement, smoking, } \\
\text { exposure to gasoline and cadmium }\end{array}$ & $\begin{array}{l}\text { Anttila et al, 1996, Finland } \\
\text { (332) }\end{array}$ \\
\hline & & 1.3 & 0.5 & $\begin{array}{l}\text { Aromatic hydrocarbon } \\
\text { solvents }\end{array}$ & $\begin{array}{l}\text { Standardized incidence ratios based on age-, } \\
\text { gender-, and period-specific incidence rates of } \\
\text { cancer in the general population }\end{array}$ & $\begin{array}{l}\text { Anttila et al, 1998, Finland } \\
\text { (318) }\end{array}$ \\
\hline \multirow[t]{2}{*}{$\begin{array}{l}\text { Hodgkin's disease } \\
\text { (C81) }\end{array}$} & 2.2 & 3.9 & 0.0 & $\begin{array}{l}\text { Farmers (pesticides and } \\
\text { other chemicals used in } \\
\text { cultivating grain, etc) }{ }^{\dagger}\end{array}$ & $\begin{array}{l}\text { Adjusted for age, gender, geographic region of } \\
\text { farm, and their interactions using Poisson } \\
\text { regression modeling }\end{array}$ & $\begin{array}{l}\text { Pukkala \& Notkola, } 1997, \\
\text { Finland (137) }\end{array}$ \\
\hline & & . & . & $\begin{array}{l}\text { Farmers (no specific } \\
\text { exposure identified) }{ }^{\dagger}\end{array}$ & $\begin{array}{l}\text { The meta-analysis estimate of risk ratio was } \\
\text { calculated using a random-effects model }\end{array}$ & $\begin{array}{l}\text { Khuder et al, 1997, mostly } \\
\text { European countries and } \\
\text { United States (136) }\end{array}$ \\
\hline \multirow{4}{*}{$\begin{array}{l}\text { Non-Hodgkin's } \\
\text { lymphoma } \\
\text { (C82-C85) }\end{array}$} & 4.7 & 13.5 & 3.1 & Combined risk factors & . & . \\
\hline & & 1.5 & 0.5 & $\begin{array}{l}\text { Halogenated hydrocar- } \\
\text { bon solvents (trichlo- } \\
\text { roethylene, tetrachlo- } \\
\text { roethylene, } 1,1,1- \\
\text { trichloroethane) }\end{array}$ & $\begin{array}{l}\text { Based on age-, gender-, and calendar-period- } \\
\text { specific rates for the general Finnish population }\end{array}$ & $\begin{array}{l}\text { Anttila et al, 1995, Finland } \\
\text { (133) }\end{array}$ \\
\hline & & 5.2 & 0.9 & $\begin{array}{l}\text { Herbicides } \\
\text { (phenoxyacetic acids) }\end{array}$ & $\begin{array}{l}\text { Restricted to men; matched for age, county, and } \\
\text { vital status }\end{array}$ & $\begin{array}{l}\text { Hardell \& Eriksson, } 1999 \\
\text { Sweden (138) }\end{array}$ \\
\hline & & 7.4 & 1.7 & Fungicides & $\begin{array}{l}\text { Restricted to men; matched for age, county, and } \\
\text { vital status }\end{array}$ & $\begin{array}{l}\text { Hardell \& Eriksson, 1999, } \\
\text { Sweden (138) }\end{array}$ \\
\hline \multirow{3}{*}{$\begin{array}{l}\text { Leukemia (C91- } \\
\text { C95) }\end{array}$} & 10.9 & 18.5 & 2.5 & Combined risk factors & & . \\
\hline & & 0.7 & 0.2 & Benzene & $\begin{array}{l}\text { Evaluation of } 4 \text { independent epidemiologic } \\
\text { studies }\end{array}$ & $\begin{array}{l}\text { Tomatis et al, 1991, } \\
\text { international (120) }\end{array}$ \\
\hline & & 17.8 & 2.3 & $\begin{array}{l}\text { Electrical occupations } \\
\text { (low-frequency magnetic } \\
\text { fields) }\end{array}$ & $\begin{array}{l}\text { Matched for age, gender, parish, and proximity } \\
\text { to a power line; adjusted for age, gender, motor } \\
\text { fuel or exhaust fumes, benzene, oil products, } \\
\text { solvents, and welding fumes }\end{array}$ & $\begin{array}{l}\text { Feychting et al, } 1997, \\
\text { Sweden (142) }\end{array}$ \\
\hline
\end{tabular}




\begin{tabular}{|c|c|c|c|c|c|c|}
\hline \multirow[t]{2}{*}{ Cause of death ${ }^{a}$} & \multicolumn{3}{|c|}{$\begin{array}{l}\text { Attributable } \\
\text { fraction }{ }^{\mathrm{b}}(\%)\end{array}$} & \multirow{2}{*}{$\begin{array}{l}\text { Potentially implicated } \\
\text { exposure or work } \\
\text { environment }{ }^{c}\end{array}$} & \multirow[t]{2}{*}{ Study design and data analysis ${ }^{d}$} & \multirow[t]{2}{*}{$\begin{array}{l}\text { Primary source of } \\
\text { quantitative estimate }\end{array}$} \\
\hline & Total & Men & Women & & & \\
\hline $\begin{array}{l}\text { Mental disorders (all } \\
\text { F codes) }\end{array}$ & 3.5 & 7.3 & 1.8 & & & \\
\hline $\begin{array}{l}\text { Vascular and un- } \\
\text { specified dementia } \\
\text { (F01, F03) }\end{array}$ & 3.9 & 10.0 & 1.8 & $\begin{array}{l}\text { Pesticides (herbicides } \\
\text { and insecticides) and } \\
\text { fertilizers }\end{array}$ & $\begin{array}{l}\text { Restricted to cases with symptoms occurring } \\
\text { not more than } 3 \text { years before diagnosis (control } \\
\text { for survival bias); adjusted for gender, education, } \\
\text { and residence in community or institution }\end{array}$ & $\begin{array}{l}\text { Lindsay et al, 1997, Canada } \\
(215)\end{array}$ \\
\hline $\begin{array}{l}\text { Depressive episode } \\
\text { (F32) }\end{array}$ & 11.3 & 14.6 & 9.8 & $\begin{array}{l}\text { Job strain (high levels } \\
\text { of psychological } \\
\text { demands, low levels of } \\
\text { decision latitude, and } \\
\text { low levels of social } \\
\text { support at work) }\end{array}$ & $\begin{array}{l}\text { Adjusted for personal and occupational } \\
\text { characteristics, including age, marital status, } \\
\text { number of children, educational level, occupa- } \\
\text { tion, previous absenteeism for mental disorders, } \\
\text { and stressful personal and occupational events } \\
\text { during the previous } 12 \text { months }\end{array}$ & $\begin{array}{l}\text { Niedhammer et al, 1998, } \\
\text { France (333) }\end{array}$ \\
\hline
\end{tabular}

\begin{tabular}{|c|c|c|c|c|c|c|}
\hline $\begin{array}{l}\text { Diseases of the } \\
\text { nervous system and } \\
\text { (all } G \text { andH codes) }\end{array}$ & 3.1 & 5.1 & 1.7 & & & \\
\hline $\begin{array}{l}\text { Spinal muscular } \\
\text { atrophy (G12) }\end{array}$ & 0.7 & 1.2 & 0.2 & $\begin{array}{l}\text { Electrical work (low- } \\
\text { frequency magnetic } \\
\text { fields) }\end{array}$ & $\begin{array}{l}\text { Restricted to men; adjusted for age, calendar } \\
\text { year, social class, and race }\end{array}$ & $\begin{array}{l}\text { Sawitz al, 1998, the United } \\
\text { States (334) }\end{array}$ \\
\hline \multirow[t]{2}{*}{$\begin{array}{l}\text { Parkinson's di- } \\
\text { sease (G20-G21) }\end{array}$} & 9.2 & 16.0 & 4.9 & $\begin{array}{l}\text { Pesticides (herbicides } \\
\text { and insecticides) }\end{array}$ & $\begin{array}{l}\text { Frequency-matched for age, gender, and race; } \\
\text { adjusted for age, gender, race, smoking status, } \\
\text { and farming }\end{array}$ & $\begin{array}{l}\text { Gorell et al, 1998, the } \\
\text { United States (216) }\end{array}$ \\
\hline & & . & . & $\begin{array}{l}\text { Pesticides (herbicides } \\
\text { and insecticides) }\end{array}$ & A review of recent evidence & $\begin{array}{l}\text { Checkoway and Nelson, } \\
\text { 1999, Canada, Germany, } \\
\text { Taiwan, the United States } \\
(335)\end{array}$ \\
\hline $\begin{array}{l}\text { Alzheimer's di- } \\
\text { sease (G30) }\end{array}$ & 2.3 & 3.4 & 1.8 & $\begin{array}{l}\text { Electrical work (low- } \\
\text { frequency magnetic } \\
\text { fields) }\end{array}$ & $\begin{array}{l}\text { Adjusted for education or social class, and age } \\
\text { at onset or age at examination; age and gender } \\
\text { not considered confounders }\end{array}$ & $\begin{array}{l}\text { Sobel et al, 1995, Finland, } \\
\text { United States (219) }\end{array}$ \\
\hline $\begin{array}{l}\text { Diseases of the } \\
\text { circulatory system } \\
\text { (all I codes) }\end{array}$ & 12.4 & 14.4 & 6.7 & & & \\
\hline \multirow{5}{*}{$\begin{array}{l}\text { Ischemic heart } \\
\text { disease (121-I25) }\end{array}$} & 16.9 & 18.9 & 9.1 & Combined risk factors & & . \\
\hline & & 10.7 & . & $\begin{array}{l}\text { Shift work (involves } \\
\text { work strain) }\end{array}$ & $\begin{array}{l}\text { Restricted to men (shift workers versus day } \\
\text { workers); total risk from ischemic heart disease } \\
\text { adjusted for age, smoking, total cholesterol, } \\
\text { systolic blood pressure, body mass index, spare } \\
\text { time physical activity, and alcohol intake }\end{array}$ & $\begin{array}{l}\text { Tenkanen et al, 1997, } \\
\text { Finland (30) }\end{array}$ \\
\hline & & . & 5.5 & $\begin{array}{l}\text { Shift work (involving } \\
\text { work strain) }\end{array}$ & $\begin{array}{l}\text { Restricted to women; mortality risk adjusted for } \\
\text { age, cigarette smoking, body mass index, history } \\
\text { of hypertension, diabetes mellitus and hyper- } \\
\text { cholesterolemia, menopausal status, current use } \\
\text { of postmenopausal hormones, past use of oral } \\
\text { contraceptives, alcohol intake, level of physical } \\
\text { activity, quintiles of vitamin E intake, average } \\
\text { aspirin use, and parental history of myocardial } \\
\text { infarction before } 60 \text { years of age; stratified by } \\
\text { spouse's educational status }\end{array}$ & $\begin{array}{l}\text { Kawachi et al, 1995, United } \\
\text { States (34) }\end{array}$ \\
\hline & & 6.2 & 2.3 & Noise & Review and quantitative estimation of risk ratio & $\begin{array}{l}\text { Olsen \& Kristensen, } 1991, \\
\text { Denmark (155) }\end{array}$ \\
\hline & & 1.0 & 0.0 & $\begin{array}{l}\text { Engine exhausts } \\
\text { (including carbon } \\
\text { monoxide) }\end{array}$ & $\begin{array}{l}\text { Adjusted for calendar time and duration of } \\
\text { employment; similar distributions of smoking } \\
\text { habits and social class among the exposed and } \\
\text { reference subjects }\end{array}$ & $\begin{array}{l}\text { Stern, 1988, United States } \\
\text { (16) }\end{array}$ \\
\hline
\end{tabular}




\begin{tabular}{|c|c|c|c|c|c|c|}
\hline \multirow[t]{2}{*}{ Cause of death a } & \multicolumn{3}{|c|}{$\begin{array}{l}\text { Attributable } \\
\text { fraction }^{\mathrm{b}}(\%)\end{array}$} & \multirow{2}{*}{$\begin{array}{l}\text { Potentially implicated } \\
\text { exposure or work } \\
\text { environment }{ }^{c}\end{array}$} & \multirow[t]{2}{*}{ Study design and data analysis ${ }^{d}$} & \multirow[t]{2}{*}{$\begin{array}{l}\text { Primary source of } \\
\text { quantitative estimate e }\end{array}$} \\
\hline & Total & Men & Women & & & \\
\hline $\begin{array}{l}\text { Ischemic heart } \\
\text { disease } \\
\text { (continued) }\end{array}$ & & 2.2 & 1.5 & $\begin{array}{l}\text { Environmental tobacco } \\
\text { smoke (carbon dioxide } \\
\text { and nicotine) }\end{array}$ & $\begin{array}{l}\text { Restricted to women; adjusted for age, alcohol } \\
\text { intake, body mass index, history of hypertension, } \\
\text { diabetes and hypercholesterolemia, current use } \\
\text { of postmenopausal hormones, past use of oral } \\
\text { contraceptives, vigorous fat intake, vitamin } \mathrm{E} \\
\text { intake, exercise, quintiles of saturated average } \\
\text { aspirin use, and parental history of myocardial } \\
\text { infarction before } 60 \text { years of age }\end{array}$ & $\begin{array}{l}\text { Kawachi et al, 1997, United } \\
\text { States (200) }\end{array}$ \\
\hline \multirow{3}{*}{$\begin{array}{l}\text { Cerebrovascular } \\
\text { diseases (I60-169) }\end{array}$} & 10.5 & 12.1 & 7.8 & Combined risk factors & . & $\cdot$ \\
\hline & & 4.8 & 4.8 & Shift work & $\begin{array}{l}\text { Longitudinal register study; adjustment by a } \\
\text { Poisson regression analysis of the impact of } \\
\text { occupational and socioeconomic variates on } \\
\text { mortality }\end{array}$ & $\begin{array}{l}\text { Virtanen \& Notkola, 2001, } \\
\text { Finland (205) }\end{array}$ \\
\hline & & 7.6 & 3.2 & $\begin{array}{l}\text { Environmental tobacco } \\
\text { smoke (including carbon } \\
\text { monoxide) }\end{array}$ & $\begin{array}{l}\text { Adjusted for age, gender, history of hyperten- } \\
\text { sion, heart disease, and diabetes }\end{array}$ & $\begin{array}{l}\text { Bonita et al, 1999, New } \\
\text { Zealand (207) }\end{array}$ \\
\hline
\end{tabular}

\section{$\begin{array}{llll}\text { Diseases of the } & 4.1 & 6.8 & 1.1\end{array}$ respiratory system (all J codes)}

Pneumonia (J12, J13, J15, J17)

Standardized mortality ratios were calculated based on age-, gender, and period-specific $\begin{array}{lll}1.1 & 1.4 & 0.3\end{array}$

Welders (metallic component of the welding fumes, oxides of nitrogen, and ozone) death rates of pneumonia in the general

population; the fact that the excess mortality among men was confined to men younger than causes improbable

\section{Chronic obstructive $11.7 \quad 14.0 \quad 3.8 \quad$ Combined risk factors} pulmonary diseases (J41-J44, J47)
Dusty work such as manufacturing industry, construction work, and farming (organic dust, microbial dusts, endotoxins)

3.6 $0.6 \quad$ Welding fumes (chromium and nickel dust in stainless steel welding)

$1.2 \quad 0.9 \quad$ Environmental tobacco smoke

\section{$18.2 \quad 17.8 \quad 18.4 \quad$ Combined risk factors}

Asthma (J45)
Occupations f: bakers, food manufacturing workers, painters and lacquerers, floor layers, farmers, animal husbandry workers, welders, plastic product workers

$8.6 \quad 5.9 \quad$ Farmers and agricultural workers, animal husbandry workers (grain dust, hay dust, animal epithelia, hairs or secretions, fodders)
Spray painters and
Adjusted for age, gender, smoking status, and country (study center) lacquerers (epoxy resins
or paints, isocyanates) 65 years makes confounding by nonoccupational
Stratified by gender, history of smoking, and social status

Isoaho et al, 1994, Finland (230)

Adjusted for age, cigarette pack-years, duration of occupational exposures, and demographic variables

Adjusted for age, gender, race, education, occupational exposure, and past smoking history States (232)

Incidence rates based on register data

Karjalainen et al, 2000 , Finland (237)

Hunting \& Welch 1993 United States (231)

Euler et al1, 1987, United
Coggon et al, 1994, United Kingdom (336)

Adjusted for age, gender, smoking status, and country (study center)

Kogevinas et al, 1999 , Australia, New Zealand United States, western Europe (226)

Kogevinas et al, 1999 Australia, New Zealand, United States, western Europe (226)

(continued) 


\begin{tabular}{|c|c|c|c|c|c|c|}
\hline \multirow[t]{2}{*}{ Cause of death ${ }^{a}$} & \multicolumn{3}{|c|}{$\begin{array}{l}\text { Attributable } \\
\text { fraction }{ }^{b}(\%)\end{array}$} & \multirow{2}{*}{$\begin{array}{l}\text { Potentially implicated } \\
\text { exposure or work } \\
\text { environment }{ }^{c}\end{array}$} & \multirow[t]{2}{*}{ Study design and data analysis ${ }^{d}$} & \multirow[t]{2}{*}{$\begin{array}{l}\text { Primary source of } \\
\text { quantitative estimate }\end{array}$} \\
\hline & Total & Men & Women & & & \\
\hline \multirow[t]{7}{*}{ Asthma (continued) } & & 0.3 & 4.7 & $\begin{array}{l}\text { Cleaners (chlorine and } \\
\text { acids, solvents, dusts) }\end{array}$ & $\begin{array}{l}\text { Adjusted for age, gender, smoking status, and } \\
\text { country (study center) }\end{array}$ & $\begin{array}{l}\text { Kogevinas et al, 1999, } \\
\text { Australia, New Zealand, } \\
\text { United States, western } \\
\text { Europe (226) }\end{array}$ \\
\hline & & 0.3 & 0.2 & $\begin{array}{l}\text { Plastics and rubber } \\
\text { workers (eg, epoxides) }\end{array}$ & $\begin{array}{l}\text { Adjusted for age, gender, smoking status, and } \\
\text { country (study center) }\end{array}$ & $\begin{array}{l}\text { Kogevinas et al, 1999, } \\
\text { Australia, New Zealand, } \\
\text { United States, western } \\
\text { Europe (226) }\end{array}$ \\
\hline & & 0.6 & 1.2 & $\begin{array}{l}\text { Bakers and pastry } \\
\text { makers (flour dust) }\end{array}$ & $\cdot$ & $\cdot$ \\
\hline & & 2.0 & 0.4 & Welding fumes & $\begin{array}{l}\text { Adjusted for age, gender, smoking, and } \\
\text { formaldehyde exposure }\end{array}$ & $\begin{array}{l}\text { Torén et al, 1999, Sweden } \\
(241)\end{array}$ \\
\hline & & 0.4 & 3.2 & Textile dust & $\cdot$ & $\begin{array}{l}\text { Torén et al, 1999, Sweden } \\
(241)\end{array}$ \\
\hline & & 0.0 & 0.2 & $\begin{array}{l}\text { Hairdressers and } \\
\text { beauticians, etc (hair, } \\
\text { acrylic monomers, resin, } \\
\text { phthalates, persulfate } \\
\text { salts, hair dyes and } \\
\text { colorants) }\end{array}$ & Adjusted for age, smoking and atopy & $\begin{array}{l}\text { Leino et al, 1997, Finland } \\
(240)\end{array}$ \\
\hline & & 5.8 & 3.9 & $\begin{array}{l}\text { Environmental tobacco } \\
\text { smoke }\end{array}$ & $\begin{array}{l}\text { Adjusted for age, gender, air pollution at work- } \\
\text { place, occupational contact with animals, atopy, } \\
\text { and ever-smoking }\end{array}$ & $\begin{array}{l}\text { Flodin et al, 1995, Sweden } \\
(244)\end{array}$ \\
\hline $\begin{array}{l}\text { Pneumoconioses } \\
\text { (J60-J64, J67) }\end{array}$ & 100 & 100 & 100 & $\begin{array}{l}\text { Asbestos dust, silica } \\
\text { dust, organic dust }\end{array}$ & $\begin{array}{l}\text { Based on the rarity of nonoccupational cases of } \\
\text { pneumoconiosis }\end{array}$ & $\begin{array}{l}\text { Karjalainen, 1998, Finland } \\
(11)\end{array}$ \\
\hline $\begin{array}{l}\text { Cryptogenic fibros- } \\
\text { ing alveolitis (J84) }\end{array}$ & 15.4 & 25.3 & 3.2 & Metal dust, wood dust & $\begin{array}{l}\text { Matched for age, gender, area of residence, and } \\
\text { general practitioner; adjusted for smoking status } \\
\text { and exposure to wood or metal dust }\end{array}$ & $\begin{array}{l}\text { Hubbard et al, 1996, } \\
\text { United Kingdom (26) }\end{array}$ \\
\hline $\begin{array}{l}\text { Diseases of the } \\
\text { digestive system } \\
\text { (all K codes) }\end{array}$ & 2.1 & 2.3 & 1.5 & & & \\
\hline $\begin{array}{l}\text { Gastric and } \\
\text { duode nal ulcer } \\
(\mathrm{K} 25-\mathrm{K} 26)\end{array}$ & 29.0 & 29.0 & 29.0 & $\begin{array}{l}\text { Shift work (involving } \\
\text { work strain) }\end{array}$ & $\begin{array}{l}\text { Restricted to men; age-standardized hospitaliza- } \\
\text { tion ratios for non-daytime workers; occupational } \\
\text { groups with similar employment status but with } \\
\text { daytime workers used only as a comparison } \\
\text { group }\end{array}$ & $\begin{array}{l}\text { Tüchsen et al, 1994, } \\
\text { Denmark (337) }\end{array}$ \\
\hline
\end{tabular}

\begin{tabular}{|c|c|c|c|c|c|c|}
\hline $\begin{array}{l}\text { Diseases of the } \\
\text { genitourinary system } \\
\text { (all N codes) }\end{array}$ & 1.3 & 3.0 & 0.4 & & & \\
\hline \multirow{5}{*}{$\begin{array}{l}\text { Chronic renal failure } \\
\text { and nephritic syn- } \\
\text { drome (N03, N11, } \\
\text { N18, N19, N28) }\end{array}$} & 2.6 & 17.6 & 2.3 & Combined risk factors & $\cdot$ & · \\
\hline & & 3.6 & 0.6 & Lead & $\begin{array}{l}\text { Matched for age, gender, and region of } \\
\text { residence (urban or rural area) }\end{array}$ & $\begin{array}{l}\text { Nuyts et al, 1995, Belgium } \\
\text { (338) }\end{array}$ \\
\hline & & 5.7 & 0.3 & Chromium & $\begin{array}{l}\text { Matched for age, gender, and region of } \\
\text { residence (urban or rural area) }\end{array}$ & $\begin{array}{l}\text { Nuyts et al, 1995, Belgium } \\
\text { (338) }\end{array}$ \\
\hline & & 7.3 & 0.7 & Quartz & $\begin{array}{l}\text { Matched for age, gender, and region of } \\
\text { residence (urban or rural area) }\end{array}$ & $\begin{array}{l}\text { Nuyts et al, 1995, Belgium } \\
\text { (338) }\end{array}$ \\
\hline & & 2.2 & 0.7 & $\begin{array}{l}\text { Oxygenated hydrocar- } \\
\text { bons }\end{array}$ & $\begin{array}{l}\text { Matched for age, gender, and region of } \\
\text { residence (urban or rural area) }\end{array}$ & $\begin{array}{l}\text { Nuyts et al, 1995, Belgium } \\
\text { (338) }\end{array}$ \\
\hline
\end{tabular}




\begin{tabular}{|c|c|c|c|c|c|c|}
\hline \multirow[t]{2}{*}{ Cause of death a } & \multicolumn{3}{|c|}{$\begin{array}{l}\text { Attributable } \\
\text { fraction }{ }^{\mathrm{b}}(\%)\end{array}$} & \multirow{2}{*}{$\begin{array}{l}\text { Potentially implicated } \\
\text { exposure or work } \\
\text { environment }{ }^{c}\end{array}$} & \multirow[t]{2}{*}{ Study design and data analysis ${ }^{d}$} & \multirow[t]{2}{*}{$\begin{array}{l}\text { Primary source of } \\
\text { quantitative estimate e }\end{array}$} \\
\hline & Total & Men & Women & & & \\
\hline $\begin{array}{l}\text { Accidents and } \\
\text { violent incidents } \\
\text { (all V, W, X, Y } \\
\text { codes) }\end{array}$ & 3.1 & 3.7 & 0.4 & & & \\
\hline $\begin{array}{l}\text { Accidents includ- } \\
\text { ing accidental } \\
\text { poisonings) } \\
\text { (V01-X59, Y85- } \\
\text { Y86) }\end{array}$ & 5.4 & 6.5 & 0.4 & $\begin{array}{l}\text { Annual rate } 3.6 \text { per } \\
100000 \text { workers }\end{array}$ & Based on statistics & $\begin{array}{l}\text { Federation of Finnish } \\
\text { Insurance Companies, } \\
\text { 1999, Finland (9), Farmer's } \\
\text { Social Insurance Institution, } \\
\text { 1999, Finland (10) }\end{array}$ \\
\hline $\begin{array}{l}\text { Homecide and in- } \\
\text { jury purposely in- } \\
\text { flicted by other } \\
\text { people (X85-Y09, } \\
\text { Y87.1) }\end{array}$ & 1.1 & 1.3 & 0.7 & Policemen and guards & Based on statistics & $\begin{array}{l}\text { Isotalus \& Saarela, 1999, } \\
\text { Finland (339) }\end{array}$ \\
\hline \multirow{3}{*}{$\begin{array}{l}\text { Suicides (X60- } \\
\text { X84, Y87.0) }\end{array}$} & 0.4 & 0.4 & 0.3 & Combined risk factors & · & $\cdot$ \\
\hline & & 0.2 & 0.2 & Physicians (work stress) & $\begin{array}{l}\text { Age-standardized death rates with other } \\
\text { professionals (high social status, all or most } \\
\text { members had an academic degree) and } \\
\text { economically active population used as a } \\
\text { comparison group }\end{array}$ & $\begin{array}{l}\text { Rimpelä et al, 1987, Finland } \\
(340)\end{array}$ \\
\hline & & 0.2 & 0.1 & Lawyers (work stress) & $\begin{array}{l}\text { Age-standardized death rates with other } \\
\text { professionals (high social status, all or most } \\
\text { members had an academic degree) and } \\
\text { economically active population used as a } \\
\text { comparison group }\end{array}$ & $\begin{array}{l}\text { Rimpelä et al, 1987, Finland } \\
(340)\end{array}$ \\
\hline
\end{tabular}

a Codes of the International classification of diseases, 10th revision, in parentheses.

${ }^{b}$ Estimates are given separately by gender for those causes of death for which there was evidence of occupational etiology.

c Agents, occupation or industry.

d Control of confounding variables.

e Authors, year, country, reference number (in parentheses as listed in the body of the text).

$f$ The implicated industries or occupations were not explicitly used as a basis for the estimates of attribured fraction. 